\title{
Chaperones directly and efficiently disperse stress-triggered biomolecular condensates
}

\author{
Haneul Yoo ${ }^{1}$, Jared A.M. Bard ${ }^{1}$, Evgeny Pilipenko ${ }^{1}$, and D. Allan Drummond ${ }^{1,2^{*}}$ \\ ${ }^{1}$ Department of Biochemistry and Molecular Biology, The University of Chicago, Chicago, IL, USA \\ ${ }^{2}$ Department of Medicine, Section of Genetic Medicine, The University of Chicago, Chicago, IL, USA \\ ${ }^{*}$ Correspondence: dadrummond@uchicago.edu
}

\begin{abstract}
Heat shock triggers formation of intracellular protein aggregates and induction of a molecular disaggregation system. Although this system (Hsp100/Hsp70/Hsp40 in most cellular life) can disperse aggregates of model misfolded proteins, its activity on these model substrates is puzzlingly weak, and its endogenous heat-induced substrates have largely eluded biochemical study. Recent work has revealed that several cases of apparent heat-induced aggregation instead reflect evolved, adaptive biomolecular condensation. In budding yeast Saccharomyces cerevisiae, the resulting condensates depend on molecular chaperones for timely dispersal in vivo, hinting that condensates may be major endogenous substrates of the disaggregation system. Here, we show that the yeast disaggregation system disperses heat-induced biomolecular condensates of poly(A)-binding protein (Pab1) orders of magnitude more rapidly than aggregates of the most commonly used model substrate, firefly luciferase. Pab1 condensate dispersal also differs from aggregate dispersal in its molecular requirements, showing no dependence on small heatshock proteins and a strict requirement for type II Hsp40. Unlike luciferase, Pab1 is not fully threaded (and thus not fully unfolded) by the disaggregase Hsp104 during dispersal, which we show can contribute to the extreme differences in dispersal efficiency. The Hsp70-related disaggregase Hsp110 shows some Pab1 dispersal activity, a potentially important link to animal systems, which lack cytosolic Hsp104. Finally, we show that the long-observed dependence of the disaggregation system on excess Hsp70 stems from the precise mechanism of the disaggregation system, which depends on the presence of multiple, closely spaced Hsp70s for Hsp104 recruitment and activation. Our results establish heat-induced biomolecular condensates of Pab1 as a direct endogenous substrate of the disaggregation machinery which differs markedly from previously studied foreign substrates, opening a crucial new window into the native mechanistic behavior and biological roles of this ancient system.
\end{abstract}




\section{Introduction}

In all cellular life, a sudden increase in temperature - heat shock - causes formation of intracellular aggregates and production of heat shock proteins, many of which act as molecular chaperones (Parsell and Lindquist, 1993). An early and long-standing interpretation of these observations, which follow a wide range of so-called "proteotoxic stresses," is that molecular chaperones are produced to protect cells from the toxic effects of stress-induced misfolded proteins and their aggregates (Lindquist, 1986; Morimoto, 2008; Vabulas et al., 2010).

Supporting this view, the molecular disaggregation system, which includes molecular chaperones Hsp100, Hsp70, and Hsp40, has been demonstrated to disperse aggregates of model substrates such as heat-misfolded firefly luciferase and restore their function in vitro (Glover and Lindquist, 1998; Goloubinoff et al., 1999). Decades of biochemical studies on these model substrates have uncovered the general mechanism of disaggregation as follows (reviewed in detail by Mogk et al. (2018)): First, J-domain proteins such as Hsp40 target Hsp70 to specific substrates while simultaneously stimulating Hsp70's ATPase activity (Laufen et al., 1999; Lu and Cyr, 1998; Jiang et al., 2019; Faust et al., 2020). Second, substrate-bound Hsp70 recruits and de-represses the AAA+ disaggregase Hsp100 (Rosenzweig et al., 2013; Carroni et al., 2014; Seyffer et al., 2012; Haslberger et al., 2007). Third, Hsp100 threads substrate delivered by Hsp70 through its central channel to extract the substrate from aggregates (Haslberger et al., 2008; Gates et al., 2017; Avellaneda et al., 2020). Lastly, the threaded substrate is released from Hsp100 and undergoes either spontaneous or Hsp70/40-assisted folding to regain its native structure (Imamoglu et al., 2020).

A surprising and universal feature of biochemical studies of model misfolded substrate dispersal has been the use of - and in the case of Hsp70, a requirement for-substantial excesses of molecular chaperones over their substrates to achieve only limited dispersal. This is unlike a typical enzymatic reaction, although Hsp70 and Hsp104 are well-characterized enzymes and no chaperones are consumed during the disaggregation reaction.

An important possibility is that model substrates are not fully accurate models of endogenous substrates - and remarkably, the endogenous heat-induced substrates of the disaggregation system have largely eluded biochemical study. Alongside nascent polypeptides and prion fibers (Shorter and Lindquist, 2004; Inoue et al., 2004), heat-induced aggregates of misfolded mature proteins are considered major substrates of the disaggregation system. However, no endogenous mature protein has yet been identified to misfold in response to physiological heat shock in eukaryotes. As a consequence, a central element in our understanding of the heat shock response that molecular chaperones directly engage and disperse endogenous aggregates induced by heat shock-has remained untested. A corollary is that the degree to which model thermolabile proteins, such as luciferase, accurately model endogenous aggregating proteins has been difficult to assess.

Recent work suggests that the proteotoxicity model, and the view that heat shock induces widespread protein misfolding, must be expanded. A proteome-wide study in budding yeast showed that a specific set of mature proteins form fully reversible aggregates in response to sublethal heat shock (Wallace et al., 2015). Closer inspection revealed that several cases of this apparent aggregation reflect evolved, adaptive biomolecular condensation (Riback et al., 2017; Iserman et al., 2020). For example, physiological heat shock temperature and pH changes cause poly(A)-binding protein (Pab1), an abundant and broadly conserved eukaryotic RNAbinding protein, to phase separate and form gel-like condensates in vitro (Riback et al., 2017). Suppressing Pab1 condensation reduces cell fitness during prolonged heat stress, indicating 
that condensation is adaptive (Riback et al., 2017). Similarly, heat-induced phase separation of translation initiation factor and DEAD-box helicase Ded1 confers an adaptive benefit to cells by promoting translational switch from housekeeping to stress-induced transcripts (Iserman et al., 2020). As illustrated by these studies, heat-induced biomolecular condensates of endogenous, mature proteins appear to be fundamentally different from misfolded protein aggregates in both mechanism of formation and, most importantly, fitness consequences.

Here we will use the term biomolecular condensates to refer to endogenous membraneless structures of concentrated biomolecules (Banani et al., 2017) regardless of the condensation mechanism, reserving the term phase separation for cases where it has been shown. We use the term aggregates to refer to amorphous clumps of misfolded proteins, which are commonly deleterious to cells,(Geiler-Samerotte et al., 2011) and which differ from endogenous condensates whose fitness consequences are adaptive in several cases.

Substantial in vivo evidence indicates that endogenous heat-induced condensates interact with $\quad 59$ the disaggregation system. All members of the yeast disaggregation system (Hsp104/Hsp70/Hsp40) 60 co-localize with stress granules, which contain both Pab1 and Ded1 (Cherkasov et al., 2013; Walters et al., 2015; Kroschwald et al., 2015, 2018). Deletion or inhibition of any member of the system, or the Hsp70 nucleotide exchange factor (NEF) Hsp110 (Sse1/2), delays dissolution of stress granules during stress recovery (Cherkasov et al., 2013; Walters et al., 2015; Kroschwald et al., 2015, 2018). Interestingly, dispersal of endogenous stress granules precedes dispersal of exogenously expressed misfolded protein aggregates (Cherkasov et al., 2013; Kroschwald et al., 2015) and only the former correlates with the resumption of translation activity and the cell cycle (Cherkasov et al., 2013; Kroschwald et al., 2018).

We and others have hypothesized that heat-induced biomolecular condensates are major endogenous substrates of molecular chaperones (Wallace et al., 2015; Riback et al., 2017; Kroschwald et al., 2018; Yoo et al., 2019; Triandafillou et al., 2020; Begovich and Wilhelm, 2020; Snead and Gladfelter, 2019). However, the questions of whether molecular chaperones directly engage heat-induced biomolecular condensates, and whether and how functional engagement differs between adaptive condensates and aggregates of model misfolded substrates, have remained unanswered.

Here, we address these major open questions by reconstituting in vitro the dispersal of heat-induced Pab1 condensates by their cognate disaggregation system. We use independent methods to demonstrate that Hsp104, Hsp70, and the type II Hsp40 Sis1 are necessary and sufficient for complete dispersal of Pab1 condensates back to functional monomers. Comparative studies of Pab1 condensates and aggregates of misfolded luciferase reveal four key differences. First, and most strikingly, chaperones which show slow and incomplete dispersal of luciferase aggregates disperse Pab1 condensates rapidly and completely. Second, unlike luciferase (Cashikar et al., 2005), Pab1 does not require co-condensation with small heat shock protein Hsp26 for subsequent efficient dispersal. Third, unlike luciferase for which type I (Ydj1) and type II (Sis1) Hsp40 show synergistic activity (Nillegoda et al., 2015, 2017), Pab1 condensate dispersal depends only on Sis1 and is antagonized by Ydj1. Fourth, we show that unlike luciferase, Pab1 is only partially threaded by Hsp104 and readily regains its function upon dispersal.

Finally, we investigate the dispersal system's puzzling dependence on excess Hsp70 for optimal activity, which we find also applies to Pab1 condensate dispersal. Combining biochemical experiments with modeling, we show that the required presence of multiple, closely-spaced Hsp70s for Hsp104 recruitment and activation suffices to render the disaggregation system sensitive to the relative Hsp70 level.

Our results establish heat-induced biomolecular condensates of Pab1 as direct endogenous 
substrates of the disaggregation system, and reveal that many important conclusions drawn from studying aggregates of "model" misfolded proteins do not generalize to endogenous condensates. Whether the remarkable efficiency of Pab1 dispersal is itself a general feature of native substrates remains to be seen. Further study of how chaperones engage with adaptive, endogenous substrates, and how this engagement differs from foreign or proteotoxic substrates, appears likely to yield substantial new insights into the mechanistic features and biological roles of this ancient molecular system.

\section{Results}

\section{Heat shock causes Pab1 condensation, which is not spontaneously reversible}

In budding yeast, Pab1 forms RNase-resistant, sedimentable condensates after physiological heat shock (Wallace et al., 2015; Riback et al., 2017). Condensates of mature, endogenous proteins disperse to their pre-stress soluble form within an hour, without degradation, as cells recover at $30^{\circ} \mathrm{C}$ (Wallace et al., 2015; Cherkasov et al., 2013).

Consistent with previous results, 20 minutes of heat shock at $42^{\circ} \mathrm{C}$ caused a roughly five-fold increase in the proportion of large sedimentable Pab1 compared to the pre-shock level (Figure $1 \mathrm{~A}-\mathrm{C})$. This fraction decreased as the cells recovered at $30^{\circ} \mathrm{C}$ and reached the pre-shock level by 60 minutes. RNase treatment to release sedimentable species formed by RNA-protein interaction decreased the fraction of Pab1 sedimented at 100,000 g spin, but did not change the fraction of Pab1 sedimented at 8,000 g spin (Figure 1B), as previously reported (Riback et al., 2017). These results confirm that under these conditions Pab1 rapidly forms RNase-resistant assemblies which persist upon return to pre-shock temperatures in vivo.

To reconstitute Pab1 condensates in vitro, we treated purified Pab1 at $42^{\circ} \mathrm{C}$ for 20 minutes in a physiological buffer at $\mathrm{pH} 6.8$, which is about the measured $\mathrm{pH}$ of budding yeast cytoplasm during the same heat shock (Triandafillou et al., 2020) (Figure 1D). We examined the size distribution of Pab1 in the soluble fraction using size exclusion chromatography (SEC) and saw a clear division of Pab1 into two peaks: one peak corresponding to Pab1 monomers and another peak in the void volume corresponding to Pab1 condensates larger than 5,000 kDa (Figure 1D). About 30\% of total recombinant Pab1 shifted to the void peak after heat shock, consistent with about $25 \%$ of total cellular Pab1 sedimented at 8,000 g spin (Figure 1B). Because a previous study indicated that misfolded proteins can nucleate stress granule formation in vivo (Kroschwald et al., 2015), we tested whether heat shocking Pab1 in the presence of firefly luciferase increases the condensation yield. Indeed, we found that heat shocking Pab1 in the presence of 100-fold lower amount of thermolabile firefly luciferase, but not thermostable BSA, increased the condensation yield to about 50\% (Figure S1A-C).

Condensation requires Pab1's folded RNA recognition motifs (RRMs) and excess RNA 128 inhibits Pab1 condensation in vitro (Riback et al., 2017), suggesting a competition between 129 Pab1's condensation and RNA-binding activity. Consistent with this, heat shock reduces the association of Pab1 with RNA in vivo (Bresson et al., 2020). We measured the RNA-binding capacity of Pab1 condensates isolated from SEC using fluorescence anisotropy. For 1:1 binding of Pab1 to RNA, we made 19-mer poly(A) RNA (A19) and labeled the 5' end of the RNA with fluorescein. Indeed, Pab1 condensates showed significantly reduced RNA binding activity compared to monomers (Figure 1E).

As expected, unlike Pab1 condensates formed in vivo, Pab1 condensates formed in vitro remained stable and RNA-binding incompetent even after dilution into $\mathrm{pH} 7.3$ buffer at $30^{\circ} \mathrm{C}$ 
(Figure 1E), consistent with a requirement for cellular disaggregation machinery as repeatedly 138 indirectly demonstrated. Thus, we next investigated whether the reversal of Pab1 condensates 139 to RNA-binding monomers depends on direct engagement the molecular disaggregation system. 140

\section{Hsp104, Hsp70, and type II Hsp40 are necessary and sufficient for complete ${ }_{141}$ dispersal of Pab1 condensates in vitro}

To monitor the dispersal Pab1 condensates into functional monomers, we developed a fluorescence 143 anisotropy-based assay in which the increase in fluorescence anisotropy of labeled A19 RNA 144 indicates RNA binding by Pab1 (Figure 2A). We mixed Pab1 condensates and labeled A19 with 145 molecular chaperones Hsp104, Ssa2 (Hsp70), Ydj1 and Sis1 (type I and II Hsp40, respectively), 146

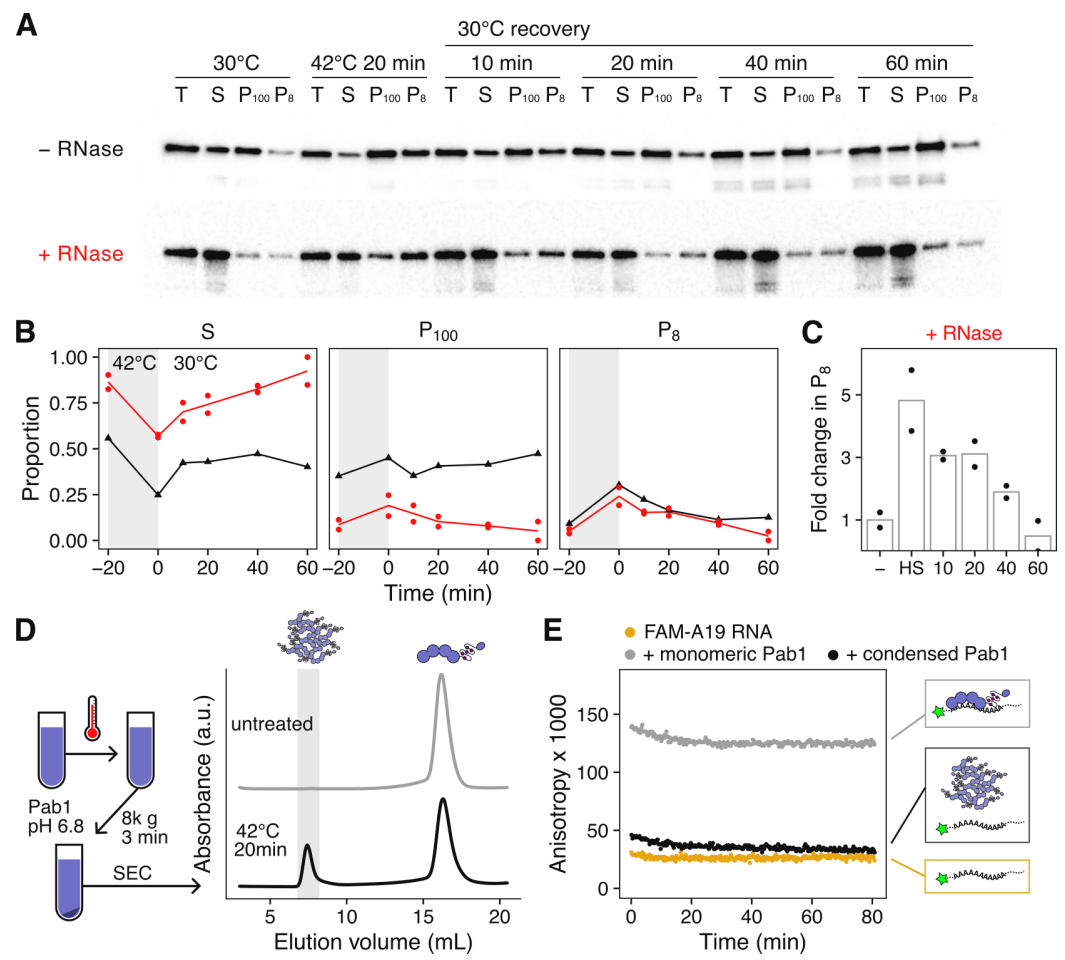

Heat shock causes Pab1 condensation, which is not spontaneously reversible.

(A) Western blot against Pab1 isolated from yeast cells before and after 20 minutes of heat shock at $42^{\circ} \mathrm{C}$, and during post-stress recovery at $30^{\circ} \mathrm{C}$. Cell lysates were incubated with or without RNase $\mathrm{I}_{\mathrm{f}}$ and centrifuged at 8,000 $\mathrm{g}$ and 100,000 $\mathrm{g}$ to separate the supernatant (S) from the pellet $\left(\mathrm{P}_{8}\right.$ and $\left.\mathrm{P}_{100}\right)$. (B) Quantification of $(\mathrm{A})$. Red and black colors correspond to the RNase- or mock-treated sample, respectively. (C) Relative change in the fraction of large sedimentable Pab1 $\left(\mathrm{P}_{8}\right)$ after heat shock and during recovery compared to pre-shock level. (D) Schematic description of in vitro Pab1 condensate purification process and the representative SEC traces for untreated and heat shocked Pab1. Only the heat shocked sample contains Pab1 condensates, which elute in the void volume shaded in gray. (E) Fluorescence anisotropy of 5' labeled 19-mer poly(A) RNA (A19) in the absence or presence of Pab1. Pab1 condensates have substantially reduced RNA binding capacity than the equimolar amount of monomeric Pab1. No spontaneous reversal of Pab1 condensates was observed at physiological recovery condition (pH 7.3 buffer at $\left.30^{\circ} \mathrm{C}\right)$. 

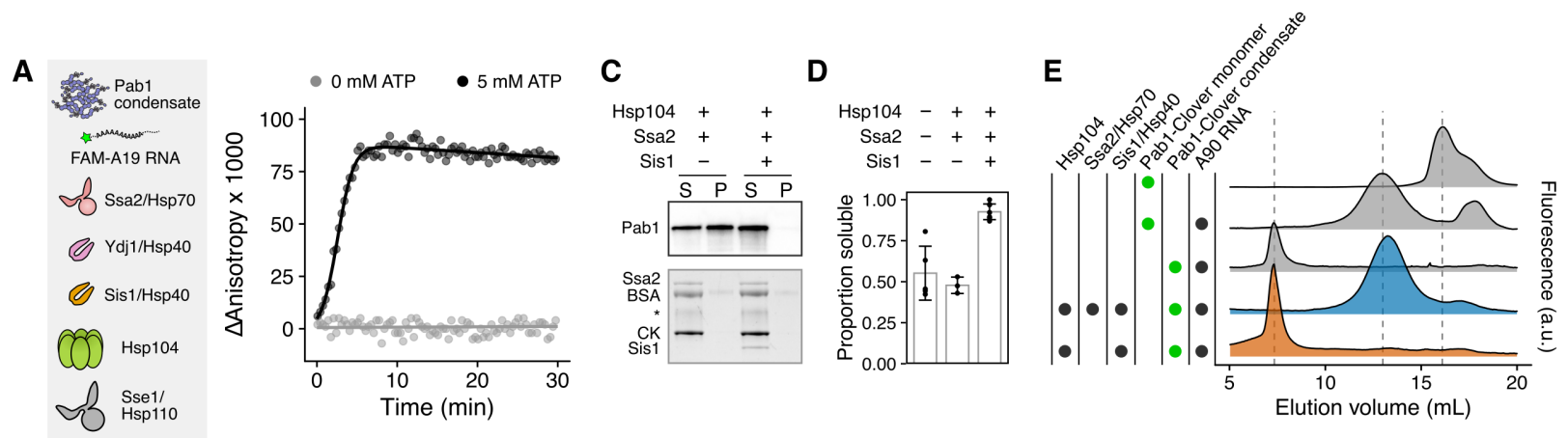

B - ATP
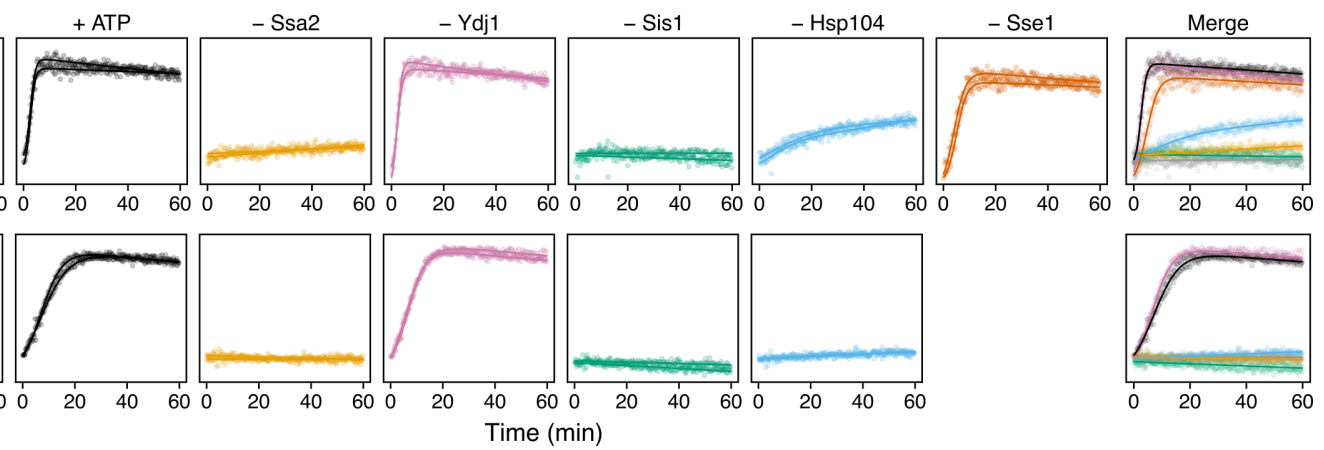

Figure 2. Hsp104, Hsp70, and Sis1 are necessary and sufficient for complete dispersal of Pab1 condensates in vitro.

(A) Schematic representation of Pab1 condensate, labeled A19 RNA, and molecular chaperones used in the fluorescence anisotropy assay. Solid line is the fit of experimental data points to the logistic equation. (B) Time-resolved fluorescence anisotropy of A19 in the presence of Pab1 condensates and a specific set of molecular chaperones. All chaperones shown in (A) except the component specified at the top of each column were included in the experiments shown in the top row. The same experiment repeated in the absence of Sse1 is shown in the bottom row. Fitted data points from two independent experiments are shown. Merged data points and a solid line fitted to the merged data are shown. (C) Western blot of Pab1 after sedimentation. Total protein image of the corresponding lanes is shown as a loading control at the bottom. CK stands for creatine kinase. Asterisk indicates unknown contaminant. (D) Quantification of Pab1 sedimentation results. (E) Fluorescence-detection SEC (FSEC) profiles of Pab1-Clover. The dashed lines mark the peaks corresponding to Pab1-Clover condensates $(7.3 \mathrm{~mL})$, RNA-bound Pab1-Clover monomers $(13 \mathrm{~mL})$, and free monomers $(16 \mathrm{~mL})$.

and Sse1 (Hsp110). In the absence of ATP, no change in fluorescence anisotropy was observed. 147 In contrast, in the presence of $5 \mathrm{mM} \mathrm{ATP}$, fluorescence anisotropy quickly increased and reached 148 a plateau after about 5 minutes, marking the completion of Pab1 dispersal (Figure 2A). ${ }_{149}$

We next tested which set of molecular chaperones are necessary and sufficient for complete 150 Pab1 dispersal in vitro by removing one component of the chaperone mix at a time and 151 monitoring the effect on Pab1 dispersal (Figure 2B). We used excess molecular chaperones 152 except Sse1, which becomes inhibitory when present in excess (Kaimal et al., 2017), to help 153 ensure even weak disaggregation activity would be detected. Condensate dispersal in the absence 154 of Sse1 absolutely required ATP, Ssa2, Sis1, and Hsp104 (Figure 2B; bottom). When Sse1 was 155 present, removal of Hsp104 led to a much slower and incomplete dispersal of Pab1 (Figure 2B; 156 
top). This is consistent with the weak disaggregation activity of Hsp110/70/40 observed against 157 amorphous aggregates and amyloid fibrils (Shorter, 2011). Sse1 and Ydj1 were dispensable in 158 the presence of Hsp104, Ssa2, and Sis1 for both condensates formed in the absence or presence 159 of luciferase (Figure S1D).

The same chaperone requirement pattern was observed when we repeated the assay with Ssa1 161 and Ssa4, which are respectively the constitutively expressed and heat-inducible paralogs of 162 Ssa2 (Figure S3 and Figure S2A-C). The overall dispersal rate was slower with Ssa4 than with 163 Ssa2, which is consistent with the weaker activity of stress-inducible human Hsp70 observed 164 against amyloid fibrils (Gao et al., 2015; Scior et al., 2018).

We verified our fluorescence anisotropy results using two additional independent methods, 166 First, we examined solubilization of Pab1 using sedimentation. About half of Pab1 condensates 167 isolated from SEC remained in the supernatant after 100,000 g spin in the absence of chaperones, 168 suggesting some condensates are too small to be pelleted (Figure 2C and 2D). Incubating 169 Pab1 condensates with the minimal disaggregation system (Hsp104, Ssa2, Sis1) completely 170 solubilized Pab1. In contrast, Pab1 solubility remained unchanged from background levels when ${ }_{171}$ the condensates were incubated with an incomplete disaggregation system.

Next, we prepared Pab1-Clover condensates and examined their size distribution by fluorescence-173 detection SEC (FSEC). Pab1-Clover condensates remained stable when incubated for an hour 174 at $30^{\circ} \mathrm{C}$ in the absence of any molecular chaperones or in the presence of an incomplete di- 175 saggregation system (Figure 2E). After incubation with the minimal complete disaggregation 176 system, however, the condensate peak disappeared and a new peak corresponding to RNA-bound 177 Pab1-Clover appeared. A similar experiment performed with unlabeled Pab1 using SEC and ${ }_{178}$ western blot confirmed that small Pab1 condensates remain stable and are reversed back to ${ }_{179}$ monomers only upon incubation with the complete disaggregation system (Figure S3B-C). 180

In summary, the results from three independent methods consistently indicate that Hsp104, 181 Hsp70, and type II Hsp40 Sis1 are necessary and sufficient for complete dispersal of Pab1 182 condensates in vitro. These results are consistent with the in vivo observations that deletion 183 or inhibition of Hsp104, Hsp70, or Hsp40 delays dispersal of Pab1 condensates (Cherkasov 184 et al., 2013) and of stress granules marked by Pab1 (Cherkasov et al., 2013; Walters et al., 2015; 185 Kroschwald et al., 2015, 2018).

\section{Pab1 condensates and misfolded protein aggregates exhibit different chape- 187 rone dependence for dispersal

The mechanism of substrate dispersal by the disaggregation system has been extensively 189 studied using non-native model substrates. The most commonly used model substrate is firefly 190 luciferase, which readily misfolds in vitro at elevated temperatures and whose light-producing 191 enzymatic activity can be easily and accurately measured as a readout for the extent of protein 192 refolding. Therefore, we used luciferase as a benchmark heat-misfolded substrate and studied 193 how Pab1 dispersal differs from luciferase disaggregation. We first focused on two chaperone- 194 related features of luciferase disaggregation which we could recapitulate: 1) dependence on 195 co-aggregation with excess Hsp26 for more efficient disaggregation (Cashikar et al., 2005) and 2) 196 synergistic disaggregation in the presence of both type I and II Hsp40s, Ydj1 and Sis1 (Figure ${ }_{197}$ 3B) (Nillegoda et al., 2015, 2017).

Heat-induced aggregation of luciferase in the presence of five-fold excess Hsp26 facilitated 199 subsequent disaggregation and reactivation of luciferase (Figure 3A) as previously reported 200 (Cashikar et al., 2005). To investigate the effect of Hsp26 on Pab1, we subjected Pab1 to a 201 
more severe heat shock condition $\left(46^{\circ} \mathrm{C}\right.$ for 20 minutes at $\left.\mathrm{pH} 6.4\right)$ in the absence or presence of ${ }_{202}$ increasing concentrations of Hsp26. Hsp26 suppressed Pab1 condensation and sedimentation in a 203 concentration-dependent manner (Figure S4A-B). Dynamic light scattering (DLS) also revealed 204 that Hsp26 suppresses nucleation of Pab1 (Figure S4C-D). Thus, unlike luciferase which readily 205 co-aggregates with Hsp26 under physiological heat shock conditions, Pab1 condensation is 206 suppressed by Hsp26. Most importantly, unlike luciferase aggregates, Pab1 condensates formed 207 in the absence of Hsp26 are rapidly and completely dispersed by the disaggregation system 208 (Figure 2).

We next investigated whether Pab1 dispersal is accelerated in the presence of both Ydj1 and 210 Sis1, as with luciferase. Ydj1 is a type I Hsp40 which has an highly conserved N-terminal J 211 domain followed by G/F-rich region, zinc-finger domain, C-terminal domains, and a dimerization 212 domain (Kampinga and Craig, 2010). Type II Sis1 largely resembles the architecture of Ydj1 213 but lacks the zinc-finger domain. To quantify the maximal rate of dispersal in the presence of ${ }_{214}$ either or both types of Hsp40s, we converted the fluorescence anisotropy to Pab1 concentration 215 using a calibration curve (Figure S4E and Eq. 3) and extracted the rate (Eqs. 4 and 5). The ${ }_{216}$ rate of dispersal did not improve when both Sis1 and Ydj1 were added to Pab1 condensates 217 compared to when only Sis1 was added (Figure 3B-C). Instead, Ydj1 slightly inhibited Pab1 218 dispersal in a concentration-dependent manner (Figure 3D and 3E). These results indicate that, 219 unlike luciferase aggregates for which Sis1 and Ydj1 show synergistic activity, Sis1 and Yd1j 220 show antagonistic activity for Pab1 condensates.

\section{The disaggregation system restores Pab1 condensates far more efficiently ${ }_{222}$ than misfolded protein aggregates

The poor activity of the disaggregation system against aggregates of model substrates has been 224 observed since the first biochemical reconstitution of the system (Glover and Lindquist, 1998; 225 Goloubinoff et al., 1999). Even with co-aggregation with 5-fold excess Hsp26, less than half of 226 luciferase activity is regained after a two-hour incubation with 37.5-fold excess Hsp104 and 227 Ssa2 (Figure 3B). Indeed, the standard in vitro disaggregation protocol requires the use of 228 10- to 100-fold excess molecular chaperones over substrates to obtain moderate to good yield 229 (Figure 6C). We found that when sub-stoichiometric concentration of Hsp104 (0.5×) and closer 230 to stoichiometric concentrations of Ssa2 $(5 \times)$ and Sis1 $(2.5 \times)$ are used, Pab1 dispersal still 231 completes within 20 minutes while less than $1 \%$ of luciferase is reactivated after an hour (Figure ${ }_{232}$ $3 \mathrm{~F})$. The heat shock condition used to prepare Pab1 condensates and luciferase aggregates was 233 identical except for the initial concentration $(2 \mu \mathrm{M}$ luciferase in the presence of five-fold excess 234 Hsp26 versus $25 \mu \mathrm{M}$ Pab1).

What causes this large difference in restoration efficiency between Pab1 and luciferase? To gain insight into the potential sources of this discrepancy, we turned to computational kinetic modeling.

\section{Higher disaggregation rate and partition coefficient lead to more efficient 239 substrate restoration in silico

Pab1 condensation requires the folded RRMs, and condensation involves only minor unfolding 241 of secondary structures (Riback et al., 2017). We hypothesized that separation of specific RRM 242 interactions and subsequent folding of the re-solvated Pab1 into native structure may be more ${ }_{243}$ efficient compared to the restoration of luciferase aggregates. To test this hypothesis within ${ }_{244}$ 

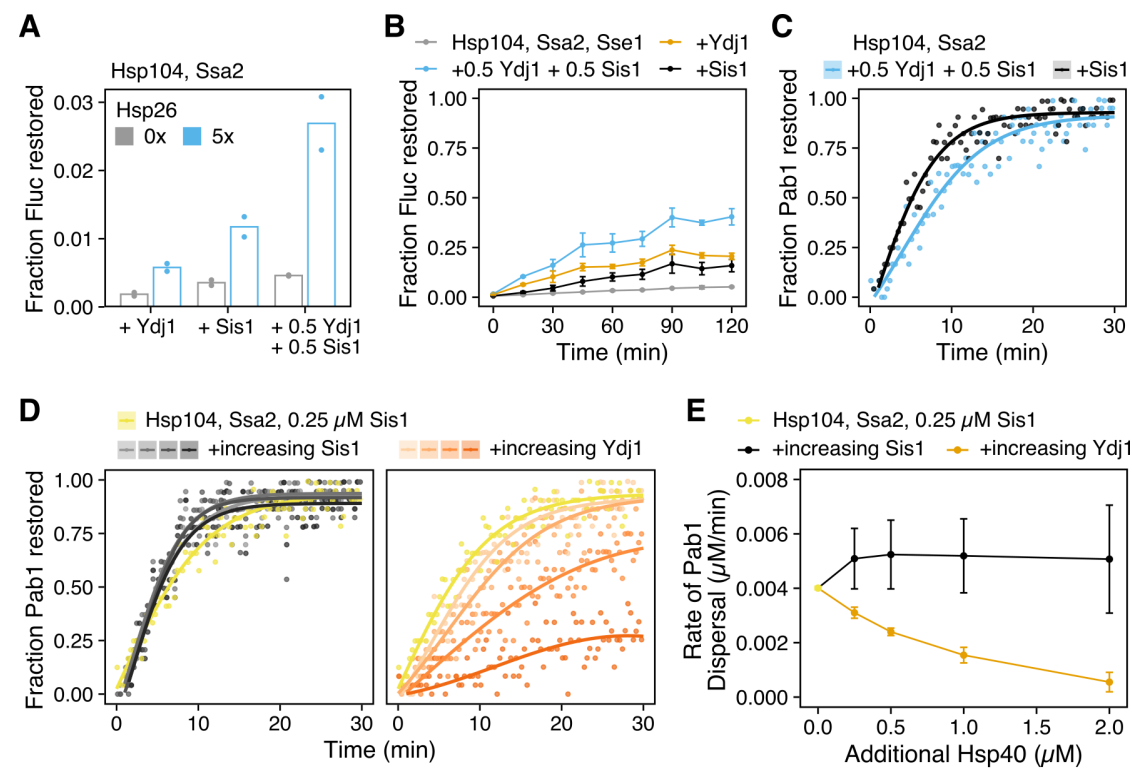

E $\rightarrow$ Hsp104, Ssa2, $0.25 \mu \mathrm{M}$ Sis1
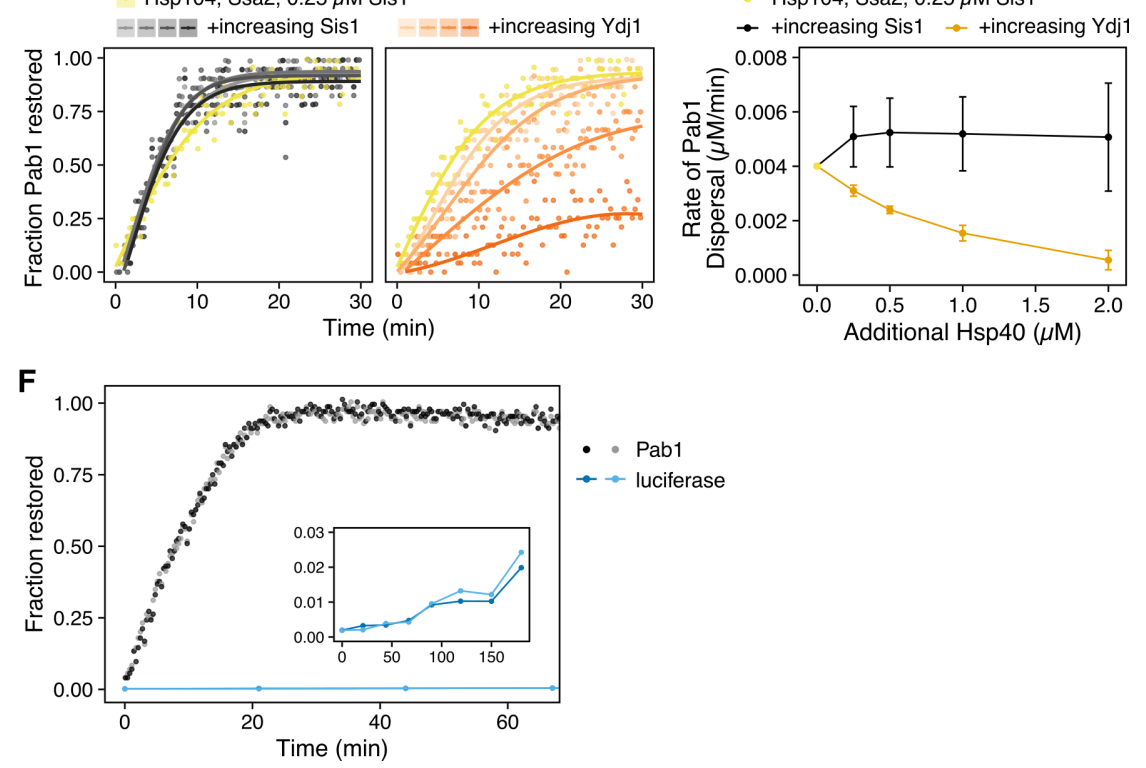

Figure 3. Pab1 condensates and misfolded protein aggregates exhibit different chaperone dependence for dispersal.

(A) Fraction of functional luciferase after a two-hour incubation of luciferase aggregates (0.2 $\mu \mathrm{M})$ with Hsp104 (0.1 $\mu \mathrm{M} ; 0.5 \mathrm{x})$, Ssa2 (1 $\mu \mathrm{M} ; 5 \mathrm{x})$, and Hsp40 (0.5 $\mu \mathrm{M}$ total; 2.5x). Luciferase was aggregated either in the absence or presence of 5-fold excess Hsp26. (B) Reactivation of $20 \mathrm{nM}$ aggregated luciferase in the presence of excess Hsp104 (0.75 $\mu \mathrm{M} ; 37.5 \mathrm{x})$, Ssa2 (0.75 $\mu \mathrm{M} ; 37.5 \mathrm{x})$ and Sis1 (0.25 $\mu \mathrm{M} ; 12.5 \mathrm{x})$. Either Sis1 (black), Ydj1 (orange), or both (blue) were used as co-chaperones. Mean and standard deviation were calculated from two independent experiments with duplicates in each experiment. (C) Pab1 dispersal using either Sis1 (black) or a combination of Sis1 and Ydj1 (blue) as co-chaperones. (D) Titration of either Sis1 (left; gradients of black) or Ydj1 (right; gradients of orange) to reactions containing $0.2 \mu \mathrm{M}$ Pab1 condensates, $0.05 \mu \mathrm{M}$ Hsp104, $0.5 \mu \mathrm{M}$ Ssa2, and $0.25 \mu \mathrm{M}$ Sis1. The amount of additional Hsp40 added was $0.25,0.5,1$, and $2 \mu \mathrm{M}$. (E) The average maximal rate of dispersal and standard deviations quantified from three independent titration experiments, one of which is shown in (D). (F) Restoration of $0.2 \mu \mathrm{M}$ of Pab1 or luciferase by $0.1 \mu \mathrm{M}$ Hsp104 (0.5x), $1 \mu \mathrm{M}$ Ssa2 (5x), and $0.5 \mu \mathrm{M}$ Sis1 $(2.5 \mathrm{x})$. The inset shows zoomed-in refolding kinetics of luciferase over three hours.

our model, we synthesized existing simulation studies (Powers et al., 2012; De Los Rios and 245 Barducci, 2014; Nguyen et al., 2017; Xu, 2018; Goloubinoff et al., 2018; Assenza et al., 2019; 246 Wentink et al., 2020) to build what we call a cooperative model of the disaggregation system 247 
A
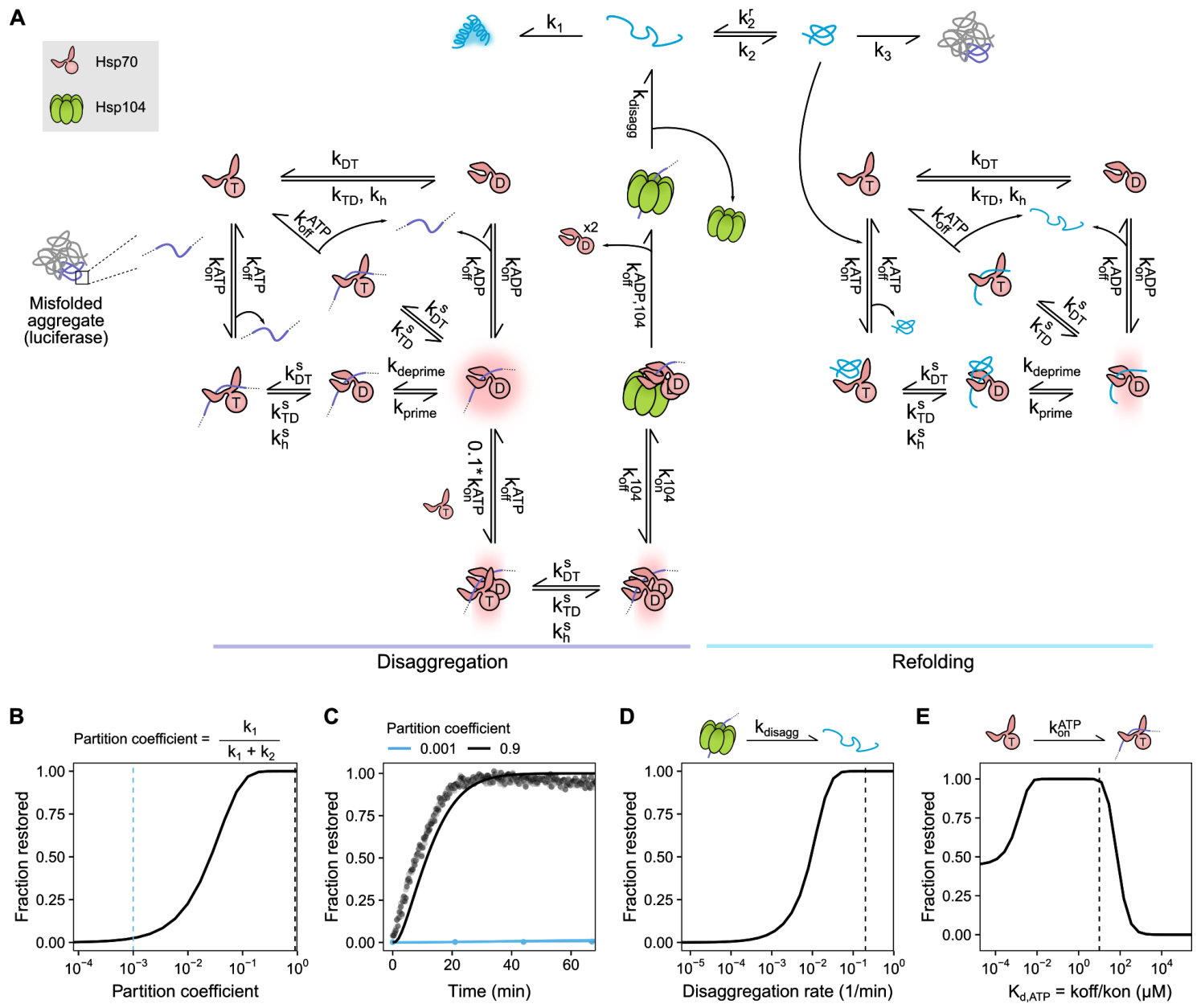

Figure 4. Higher disaggregation rate and folding partition coefficient lead to more efficient substrate restoration in silico.

(A) Cooperative model of the disaggregation system. For more details, see Methods and Figure S5. (B) Summary of model output in terms of fraction substrate restored as a function of partition coefficient. Dashed lines indicate the partition coefficient used to simulate Pab1 (black) and luciferase (light blue) results in (C). For all simulation experiments in this figure, fraction restored at 2 hours is shown. The starting simulation condition was $0.2 \mu \mathrm{M}$ substrate, $0.1 \mu \mathrm{M}$ Hsp104, and $1 \mu \mathrm{M}$ Hsp70. (C) Simulated substrate dispersal kinetics with either high (black) or low (light blue) partition coefficients. Simulation results (solid line) are overlaid on top of Pab1 and luciferase experimental data from Figure 3F. (D) Simulated fraction substrate restored as a function of disaggregation rate. (E) Simulated fraction substrate restored as a function of Hsp70(ATP) substrate affinity. Dashed lines in (D) and (E) indicate the default value used in the simulation experiments.

(Figure 4A and Figure S5A). The cooperative model captures the current model of Hsp104 248 regulation by Hsp70, in which binding of more than one Hsp70 is required to activate Hsp104 249 (Seyffer et al., 2012; Carroni et al., 2014). Many of the rate parameters involved, especially 250 
in the refolding step, have been measured using bacterial chaperones and model substrates or 251 peptides (Table 1). We assumed that these parameters are generally consistent in the eukaryotic 252 system, and that the same model architecture can be used for both luciferase and Pab1. For ${ }_{253}$ details of this ordinary differential equation model, see Methods.

We examined how varying each of the following parameters affected the substrate restoration 255 yield: 1) rate of disaggregation by Hsp104, 2) efficiency of the released substrate from regaining 256 its native structure, which we define as the partition coefficient, and 3) substrate affinity for 257 Hsp70. Modulation of each parameter over 1-2 orders of magnitude substantially affected the 258 restoration yield, measured from 0 to 1 (Figure 4B, D, E). A large difference in partition ${ }_{259}$ coefficient alone reproduced the Pab1 and luciferase dispersal data (Figure 4C). The simulation 260 also revealed Hsp70 affinity as a potential factor which can contribute to the observed difference ${ }_{261}$ in dispersal efficiency.

Because Hsp104 is associated with both the disaggregation rate and the partition coefficient 263 of a substrate, e.g., through complete threading vs. partial threading of a substrate, we decided 264 to investigate experimentally and compare how Hsp104 engages with Pab1 condensates and ${ }_{265}$ luciferase aggregates.

\section{Pab1 is partially threaded by Hsp104}

Substrate threading through the central channel of Hsp104 is a common mechanism for protein 268 disaggregation (Tessarz et al., 2008). Complete threading requires complete substrate unfolding. 269 To probe the folding state of Pab1 and luciferase during their release from Hsp104, we used a 270 mutated version of a bacterial chaperonin, GroEL, which traps unfolded protein (Weber-Ban ${ }_{271}$ et al., 1999) (Figure 5A). We verified that this GroEL variant traps unfolded luciferase released ${ }_{272}$ during disaggregation and prevents folding (Figure 5B).

273

We then tested whether Pab1 becomes unfolded during dispersal by dispersing Pab1 $\Delta \mathrm{P}$ in $\quad 274$ the presence of excess GroEL trap. We used Pab1 $\Delta \mathrm{P}(55 \mathrm{kDa})$ because most GroEL substrates are known to have molecular weight less than $60 \mathrm{kDa}$ (Houry et al., 1999) and full-length Pab1 (64 kDa) exceeds that limit. Pab1 $\Delta \mathrm{P}$ lacks the disordered $\mathrm{P}$ domain but retains the ability to phase separate (Riback et al., 2017). Pab1 $\Delta \mathrm{P}$ condensates were readily dispersed by the disaggregation system, indicating that the $\mathrm{P}$ domain is dispensable for the condensate's engagement with chaperones (Figure $5 \mathrm{C}$ ). The rate of dispersal was almost identical for Pab1 $\Delta \mathrm{P}$ dispersed in the absence or presence of GroEL trap. However, when we chemically denatured both full-length Pab1 and Pab1 $\Delta \mathrm{P}$ in $8 \mathrm{M}$ urea and refolded the proteins in buffer containing no or 10-fold excess GroEL trap, both constructs refolded to the same level regardless of the presence of GroEL trap (Figure 5D). This indicated to us that GroEL trap is unable to engage with fully unfolded Pab1 and thus not applicable to investigating the folding state of Pab1.

To circumvent the limitation of the GroEL trap, we turned to the HAP/ClpP system (Tessarz et al., 2008). HAP (Hsp104-ClpA-P loop) is an engineered Hsp104 that interacts with the bacterial peptidase ClpP to form a proteolytic system (Figure 5E). HAP behaved like wild type Hsp104 and quickly degraded luciferase in the presence of ClpP (Figure 5F-G), consistent with a previous report that luciferase is fully threaded and degraded by HAP/ClpP (Haslberger et al., 2008). HAP also behaved like wild type Hsp104 during Pab1 dispersal (Figure S6A-B).

If complete threading of Pab1 were required for condensate dispersal, we would expect to see complete degradation of Pab1 by HAP/ClpP. We made condensates using Pab1-fluorescein-ssrA and examined the degradation pattern after dispersal using SDS-PAGE (Figure 5H and Figure S6C-D) and FSEC (Figure 5K). A mixed group of full-length and degraded Pab1 populations 
A

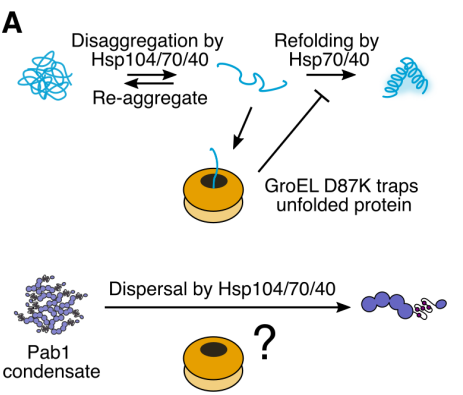

E

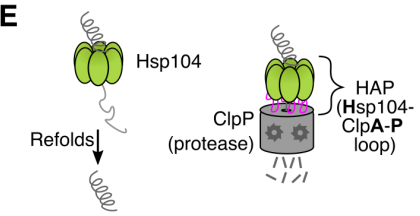

$\mathbf{F}$

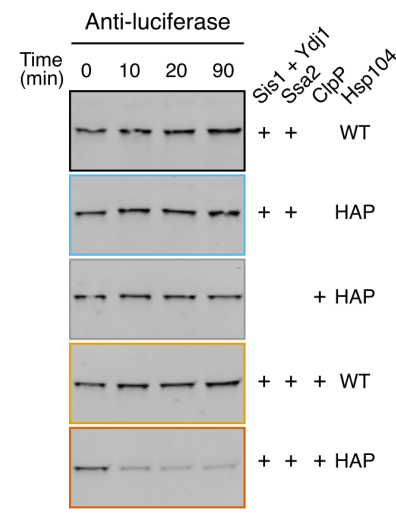

G

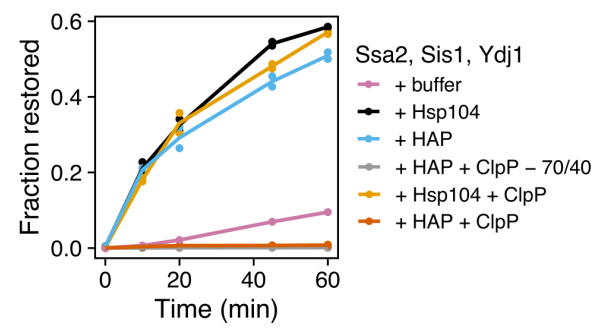

\section{H}

B Fluc aggregates, Hsp104, Ssa2, Sis1, Ydj1, Sse1

$\theta+$ buffer

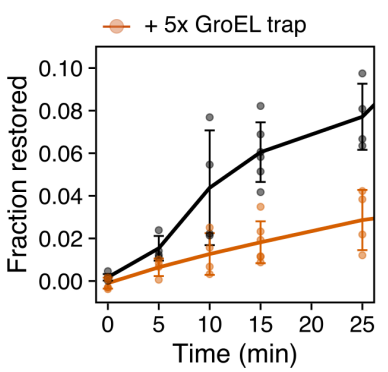

C

Pab1 $1 \mathrm{P}$ condensates, Hsp104, Ssa2, Sis1

$\ominus+$ buffer

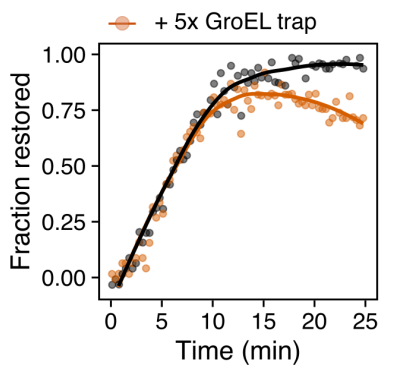

D

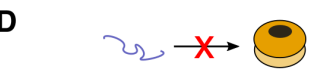

๑Pab1

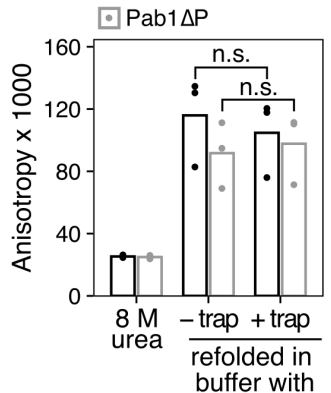

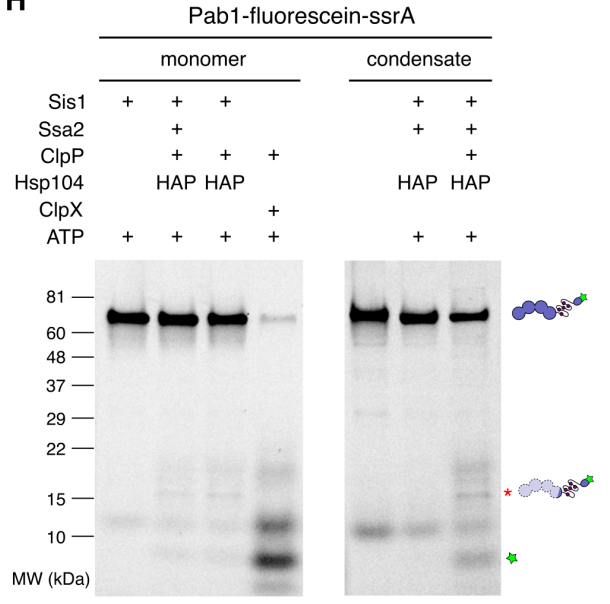
I Hsp104, Hsp70, Hsp40 + HAP + HAP + ClPP

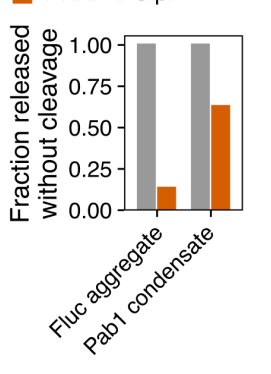
$+\mathrm{ClpX}+\mathrm{ClpP}$

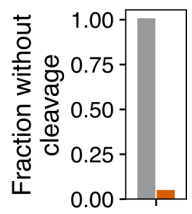

Figure 5. Pab1 is partially threaded by Hsp104.

(A) Schematic description of GroEL trap system. (B) Luciferase disaggregation in the absence or presence of 5 -fold excess GroEL trap. Mean and standard deviation were calculated from three independent experiments. (C) Pab1 $\Delta \mathrm{P}$ dispersal in the absence or presence of 5 -fold excess GroEL trap. Solid lines represent smoothed data from a representative experiment. The decrease in the signal in the presence of GroEL trap after 10 min is due to RNA degradation. (D) Refolding of urea-denatured Pab1 (black) and Pab1 $\Delta \mathrm{P}$ (gray) in buffer containing no or 10-fold excess GroEL trap. (E) Schematic description of HAP/ClpP system. (F) Chemically aggregated luciferase were incubated with the indicated components and the extent of luciferase degradation was visualized by western blot. 
(G) Refolding kinetics of chemically aggregated luciferase in the presence of indicated components. (H) SDS-PAGE gels of Pab1-fluorescein-ssrA monomers or condensates after an hour incubation with the indicated components. Full-length Pab1 and C-terminal fragments are indicated by the fluorescein band signal. Asterisk indicates HAP/ClpP-specific band. (I) Fraction of full-length protein released from luciferase aggregates or Pab1 condensates, normalized to HAP control. The restoration yield of $60 \%$ was used for both luciferase and Pab1 based on the disaggregation and FSEC results, respectively. ( $\mathrm{J}$ ) Fraction of full-length Pab1-ssrA monomers after incubation with ClpX and ClpP. (K) FSEC traces of Pab1-fluorescein-ssrA condensates after an hour incubation with the indicated components. Dashed lines indicate peaks corresponding to Pab1 condensates $(8 \mathrm{~mL})$, full-length monomers $(14.5 \mathrm{~mL})$, and HAP/ClpP-specific C-terminal fragment (18.5 $\mathrm{mL})$. Unmarked peaks in the control reactions are unknown contaminants.

were observed after dispersal. The appearance of full-length Pab1 monomers suggested partial 296 translocation of Pab1 by HAP and release before Pab1 enters the proteolytic chamber of ClpP ${ }_{297}$ (Figure 5I and Figure 5K). We confirmed that ClpP can degrade Pab1 using ClpX, which 298 recognizes the ssrA degradation tag and unfolds the substrate for ClpP (Figure 5H and Figure 299 5J). Specific degradation fragments appeared upon incubation of HAP/ClpP and chaperones 300 with Pab1 condensates, but also to a lesser extent with Pab1 monomers, suggesting a basal 301 level of interaction between Pab1 and HAP/ClpP (Figure 5H). Similar C-terminal fragments 302 containing a part of the $\mathrm{P}$ domain and the C-terminal domain of Pab1 appeared for Pab1-Clover 303 and Pab1-fluorescein without the ssrA tag (Figure S6E and Figure S6H). However, much 304 less full-length monomer appeared for Pab1-Clover than Pab1-fluorescein-ssrA (Figure S6F), 305 suggesting that a fluorescent label can affect the processing by $\mathrm{HAP} / \mathrm{ClpP}$. We also examined 306 the N-terminal fragments using fluorescein-Pab1 and saw appearance of both large fragments of 307 the RRMs and small peptides (Figure S6G). HAP/ClpP fails to completely disperse condensates 308 of Pab1-Clover (Figure S6F), which limited our ability to quantify the fraction of Pab1 released 309 without cleavage for these constructs.

Together, these results show that, unlike luciferase which requires complete threading and 311 unfolding by HAP for disaggregation, partial threading of Pab1 still leads to condensate dispersal. 312 This is consistent with the partial threading mechanism proposed for proteins with a mixture 313 of misfolded and folded domains (Haslberger et al., 2008; Sweeny and Shorter, 2016) and the 314 lack of major secondary structure changes in Pab1 at condensation temperature (Riback et al., 315 2017). However, we cannot rule out the possibility that wild type Hsp104 processes unlabeled 316 Pab1 differently from what we observed with HAP and labeled Pab1 constructs.

How does the disaggregation system recognize Pab1 condensates? To address this question, we 319 first performed a series of fluorescence anisotropy Pab1 dispersal assays with varying chaperone 320 concentrations and quantified the maximal rate of dispersal (Figure 6A and 6B). Pab1 condensate ${ }_{321}$ dispersal was most robust to the Hsp104 concentration, showing half-maximal dispersal rate at 1:10 Hsp104:Pab1 ratio. Excess Sse1 was inhibitory and Sse1 worked most optimally at sub-stoichiometric level, consistent with previous observations (Kaimal et al., 2017; Wentink et al., 2020). Pab1 condensate dispersal was most sensitive to the concentrations of Sis1 and Ssa2. In particular, the rate of dispersal plummeted as the Ssa2 concentration approached the stoichiometric level (Figure 6A). 
A
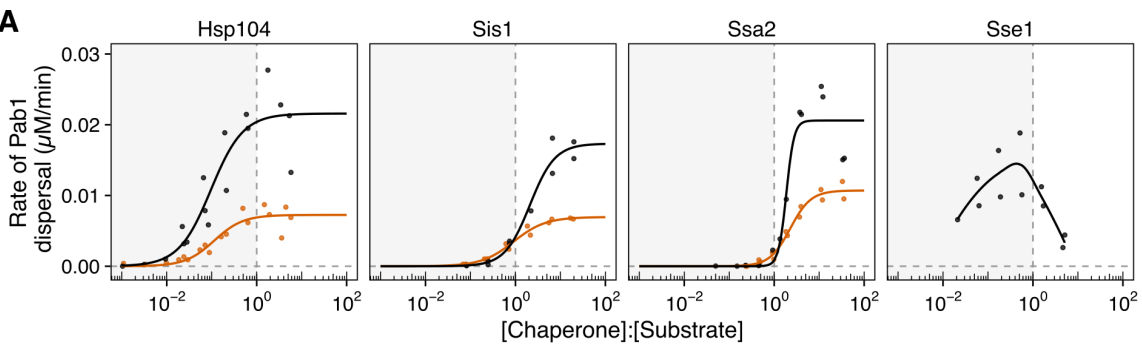

C

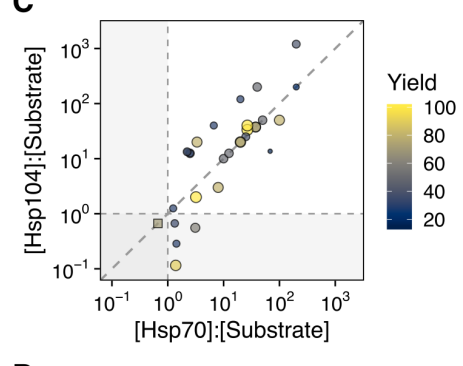

D

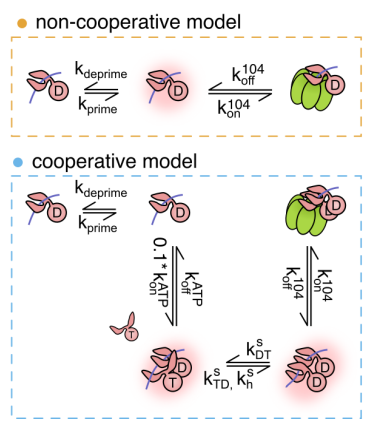

E
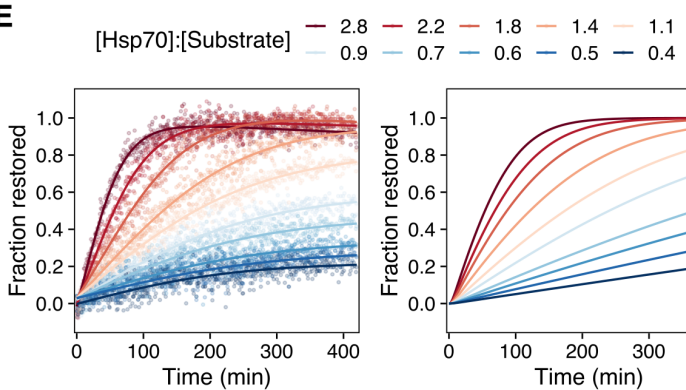

$\mathbf{F}$

- experiment - non-cooperative model - cooperative model

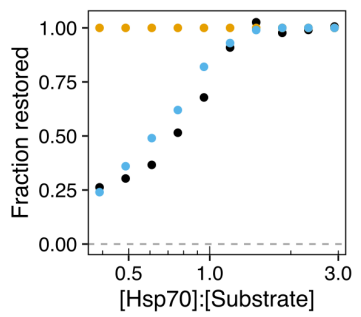

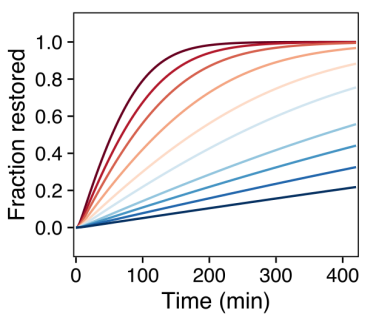

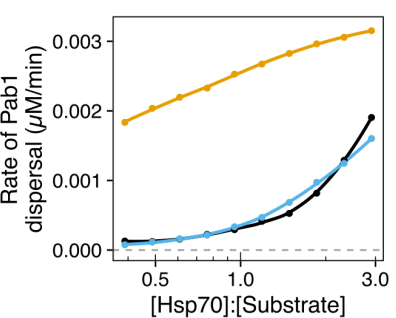

B

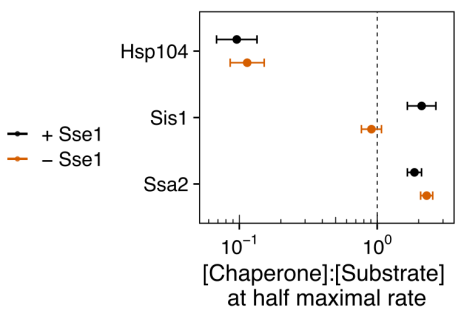

G

$\mathrm{Gse} 1(\mathrm{nM})-360-120-40$
$-13-4$

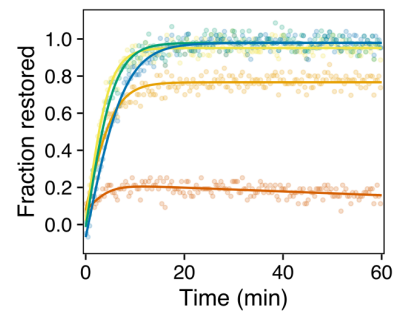

H ADP exchange $-12-4-1.33$ rate $(1 / \mathrm{min}) \quad-0.44-0.15$

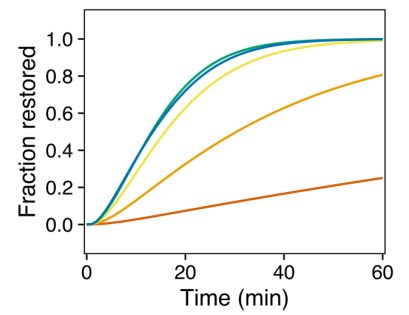

Figure 6. Cooperative binding of Hsp70 labels condensates for disaggregation.

(A) Maximal rate of Pab1 dispersal in the presence (black) or absence (brown) of Sse1. Solid lines in Hsp104, Sis1, and Ssa2 panels represent logistic fit to the data. Solid line in Sse1 panel is the smoothing line. The baseline concentrations of the proteins were $0.2 \mu \mathrm{M}$ Pab1, $0.5 \mu \mathrm{M}$ Ssa2, 0.5 $\mu \mathrm{M}$ Sis1, $0.2 \mu \mathrm{M}$ Hsp104, and 0.1 $\mu \mathrm{M}$ Sse1. Shaded area denotes the sub-stoichiometric region. The lower rate with the highest Hsp70 concentration is due to RNA degradation. (B) Relative chaperone concentration at half-maximal dispersal rate, extracted from the fits in (A). Error bars represent standard errors around the estimated parameter. (C) Survey of disaggregation studies in the literature. Maximal yield of disaggregation experiments and the relative amount of Hsp104 and Hsp70 used in the experiment are shown. Color and size of each data point correspond to the yield. Circles represent studies with wild type Hsp104. One square data point in the sub-stoichiometric Hsp70 area represents a study which used a hyperactive D484K variant of Hsp104. (D) Schematic comparison of the cooperative and non-cooperative models. (E) Pab1 dispersal monitored by fluorescence anisotropy (left) and the simulated Pab1 dispersal results from the cooperative model (right). (F) Quantitative comparison of Pab1 dispersal data (black) to the simulated results from the cooperative (blue) and non-cooperative models (orange). Fraction restored at the end of the 8 hour experiment (left) and the maximal rate of dispersal (right) were used for comparison. (G) Representative Sse1 titration Pab1 dispersal data. $(\mathrm{H})$ Simulation of Pab1 dispersal with different ADP nucleotide exchange rates using the cooperative model. 
Indeed, the disaggregation system's dependence on super-stoichiometric Hsp70 for optimal 328 activity has been a long-standing puzzle. Earlier studies investigating this problem with a 329 reconstituted bacterial disaggregation system found that DnaK (bacterial Hsp70) has to be ${ }_{330}$ present in excess for maximal disaggregation yield (Goloubinoff et al., 1999; Ben-Zvi et al., 2004). 331 We surveyed in vitro disaggregation studies in the literature and found that this dependence on 332 excess Hsp70 is widespread across studies, precise conditions, and substrates (Figure 6C), and 333 our results are no exception.

We decided to investigate why excess Hsp70 over substrate is needed for what is still a 335 catalytic series of reactions. We titrated Ssa2 over a narrow window around the stoichiometric 336 Hsp70:Pab1 ratio and monitored Pab1 dispersal reaction for eight hours (Figure 6E). We also 337 simulated the cooperative model (Figure 4A) using the same chaperone concentrations used in 338 the in vitro experiment (Figure 6E). The cooperative model recapitulated the disaggregation 339 system's Hsp70-sensitive Pab1 dispersal activity (Figure 6F). This model reflects the results from 340 recent studies which indicate that interaction with more than one Hsp70 is required for activation 341 of Hsp104 (Carroni et al., 2014; Seyffer et al., 2012). Indeed, simulation of non-cooperative 342 model, in which single Hsp70 is sufficient to recruit and activate Hsp104, resulted in high Pab1 343 dispersal activity even with sub-stoichiometric Hsp70 (Figure 6D and 6F).

The cooperative model was also able to recapitulate the general trend seen in the Hsp104 345 and Ssa2 titration experiments (Figure 6A and Figure S5B). Although Sis1 and Sse1 were not 346 explicitly included in the model, modulating the ATP hydrolysis rate and ADP exchange rate 347 allowed us to mimic the effect of titrating Sis1 and Sse1, respectively (Figure S5B). Interestingly, 348 although we were able to recapitulate the inhibitory effect of Sse1 with high ADP exchange 349 rate, modulating ADP exchange rate was not enough to recapitulate the facilitative effect of 350 sub-stoichiometric Sse1 (Figure 6G and Figure 6H).

These results converge on a picture in which the presence of multiple, closely spaced Hsp70 352 molecules on the surface of condensates provide a molecular marker labeling condensates for 353 Hsp104-dependent dispersal, as proposed in the bacterial disaggregation system by Seyffer et al. 354 (2012). Our simulation results indicate that a cooperative Hsp70 effect on Hsp104 binding and 355 activation suffices to explain the disaggregation system's intrinsic sensitivity to the level of 356 Hsp70.

\section{Discussion}

We demonstrated that the yeast disaggregation system composed of molecular chaperones Hsp104, Hsp70, and Hsp40 can directly reverse heat-induced biomolecular condensates of Pab1 back to functional monomers in vitro. This establishes heat-induced biomolecular condensates of Pab1 as endogenous substrates of the molecular disaggregation system. Through comparative studies of Pab1 and the model substrate firefly luciferase, we uncovered a number of distinctions in the way chaperones engage with each substrate. The most notable distinction was the large difference in the restoration efficiency between Pab1 condensates and luciferase aggregates. Our results show that partial threading of Pab1 by Hsp104 during dispersal can contribute to this large difference in the restoration efficiency. Finally, we find that efficient Pab1 dispersal depends on the presence of excess Hsp70, which serves as a condensate detector through cooperative recruitment and activation of Hsp104 near the surface of condensates (Figure 7).

359 360 361 362 363 364 365 366 367 368 369 


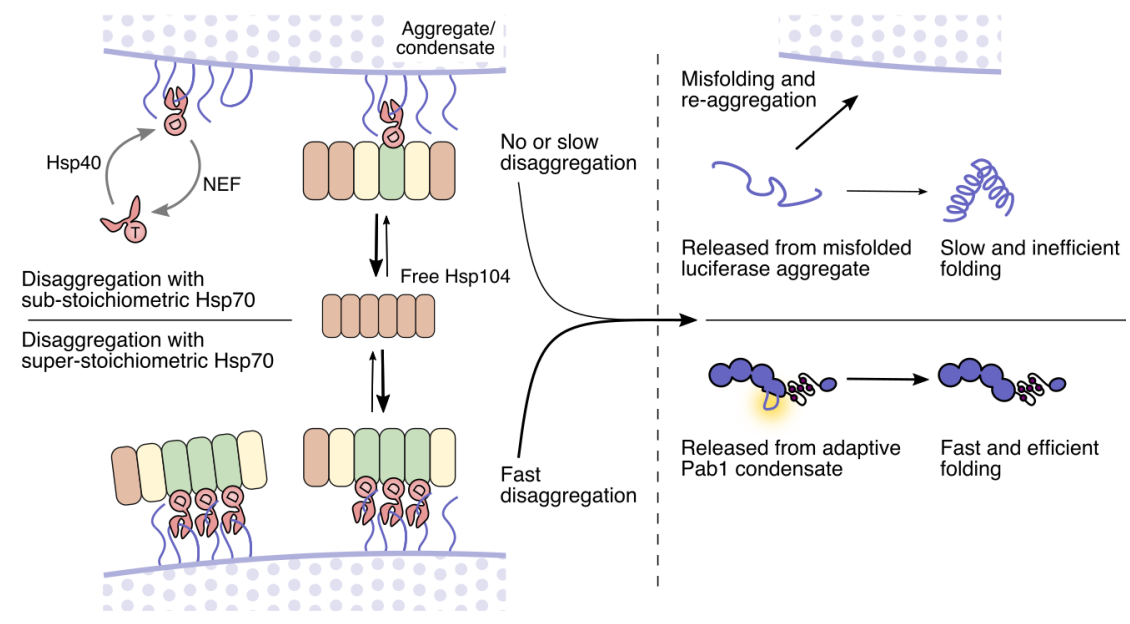

Figure 7. Model of Pab1 dispersal by the Hsp104/Hsp70/Hsp40 disaggregation system.

Productive recruitment and activation of Hsp104 depend on the presence of multiple closely spaced Hsp70 molecules on the surface of aggregate/condensate, a condition which is most likely to be achieved with excess Hsp70. Luciferase is fully threaded by Hsp104 and released as unfolded protein; This leads to slow and inefficient folding because unfolded protein is prone to misfolding and re-aggregation. In contrast, Pab1 is released after partial threading by Hsp104 and readily re-folds into native structure, resulting in faster and more efficient folding compared to luciferase. The schematic of Hsp104 with repressed (red) and activated (green) protomers is adapted from Carroni et al. (2014).

\section{Heat-induced biomolecular condensates are endogenous substrates of the mo- 370 lecular disaggregation system}

In yeast, heat-induced biomolecular condensates including stress granules adopt a solid-like 372 characteristic (Kroschwald et al., 2015; Riback et al., 2017). Timely dispersal of endogenous 373 condensates depends on molecular chaperones (Cherkasov et al., 2013; Walters et al., 2015; 374 Kroschwald et al., 2015, 2018), and the timing of dispersal correlates with resumption of active 375 cellular translation and growth (Cherkasov et al., 2013; Kroschwald et al., 2015, 2018). These in 376 vivo observations strongly suggest heat-induced biomolecular condensates are the endogenous 377 substrates of the molecular disaggregation system. However, direct biochemical evidence for 378 chaperone-mediated condensate dispersal has been missing.

In this study, we showed using in vitro reconstitution that the Hsp104/70/40 disaggregation 380 system directly engages and disperses heat-induced condensates of Pab1. The contrast between 381 Pab1 condensates and luciferase aggregates on multiple important dimensions (requirements for 382 specific chaperones and for small heat-shock proteins, rate and yield of dispersal, the nature 383 of engagement with Hsp104) demonstrates that luciferase, and by extension other similarly 384 behaving "model" misfolded proteins, have severe limitations as models of endogenous heat- 385 induced chaperone substrates. Whether the authentic substrate Pab1 is itself a suitable model 386 for other endogenous substrates remains an important open question.

We also showed that Hsp110, Hsp70, and Hsp40 can disperse Pab1 condensates. This 388 alternative disaggregation system is also capable of disaggregating luciferase aggregates and 389 
amyloid fibrils, although with much weaker disaggregation activity than with Hsp104 (Shorter, 390 2011). The disaggregation activity of the Hsp110/70/40 system is conserved in animals (Shorter, 391 2011; Wentink et al., 2020), which lack cytosolic Hsp104 (Erives and Fassler, 2015), suggesting 392 a potential evolutionary and biochemical bridge to chaperone-mediated condensate dispersal in 393 animals.

\section{Different engagement of molecular chaperones with biomolecular condensates and misfolded protein aggregates}

Co-aggregation of luciferase with Hsp26 keeps luciferase in a near-native conformation, generates 397 smaller aggregates, and facilitates aggregate interaction with Hsp70 (Cashikar et al., 2005; 398 Ungelenk et al., 2016; Żwirowski et al., 2017). However, Hsp26 is almost undetectable in cells 399 pre-stress (Cashikar et al., 2005). Because biomolecular condensation of endogenous proteins 400 occurs within a few minutes of heat stress (Wallace et al., 2015), Hsp26 is unlikely to be involved 401 in condensate regulation during the initial exposure to stress. We showed that Hsp26 prevents condensation of Pab1 in vitro. Human small heat shock protein Hsp27 has also been shown to repress phase separation of FUS (Liu et al., 2020). Post-stress accumulation of Hsp26 in cells may be involved in desensitization of the cells to sustained or repeated stress by modulating the phase boundary of endogenous mature proteins.

The canonical type I (Ydj1; DNAJA2 in humans) and type II Hsp40 (Sis1; DNAJB1) chaperones show synergistic activity toward luciferase aggregates (Nillegoda et al., 2015, 2017). This synergistic activity stems from the preference of type I and II Hsp40 chaperones for small (200-700 kDa) and large (>5,000 kDa) aggregates, respectively (Nillegoda et al., 2017), although how aggregates of different sizes can be distinguished at the molecular level remains unclear. Sis1 and Ydj1 also exhibit different amino acid sequence preference (Jiang et al., 2019) and different mode of binding Hsp70, the latter of which has been shown to be responsible for amyloid disaggregation activity unique to type II chaperones (Faust et al., 2020). The inability of Ydj1 to support Pab1 dispersal could be due to the large size of Pab1 condensates, the lack of Ydj1 binding sites among the exposed region of Pab1 in condensates, dependence on the Hsp70 binding mode unique to type II Hsp40, or any combination of these.

The antagonistic effect of Ydj1 on Sis1 suggests a competition between the two co-chaperones for Hsp70. In cells, stress-induced phosphorylation of Hsp70 reprograms Hsp70's substrate specificity, e.g., by preventing Hsp70 from interacting with Ydj1 but not with Sis1 (Truman et al., 2012). Similar post-translational modifications may also regulate the activity of the disaggregation system toward specific substrates.

Hsp104 functions by threading substrate through its central channel (Gates et al., 2017). ${ }_{423}$ However, both our simulation and biochemical experiments suggest Pab1 is partially threaded ${ }_{424}$ by Hsp104. A partial threading activity of Hsp104 and its bacterial homolog ClpB has been reported previously, where both proteins selectively thread misfolded moiety of the substrate while leaving the natively folded domains intact (Haslberger et al., 2008; Sweeny and Shorter, 2016). We hypothesize that partial threading of the locally "unfolded" region of Pab1, possibly the same or near the region mediating Pab1 condensation interaction, allows for condensate dispersal without substantial protein unfolding.

395 396 7
8
9
1
02 403 404 405 


\section{Hsp70 clusters are a potential condensate-specific marker for Hsp104}

Efficient dispersal of Pab1 condensates depends on the presence of excess Hsp70. Nearby Hsp70s, 432 which would be rare on monomers but common on condensates, both increase Hsp104 binding 433 and stimulate additional Hsp104 activity. In this sense, consistent with an insightful proposal 434 from Seyffer et al. (2012) working in the homologous bacterial system, Hsp70 clusters provide 435 an active label for engagement and activation of powerful dispersal machinery only in spatial 436 proximity to condensed substrates.

Cooperative action of Hsp70 in substrate unfolding has been proposed to explain the requirement of excess Hsp70 during glucose-6-phosphate dehydrogenase (G6PDH) disaggregation (Ben-Zvi et al., 2004). We find by simulation that cooperative action of Hsp70 in the recruitment and activation of Hsp104 is sufficient to reproduce the in vitro Hsp70 titration data. We also found that, in the cooperative model, modulating the ADP exchange rate alone was not enough to reproduce the facilitative effect of Sse1 (Figure 6H). A recent study by Wentink et al. (2020) uncovered an additional function of human Hsp110 in promoting local clustering of Hsp70 on the substrate surface. A similar function in the yeast Hsp110, Sse1/2, may explain the discrepancy between our model and the data.

\section{Biomolecular condensates in the cellular heat shock response}

Engagement of molecular chaperones, especially Hsp40 and Hsp70, with stress-induced bio- 448 molecular condensates provides a tangible means to explain how yeast cells integrate multiple physical cues from the environment to sense temperature. In yeast, the transcriptional heat shock response is triggered when Hsp70, which is bound repressively to the transcriptional factor Hsf1, is titrated away by stress-induced substrates (Zheng et al., 2016; Krakowiak et al., 2018; Peffer et al., 2019; Masser et al., 2019; Feder et al., 2021).

S. cerevisiae cultured at $30^{\circ} \mathrm{C}$ begins mounting the transcriptional heat shock response when the temperature is raised above $36^{\circ} \mathrm{C}$. The identities of these stress-induced substrates remain elusive. Although misfolding-prone nascent or newly synthesized polypeptides are known to help trigger the response, suppression of protein synthesis is not sufficient to suppress the transcriptional response, implying the existence of mature substrates which, we recently showed, also like depend on stress-associated intracellular acidification for formation (Triandafillou et al., 2020). Notably, condensation of Pab1 and other heat-sensitive proteins is strongly pH-sensitive (Riback et al., 2017; Iserman et al., 2020; Kroschwald et al., 2018). Here, we provide an additional important piece of circumstantial evidence for the model of stress-triggered condensation as an activator of Hsf1: heat-induced condensates of Pab1 are authentic chaperone substrates which depend on Hsp70 for dispersal. Thus, Pab1 can autonomously transduce physiological heat shock temperatures into biomolecular condensation, dependent on $\mathrm{pH}$, and recruit molecular chaperones including Hsp70. In short, Pab1 — and by extension presumably others of the dozens of previously identified heat-condensing proteins (Wallace et al., 2015; Cherkasov et al., 2015), including more than a dozen which condense in response to a $37^{\circ} \mathrm{C}$ heat shock-now appears to have all the characteristics needed to act as an inducer of the transcriptional heat shock response. An important conceptual difference is that while the proteotoxicity model has invoked toxic misfolding, biomolecular condensation is known to be an evolved, adaptive response (Riback et al., 2017; Iserman et al., 2020). 


\section{Molecular chaperones as biomolecular condensate remodelers}

473

In this work, we show that molecular chaperones can regulate biomolecular condensates by ${ }_{474}$ acting as dispersal factors. This expands the list of known condensate dispersal factors, which currently includes the dual specificity kinase DYRK3 (Wippich et al., 2013) and nuclear-import receptor karyopherin- $\beta 2$ (Guo et al., 2018). The functional repertoire of molecular chaperones in biomolecular condensate regulation is likely to be much broader than just dispersal. For example, Hsp104, Hsp70, and Hsp40 in yeast are required for condensate formation of SNF1 kinase activator Std1 during fermentation (Simpson-Lavy et al., 2017). Another example is Hsp27, which partitions into liquid-like FUS condensates upon stress-induced phosphorylation and prevents amyloid transition of FUS (Liu et al., 2020). Illumination of the roles of molecular chaperones as facilitators, remodelers, and dispersers of biomolecular condensates - and the mechanisms and biological consequences of this regulation-presents an enormous opportunity for expanding our understanding of these ancient molecules.
475 476 477 478 479 480 481 482 483 484 485 


\section{Methods}

\section{Lead Contact}

Further information and requests for resources and reagents should be directed to and will be 489 fulfilled by Lead Contact, D. Allan Drummond (dadrummond@uchicago.edu).

All unique and stable reagents generated in this study are available from the Lead Contact.

All data analysis and visualization were performed with R (version 3.5.2) in RStudio (RStudio 495 Team, 2018). The raw and processed data, and the custom scripts for data process, data analysis, 496 and figure generation will be available on Data Dryad.

Code for simulation and data analysis

Simulation was performed with Python (version 3.7.7) in Jupyter notebook (Kluyver et al., 2016). 499 The code is be available on GitHub (https://github.com/haneulyoo/sim_disagg_2021). 500

\section{Experimental Model and Subject Details}

S. cerevisiae strain BY4741 (MATa ura3 $\Delta 0$ leu2 $\Delta 0$ his $3 \Delta 1$ met15 $\Delta 0$ ) cells were cultured in 503 yeast extract peptone dextrose (YPD) media in shaking baffled flasks at $30^{\circ} \mathrm{C}$. The strain 504 background used was S288C.

Unless specified otherwise under Chemicals, Peptides, and Recombinant proteins of the Key ${ }_{507}$ Resources Table, all recombinant proteins used in this work are expressed in and purified from 508 E. coli BL21(DE3). Cells were first grown in Luria broth (LB) at $37^{\circ} \mathrm{C}$ for 12 to 16 hours and 509 then inoculated to 1-2 L Terrific Broth (TB) culture. Specific growth condition used for each 510 recombinant protein is described in Method Details.

\section{Method Details}

Protein expression and purification protocols were adapted with modification from (Riback 514 et al., 2017). N-terminally 8xHis-tagged Pab1 constructs were transformed into an E. coli strain 515 BL21(DE3) and grown overnight at $37^{\circ} \mathrm{C}$. The overnight culture was used to inoculate $1 \mathrm{~L} 516$ Terrific Broth (TB). Cells were grown until the optical density at $600 \mathrm{~nm}\left(\mathrm{OD}_{600}\right)$ reached 517 between 0.4 and 0.6 and then the flask was moved into a $30^{\circ} \mathrm{C}$ incubator. After 30 minutes, 518 
$0.2 \mathrm{mM}$ IPTG was added to induce protein expression. Cells were harvested after 4 hours 519 and lysed by sonication in His binding buffer $(20 \mathrm{mM}$ HEPES pH 7.3, $150 \mathrm{mM} \mathrm{KCl,} 2.5 \mathrm{mM} \quad 520$ $\mathrm{MgCl}_{2}, 20 \mathrm{mM}$ imidazole, $10 \%$ glycerol, and $1 \mathrm{mM} \mathrm{BME}$ ) supplemented with 1 Pierce protease ${ }_{521}$ inhibitor tablet (Thermo Fisher A32965). Lysate was cleared by spinning at 20,000 g for 15522 minutes. Cleared lysate was loaded onto a 5 mL HisTrap FF column (Thermo Fisher 17525501) ${ }_{523}$ equilibrated with His binding buffer on an AKTA FPLC system. Protein was eluted with a 524 $20 \mathrm{~mL}$ gradient from 0 to $100 \%$ His elution buffer $(20 \mathrm{mM}$ HEPES pH 7.3, $150 \mathrm{mM} \mathrm{KCl,} 2.5 \quad 525$ $\mathrm{mM} \mathrm{MgCl} 2,400 \mathrm{mM}$ imidazole, $10 \%$ glycerol, and $1 \mathrm{mM} \mathrm{BME}$ ). Fractions containing Pab1 526 were buffer exchanged into a Q binding buffer (20 mM HEPES pH 7.3, $50 \mathrm{mM} \mathrm{KCl,} 2.5 \mathrm{mM} \quad 527$ $\mathrm{MgCl}_{2}, 10 \%$ glycerol, and $1 \mathrm{mM} \mathrm{DTT}$ ) and loaded onto a $5 \mathrm{~mL}$ HiTrap Heparin HP column ${ }_{528}$ (GE Healthcare 17040701) to remove nucleic acids. Nucleic acid-free protein was eluted over a 529 $20 \mathrm{~mL}$ gradient from 0 to $100 \%$ Q elution buffer $(20 \mathrm{mM}$ HEPES pH 7.3, $1 \mathrm{M} \mathrm{KCl,} 2.5 \mathrm{mM} 530$ $\mathrm{MgCl}_{2}, 10 \%$ glycerol, $1 \mathrm{mM}$ DTT). Fractions of interest were combined with an aliquot of ${ }_{531}$ a homemade tobacco etch virus (TEV) protease and dialyzed against 1 L His binding buffer ${ }_{532}$ overnight to remove the N-terminal tag and to lower the salt concentration. On the next day, 533 the dialyzed solution was loaded again onto a $5 \mathrm{~mL}$ HisTrap FF column and the flow-through 534 which contains the cleaved protein was collected. The protein was concentrated and loaded onto 535 a Superose 6 10/300 GL column (GE Healthcare) equilibrated with SEC/Storage buffer (20 ${ }_{536}$ $\mathrm{mM}$ HEPES pH 7.3, $150 \mathrm{mM} \mathrm{KCl}, 2.5 \mathrm{mM} \mathrm{MgCl}_{2}$, and $\left.1 \mathrm{mM} \mathrm{DTT}\right)$. Monomeric proteins were 537 pooled together, further concentrated if necessary, and stored at $-80^{\circ} \mathrm{C}$. Protein concentration 538 was measured using Bradford assay (Bio-Rad 5000201).

\section{Purification of Hsp70 chaperones}

We adapted with minor modifications the protocol provided by Zachary March in James ${ }_{541}$ Shorter's group. N-terminally 6xHis-SUMO-tagged Hsp70 proteins were transformed into an E. ${ }_{542}$ coli strain BL21(DE3) and grown overnight at $37^{\circ} \mathrm{C}$. The overnight culture was used to inoculate 543 1L Terrific Broth (TB). Cells were grown until $\mathrm{OD}_{600}$ between 0.4 and 0.6 and then the flask ${ }_{544}$ was moved into a $18^{\circ} \mathrm{C}$ incubator. After 30 minutes, $0.2 \mathrm{mM}$ IPTG was added to induce protein 545 expression overnight. Cells were harvested after 14 - 18 hours and lysed by sonication in Hsp70 546 His binding buffer (50 mM HEPES pH 7.3, $750 \mathrm{mM} \mathrm{KCl,} 5 \mathrm{mM} \mathrm{MgCl}_{2}, 20 \mathrm{mM}$ imidazole, $10 \quad 547$ $\%$ glycerol, $1 \mathrm{mM} \mathrm{BME}$, and $1 \mathrm{mM}$ ATP) supplemented with 1 Pierce protease inhibitor tablet. 548 Cleared lysate was loaded onto a $5 \mathrm{~mL}$ HisTrap FF column equilibrated with Hsp70 His binding 549 buffer on an AKTA FPLC system. After loading, the column was washed with more Hsp70 His 550 binding buffer until the UV reading returned to a steady, baseline level. The column was further ${ }_{551}$ washed with about $20 \mathrm{~mL}$ high ATP buffer (50 mM HEPES pH 7.3, $750 \mathrm{mM} \mathrm{KCl,} 5 \mathrm{mM} \mathrm{MgCl}_{2}$, 552 $20 \mathrm{mM}$ imidazole, $10 \%$ glycerol, $1 \mathrm{mM} \mathrm{BME}$, and $20 \mathrm{mM}$ ATP) and incubated in this buffer for ${ }_{553}$ at least 30 minutes. The high ATP buffer was washed out with Hsp70 His binding buffer and ${ }_{554}$ the protein was eluted with a $20 \mathrm{~mL}$ gradient from 0 to $100 \%$ Hsp70 His elution buffer $(50 \mathrm{mM} 555$

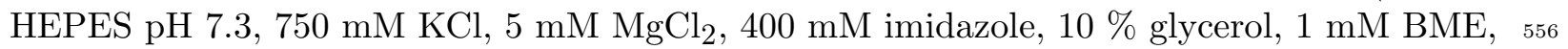
and $1 \mathrm{mM} \mathrm{ATP}$ ). The fractions of interest were combined and dialyzed against $1 \mathrm{~L}$ Hsp70 His 557 binding buffer for at least 2 hours to remove excess imidazole. An aliquot of homemade SUMO 558 protease Ulp1 was added to the dialysis bag. Dialysis was continued overnight at $4^{\circ} \mathrm{C}$. Next ${ }_{559}$ day, the cleaved protein was recovered by running the dialyzed solution through His column 560 and collecting flow-through. Flow-through fractions containing tag-free Hsp70 proteins were 561 combined, diluted in Hsp70 Q binding buffer (20 mM HEPES pH 7.3, $50 \mathrm{mM} \mathrm{KCl,} 5 \mathrm{mM} \mathrm{MgCl}_{2}, 562$ $0.5 \mathrm{mM}$ EDTA, $2 \mathrm{mM}$ DTT, and $1 \mathrm{mM} \mathrm{ATP}$ ), and loaded onto an equilibrated $5 \mathrm{~mL}$ HiTrap Q 563 
HP anion exchange column (GE Healthcare 17115401). Hsp70 was eluted over a $50 \mathrm{~mL}$ gradient 564 from 0 to $100 \%$ Hsp70 Q elution buffer (20 mM HEPES pH 7.3, $1 \mathrm{M} \mathrm{KCl,} 5 \mathrm{mM} \mathrm{MgCl}_{2}, 0.5 \quad 565$ mM EDTA, $2 \mathrm{mM}$ DTT, and $1 \mathrm{mM}$ ATP). Fractions containing Hsp70 were determined by 566 SDS-PAGE. We observed a peak with a left shoulder or two closely overlapping peaks around 567 $25 \mathrm{mS} / \mathrm{cm}$. Both peaks contained Hsp70, but only the later peak fractions exhibited activity in 568 both luciferase and Pab1 disaggregation assays. We combined the fractions corresponding to 569 the second peak, concentrated, and buffer exchanged the protein into Hsp70 storage buffer (50 570 mM HEPES pH 7.3, $150 \mathrm{mM} \mathrm{KCl,} 5 \mathrm{mM} \mathrm{MgCl}_{2}, 10 \%$ glycerol, $2 \mathrm{mM} \mathrm{DTT}$, and $1 \mathrm{mM} \mathrm{ATP).} 571$ Protein concentration was measured using Bradford assay. Protein aliquots were snap-frozen in 572 liquid nitrogen and stored at $-80^{\circ} \mathrm{C}$.

\section{Purification of sortase A enzymes}

Wild-type (Guimaraes et al., 2013) (used for N-terminal labeling) and heptamutant sortase A 575 (Hirakawa et al., 2015) (used for C-terminal labeling) were purified using the same protocol. 576 Constructs were transformed into E. coli strain BL21(DE3), grown in 1 L of TB until they 577 reached an $\mathrm{OD}_{600}$ of 0.6 . Protein production was induced with $0.5 \mathrm{mM}$ IPTG. The cells were 578 incubated overnight at $18^{\circ} \mathrm{C}$, and harvested in His binding buffer $(20 \mathrm{mM}$ HEPES pH 7.5, $150 \quad 579$ $\mathrm{mM} \mathrm{KCl}, 2.5 \mathrm{mM} \mathrm{MgCl} 2,20 \mathrm{mM}$ imidazole, $10 \%$ glycerol, and $1 \mathrm{mM}$ BME), supplemented 580 with protease inhibitors and Pierce Universal Nuclease (Thermo Scientific PI88702). Cells were 581 lysed by sonication, clarified by centrifugation at 20,000 g for 30 minutes, then bound to 5582 $\mathrm{mL}$ of Ni-NTA resin (Thermo Scientific 88222) for 1 hour at $4^{\circ} \mathrm{C}$. The resin was washed with 583 $100 \mathrm{~mL}$ of His binding buffer, then the protein was eluted in $20 \mathrm{~mL}$ of His elution buffer $\left(20{ }_{584}\right.$ mM HEPES pH 7.5, $150 \mathrm{mM} \mathrm{KCl,} 2.5 \mathrm{mM} \mathrm{MgCl}_{2}, 250 \mathrm{mM}$ imidazole, and $\left.1 \mathrm{mM} \mathrm{BME}\right)$. The ${ }_{585}$ protein was concentrated in a spin concentrator, then loaded onto a Superdex 200 16/60 column 586 (GE Healthcare) equilibrated in buffer (20 mM HEPES pH 7.5, $150 \mathrm{mM} \mathrm{KCl,} 2.5 \mathrm{mM} \mathrm{MgCl}_{2}$, 587 $10 \%$ glycerol, and $0.5 \mathrm{mM}$ TCEP). Fractions corresponding to the monomeric protein were ${ }_{588}$ pooled together, concentrated, and aliquoted for storage at $-80^{\circ} \mathrm{C}$.

\section{Purification of ClpX and ClpP}

The purification of $\mathrm{ClpX} \Delta \mathrm{N}$ and $\mathrm{ClpP}$ were done as previously described (Martin et al., 2005). 591 A plasmid encoding a linked trimer of ClpX $\Delta \mathrm{N}$ with an N-terminal 6xHis affinity tag was 592 transformed into E. coli BL21(DE3) and grown in $1 \mathrm{~L}$ of TB until $\mathrm{OD}_{600}$ of 0.6. Protein 593 production was induced with $0.5 \mathrm{mM}$ IPTG. Cells were harvested after 4 hours at $37^{\circ} \mathrm{C}$ and ${ }_{594}$ resuspended in His binding buffer (20 mM HEPES pH 7.5, $100 \mathrm{mM} \mathrm{KCl,} 400 \mathrm{mM} \mathrm{NaCl}, 20 \quad 595$ $\mathrm{mM}$ imidazole, $10 \%$ glycerol, and $1 \mathrm{mM} \mathrm{BME}$ ), supplemented with protease inhibitors and 596 Pierce Universal Nuclease (Thermo Scientific PI88702). Cells were lysed by sonication, clarified 597 by centrifugation at $20,000 \mathrm{~g}$ for 30 minutes, then bound to $5 \mathrm{~mL}$ of Ni-NTA resin (Thermo 598 Scientific 88222) for 1 hour at $4^{\circ} \mathrm{C}$. The resin was washed with $100 \mathrm{~mL}$ of His binding buffer, 599 then the protein was eluted in $20 \mathrm{~mL}$ of His elution buffer $(20 \mathrm{mM}$ HEPES pH 7.5, $100 \mathrm{mM} 600$ $\mathrm{KCl}, 400 \mathrm{mM} \mathrm{NaCl}, 250 \mathrm{mM}$ imidazole, $10 \%$ glycerol, and $1 \mathrm{mM} \mathrm{BME}$ ). The protein was 601 concentrated in a spin concentrator, then loaded onto a Superdex 200 16/60 column (GE ${ }_{602}$ Healthcare) equilibrated in buffer (20 mM HEPES pH 7.5, $300 \mathrm{mM} \mathrm{KCl,} 0.1 \mathrm{mM}$ EDTA, 10603 $\%$ glycerol and $1 \mathrm{mM}$ DTT). Fractions corresponding to the monomeric protein were pooled 604 together, concentrated and aliquoted for storage at $-80^{\circ} \mathrm{C}$. Protein concentration was determined 605 by measuring $\mathrm{A}_{280}$. 
A plasmid encoding $\mathrm{ClpP}$ with a C-terminal 6xHis affinity tag was transformed into E. coli 607 BL21(DE3), grown in $1 \mathrm{~L}$ of TB until $\mathrm{OD}_{600}$ of 0.6. Protein production was induced with 0.5608 $\mathrm{mM}$ IPTG, and cells were harvested after 4 hours at $37^{\circ} \mathrm{C}$, and resuspended in His binding 609 buffer (20 mM HEPES pH 7.5, $100 \mathrm{mM} \mathrm{KCl,} 400 \mathrm{mM} \mathrm{NaCl}, 20 \mathrm{mM}$ imidazole, $10 \%$ glycerol, 610 and $1 \mathrm{mM} \mathrm{BME}$ ), supplemented with Pierce Universal Nuclease (Thermo Scientific PI88702). 611 Protease inhibitors were omitted. Cells were lysed by sonication, clarified by centrifugation at 612 20,000 g for 30 minutes, then bound to $5 \mathrm{~mL}$ of Ni-NTA resin (Thermo Scientific 88222) for 1613 hour at $4^{\circ} \mathrm{C}$. The resin was washed with $100 \mathrm{~mL}$ of His binding buffer, then the protein was 614 eluted in $20 \mathrm{~mL}$ of His elution buffer (20 mM HEPES pH 7.5, $100 \mathrm{mM} \mathrm{KCl,} 400 \mathrm{mM} \mathrm{NaCl,} 615$ $250 \mathrm{mM}$ imidazole, $10 \%$ glycerol, and $1 \mathrm{mM} \mathrm{BME}$ ). The protein was then bound to a $5 \mathrm{~mL} 616$ HiTrap MonoQ column equilibrated in low salt buffer $(50 \mathrm{mM}$ Tris-HCL pH 8.0, $50 \mathrm{mM} \mathrm{KCl,} 617$ $10 \mathrm{mM} \mathrm{MgCl} 2,0.1 \mathrm{mM}$ EDTA, $10 \%$ glycerol, and $1 \mathrm{mM} \mathrm{BME}$ ), washed with $20 \mathrm{~mL}$ of low salt 618 buffer and then eluted using a $100 \mathrm{~mL}$ gradient between low salt buffer and high salt buffer $\left(\begin{array}{lll}50 & 619\end{array}\right.$ $\mathrm{mM}$ Tris-HCL pH 8.0, $200 \mathrm{mM} \mathrm{KCl,} 10 \mathrm{mM} \mathrm{MgCl}_{2}, 0.1 \mathrm{mM}$ EDTA, $10 \%$ glycerol, and $1 \mathrm{mM}{ }_{620}$ $\mathrm{BME})$. The protein was concentrated in a spin concentrator, then loaded onto a Superdex 200621 16/60 column (GE Healthcare) equilibrated in buffer (20 mM HEPES pH 7.5, $200 \mathrm{mM} \mathrm{KCl,} 622$ $0.1 \mathrm{mM}$ EDTA, $10 \mathrm{mM} \mathrm{MgCl} 2,10 \%$ glycerol and $1 \mathrm{mM}$ DTT). Fractions corresponding to ${ }_{623}$ the monomeric protein were pooled together, concentrated and aliquoted for storage at $-80^{\circ} \mathrm{C} .624$ Protein concentration was determined by measuring $\mathrm{A}_{280}$.

The rest of the recombinant proteins used in this paper were expressed with an N-terminal 627 6xHis-SUMO tag in E. coli strain BL21(DE3) and purified as described for Pab1, but using ${ }_{628}$ anion exchange instead of Heparin column.

\section{Fluorescein labeling of Pab1}

Fluorescein labeling of Pab1 termini was done using sortase catalyzed ligation of labeled peptides. 631 For N-terminal labeling, 6xHis-TEV-GGG-Pab1 was purified using the same protocol described 632 for wild-type Pab1 above. The labeling was done in SEC buffer (20 mM HEPES 7.3, $150 \mathrm{mM}{ }_{633}$ $\mathrm{KCl}$, and $2.5 \mathrm{mM} \mathrm{MgCl}_{2}$ ) as a $500 \mu \mathrm{L}$ reaction with $100 \mu \mathrm{M} \mathrm{Pab1,} 20 \mu \mathrm{M}$ wild-type sortase A, 634 $0.5 \mathrm{mM}$ TCEP, $10 \mathrm{mM} \mathrm{CaCl}_{2}$ and $0.5 \mathrm{mM}$ 5-FAM-HHHHHHLPETGG peptide (Biomatik). ${ }_{635}$ After an hour incubation at room temperature, labeled protein was separated from free peptide 636 on a $5 \mathrm{~mL}$ HiTrap Desalting column equilibrated in aggregation buffer (20 mM HEPES pH 6.8, 637 $150 \mathrm{mM} \mathrm{KCl}, 2.5 \mathrm{mM} \mathrm{MgCl}_{2}$, and $1 \mathrm{mM} \mathrm{DTT}$ ). The C-terminally labeled Pab1 was prepared ${ }_{638}$ similarly, but the labeling reaction was done with the following condition: $100 \mu \mathrm{M}$ Pab1, 639 $20 \mu \mathrm{M}$ heptamutant sortase A, $0.5 \mathrm{mM}$ TCEP, and 0.5 mM GGGK(FAM)AANDENYALAA or $\quad 640$ GGGK(FAM) peptide (Biomatik).

Yeast cells were diluted to $\mathrm{OD}_{600}$ of approximately 0.001 in $250 \mathrm{~mL}$ YPD and incubated at 643 $30^{\circ} \mathrm{C}$ until $\mathrm{OD}_{600}$ reached between 0.3 and $0.4 .30 \mathrm{~mL}$ of the cell culture was harvested as 644 the pre-shock sample by spinning in a $50 \mathrm{~mL}$ conical tube at 3,000 g for 5 minutes at room 645 temperature (RT). The cell pellet was resuspended in $1 \mathrm{~mL}$ of cold soluble protein buffer (SPB; 646 $20 \mathrm{mM}$ HEPES pH7.3, $120 \mathrm{mM} \mathrm{KCl,} 2 \mathrm{mM}$ EDTA, 0.2 mM DTT, 1:100 PMSF, and 1:100 647 protease inhibitors cocktail IV (MilliporeSigma 539136)), transferred to a pre-chilled $1.5 \mathrm{~mL} 648$ 
microcentrifuge tube, and centrifuged again at 5,000 g for 30 seconds at RT. Supernatant 649 was removed and the pellet was resuspended in $170 \mu \mathrm{L}$ SPB. Two $100 \mu \mathrm{L}$ aliquots from the 650 resuspended sample were snap-frozen in liquid nitrogen. The remaining cell culture was vacumm 651 filtered and the cell pellet was transferred to a $50 \mathrm{~mL}$ conical tube. The conical tube was placed ${ }_{652}$ in a $42^{\circ} \mathrm{C}$ water bath to heat shock the cells. After 20 minutes, the cell pellet was resuspended ${ }_{653}$ in $220 \mathrm{~mL}$ of pre-warmed $30^{\circ} \mathrm{C}$ YPD media. $30 \mathrm{~mL}$ of this culture was harvested as the heat ${ }_{654}$ shock sample and processed as described earlier. The remaining cell culture was transferred to a 655 $1 \mathrm{~L}$ flask and the cells were recovered in a $30^{\circ} \mathrm{C}$ water bath. Recovery samples were collected at 656 different time points and processed in the same way as the pre-shock sample. Cells were lysed 657 by cryomilling and fractionated as described in Wallace et al. (2015), with minor modifications 658 on spin conditions. Briefly, cell lysates were cleared at 3,000 g for 30 seconds. $150 \mu \mathrm{L}$ of the ${ }_{659}$ cleared lysate was transferred to a new $1.5 \mathrm{~mL}$ tube. To remove RNA, RNase $\mathrm{I}_{\mathrm{f}}$ (NEB M0243S) 660 was added to the final concentration of 0.3 units $/ \mu \mathrm{L}$ and the sample was incubated at RT for ${ }_{661}$ 30 minutes. $50 \mu \mathrm{L}$ of the sample was transferred to a new tube, mixed with Total protein buffer ${ }_{662}$ (TPB; 20 mM HEPES pH 7.3, 150 mM NaCl, 5 mM EDTA, 3\% SDS, 1:100 PMSF, 2 mM DTT, 663 and 1:1000 protease inhibitors IV (MilliporeSigma 539136)), and spun at 6,000 $\mathrm{g}$ for 1 minute ${ }_{664}$ to collect Total protein sample. Pellet samples were collected by spinning the remaining $100 \quad 665$ $\mu \mathrm{L}$ sample at 8,000 $\mathrm{g}$ for 5 minutes $\left(\mathrm{P}_{8}\right)$ and at $100,000 \mathrm{~g}$ for 20 minutes $\left(\mathrm{P}_{100}\right)$ at $4^{\circ} \mathrm{C}$, and ${ }_{666}$ resuspending the pellet in Insoluble protein buffer (IPB; TPB with $8 \mathrm{M}$ urea). Supernatant from ${ }_{667}$ this last spin was collected as the Soluble protein sample. Pab1 in each sample were visualized ${ }_{668}$ by SDS-PAGE and western blot as described in (Wallace et al., 2015) using mouse monoclonal ${ }_{669}$ anti-Pab1p antibody (EnCor Biotechnology MCA-1G1) and Image Lab software (Bio-Rad). $\quad 670$

\section{In vitro Total/Soluble/Pellet (TSP) assay}

Reaction mixture containing Pab1 condensates and molecular chaperones were prepared and incubated at $30^{\circ} \mathrm{C}$ for an hour either in the absence or presence of $5 \mathrm{mM}$ ATP. The reaction mixture (Table 2) were centrifuged at 100,000 g for 20 minutes at $4^{\circ} \mathrm{C}$. Supernatant was collected as the soluble fraction sample. Buffer (20 mM HEPES pH 7.3, $150 \mathrm{mM} \mathrm{KCl,} 2.5 \mathrm{mM} \mathrm{MgCl} 2$, $0.01 \%$ Triton X-100, $0.5 \mathrm{mg} / \mathrm{mL}$ BSA, and $1 \mathrm{mM} \mathrm{DTT}$ ) was added to the pellet and the sample was centrifuged again under the same condition. After removing the supernatant, the pellet was directly resuspended in 1x Laemmli buffer. Pab1 in each sample was visualized by SDS-PAGE and western blot as described in (Wallace et al., 2015) using Image Lab software (Bio-Rad).

\section{Preparation of Pab1 condensates}

Pab1 monomers were buffer exchanged into aggregation buffer $\left(20 \mathrm{mM}\right.$ HEPES pH 6.8, $150{ }_{681}$ $\mathrm{mM} \mathrm{KCl}, 2.5 \mathrm{mM} \mathrm{MgCl}_{2}$, and $1 \mathrm{mM} \mathrm{DTT}$ ) and diluted to make a $500 \mu \mathrm{L}$ sample of $25 \mu \mathrm{M}$ Pab1. The sample was sometimes supplemented with 100-fold lower firefly luciferase to increase yield. The sample was incubated in a $42^{\circ} \mathrm{C}$ water bath for 20 minutes at $\mathrm{pH} 6.8$. Under this heat shock condition, the solution remained clear and minimal protein pelleting was observed after a 3 minute centrifugation at $8,000 \mathrm{~g}$. N-terminally fluorescein labeled Pab1 aggregates were prepared at $39^{\circ} \mathrm{C}$. The supernatant was loaded onto a Superose 6 10/300 GL column (GE Healthcare) equilibrated with SEC/Storage buffer (20 mM HEPES pH 7.3, $150 \mathrm{mM} \mathrm{KCl,} 2.5 \mathrm{mM}$ $\mathrm{MgCl}_{2}$, and $1 \mathrm{mM}$ DTT). Void fractions containing small Pab1 assemblies (>5,000 kDa) were collected. About half of the loaded protein eluted in the void volume while the remaining protein eluted as monomers. Concentration of Pab1 condensates in each void fraction was measured

672 673 674 675 676 677 678 679 
using Bradford assay and/or SDS-PAGE with Pab1 standards of known concentrations. Protein 692 aliquots were snap-frozen in liquid nitrogen and stored at $-80^{\circ} \mathrm{C}$.

Because Pab1 binds 12-mer poly(A) with full affinity and has a binding footprint of roughly 25695 nucleotides (Sachs et al., 1987), we used 19-mer poly(A) RNA to get 1:1 binding of Pab1 to RNA. 696 Pab1 condensates, molecular chaperones, and 5' labeled A19 RNA (FAM-A19 or Atto550-A19) 697 were diluted to desired concentrations in disaggregation buffer (20 mM HEPES pH 7.3, $150 \mathrm{mM} \quad 698$ $\mathrm{KCl}, 2.5 \mathrm{mM} \mathrm{MgCl}_{2}, 0.5 \mathrm{mg} / \mathrm{mL} \mathrm{BSA}, 0.01 \%$ Triton X-100, and $1 \mathrm{mM} \mathrm{DTT}$ ). The reaction 699 mixture (Table 2) was supplemented with $5 \mathrm{mM} \mathrm{ATP}$, and $8 \mathrm{mM}$ creatine phosphate $(\mathrm{CP})$ and 700 $1 \mu \mathrm{M}$ creatine kinase (CK) for ATP regeneration. The reaction mixture was also supplemented 701 with $2 \%$ SUPERase RNase Inhibitor (Thermo Fisher AM2694) to prevent RNA degradation. 702 The final reaction volume was $15 \mu \mathrm{L}$. Calibration samples were prepared by adding known 703 concentrations of monomeric Pab1 to a fixed concentration of FAM-A19 used in the reaction 704 samples, typically $200 \mathrm{nM}$.

A new calibration curve was measured each time an experiment was performed. The reaction 706 mixtures were added to non-binding surface 384-well plate (Corning CLS3575). The plate 707 wells were sealed with a plate sealer (Thermo Fisher 235307) to prevent liquid evaporation. 708 Fluorescence anisotropy was measured every 20 second in Spark microplate reader (TECAN) 709 using excitation/emission wavelengths of $485 \mathrm{~nm} / 535 \mathrm{~nm}$, each with a bandwidth of $20 \mathrm{~nm}$, at 710 $30^{\circ} \mathrm{C}$. Disaggregation buffer was used as blank. G factor was calibrated with a solution of free 711 6-iodoacetamidofluorescein to produce a fluorescence polarization reading of $20 \mathrm{mP}$.

\section{Anisotropy data fitting and analysis}

The reaction data were fitted with the following logistic equation:

$$
\mathrm{y}=\mathrm{d}+\frac{\mathrm{m}}{1+\mathrm{e}^{-\mathrm{a}(\mathrm{x}-\mathrm{b})}}-\mathrm{x} * \mathrm{c}
$$

where $\mathrm{d}, \mathrm{m}, \mathrm{a}, \mathrm{b}$, and $\mathrm{c}$ are fitting parameters. The negative linear term accounts for the chaperone 715 concentration-dependent signal decay, which comes from RNA-degrading contaminants co- 716 purified with chaperones.

To extract maximal rate of Pab1 dispersal, the fluorescence anisotropy values were first 718 converted to the concentration of RNA-binding competent monomeric Pab1 using the calibration 719 curve. Fluorescence anisotropy data of the calibration samples were fitted with the following 720 equation:

$$
\mathrm{y}=\min +(\max -\min ) \frac{\left(\mathrm{RNA}+\mathrm{Pab} 1^{\mathrm{n}}+\mathrm{d}\right)-\sqrt{\left(\mathrm{RNA}+\mathrm{Pab} 1^{\mathrm{n}}+\mathrm{d}\right)^{2}-4\left(\mathrm{RNA} * \mathrm{Pab} 1^{\mathrm{n}}\right)}}{2 * \mathrm{RNA}}
$$

Min and max refer to the fluorescence anisotropy values of the calibration samples with no or 722 saturating amount of monomeric Pab1, respectively. The values of $\mathrm{d}$ and $\mathrm{n}$ extracted from the 723 calibration fit were used to convert fluorescence anisotropy values in the reaction samples to 724 concentrations of Pab1 with this rearranged equation (2): 


$$
\text { Pab1 }=\sqrt[n]{\frac{\left((\mathrm{y}-\mathrm{min})^{2} * \frac{\mathrm{RNA}}{\mathrm{max}-\min }-(\mathrm{y}-\min ) *(\mathrm{RNA}+\mathrm{d})\right)}{\mathrm{y}-\max }}
$$

The converted data were fitted again with equation (1). Maximal rate of dispersal was 726 calculated by computing the extracted fit parameters to the derivative of equation (1) when $\mathrm{x} 727$ $=\mathrm{b}$ :

$$
\begin{gathered}
\frac{\mathrm{dy}}{\mathrm{dx}}=\frac{\mathrm{a} * \mathrm{~m} * \mathrm{e}^{-\mathrm{a}(\mathrm{x}-\mathrm{b})}}{\left(1+\mathrm{e}^{-\mathrm{a}(\mathrm{x}-\mathrm{b})}\right)^{2}}-\mathrm{c} \\
\text { rate }_{\max }=\frac{\mathrm{a} * \mathrm{~m}}{4}-\mathrm{c}
\end{gathered}
$$

Note that, because Pab1 condensates exhibit substantially reduced but non-zero binding to 730 FAM-A19 in a concentration-dependent manner, the maximal rate of dispersal quantified from 731 fluorescence anisotropy data may be systematically underestimating the true rate of dispersal. 732

To convert the y-axis from Pab1 concentration to fraction restored Pab1, we first subtracted 733 background signal using the negative control data (no ATP). Background-subtracted data 734 were divided by the total concentration of Pab1, which was approximated by taking the mean 735 of highest 50-100 data points, i.e., data points in the plateau region of the positive control. 736 Total Pab1 concentration in the reaction had to be approximated this way for more accurate 737 quantification because we noticed that Pab1 condensates adhere to plastic, causing loss of ${ }_{738}$ about 30-50\% substrate during transfer. To compensate for this, 1.5 to 2-fold excess Pab1 739 was added to aim for, e.g., the final concentration of $0.2 \mu \mathrm{M}$ Pab1 in the reaction. The same 740 total Pab1 concentration was used to normalize reactions prepared from the same master mix. 741 The presence of $5 \mathrm{mM}$ ATP slightly lowered the fluorescence anisotropy baseline compared to 742 the no ATP control, and this led to negative starting values for all ATP-containing reactions 743 after background subtraction; All traces were shifted upward by the same amount to make the ${ }_{744}$ positive control reactions to start around the value of zero.

The rate data in Figure $6 \mathrm{~A}$ were fitted with a logistic equation:

$$
\mathrm{y}=\frac{\mathrm{a}}{1+\mathrm{e}^{-\mathrm{b}(\mathrm{x}-\mathrm{c})}}
$$

with a, b, and c as fitting parameters. We used the total Pab1 concentration to calculate the 747 ratio of chaperone to substrate.

Fluorescence-detection size-exclusion chromatography (FSEC)

Small Pab1-Clover condensates were prepared and mixed with chaperones, ATP, ATP regene- 750 ration system, and SUPERase RNase Inhibitor as described above for wild type Pab1 (Table 751 2). The reaction samples $\left(120 \mu \mathrm{L}\right.$ per run) were incubated at $30^{\circ} \mathrm{C}$ for an hour. $120 \mu \mathrm{L}$ of the 752 sample was loaded to a Superdex 200 10/300 GL column (GE Healthcare) equilibrated with 753 filtered running buffer (20 mM HEPES pH 7.3, $150 \mathrm{mM} \mathrm{KCl,} 2.5 \mathrm{mM} \mathrm{MgCl}_{2}$, and $1 \mathrm{mM} \mathrm{DTT}$ ) 754 using Akta system. Fluorescence was measured by a fluorescence detector (JASCO FP-2020 755 Plus) connected to the Akta system.

756 
Recombinant firefly luciferase was aggregated by incubating $2 \mu \mathrm{M}$ of luciferase with $10 \mu \mathrm{M} \quad 758$ Hsp26 in aggregation buffer (20 mM HEPES pH 6.8, $150 \mathrm{mM} \mathrm{KCl,} 2.5 \mathrm{mM} \mathrm{MgCl}_{2}$, and $1 \mathrm{mM} \quad 759$ DTT) at $42^{\circ} \mathrm{C}$ for 20 minutes. After cooling on ice for 2 minutes, the aggregates were diluted 760 to $0.2 \mu \mathrm{M}$ in the disaggregation buffer $\left(20 \mathrm{mM}\right.$ HEPES pH 7.3, $150 \mathrm{mM} \mathrm{KCl}, 2.5 \mathrm{mM} \mathrm{MgCl}_{2}, 761$ $0.5 \mathrm{mg} / \mathrm{mL}$ BSA, $0.01 \%$ Triton X-100, and $1 \mathrm{mM}$ DTT) supplemented with $5 \mathrm{mM} \mathrm{ATP,} 8 \quad 762$ mM CP, $1 \mu \mathrm{M}$ CK, and specified concentrations of chaperones (Table 2). The mixed sample 763 was incubated at $30^{\circ} \mathrm{C}$. At each time point, $2 \mu \mathrm{L}$ of the reaction sample was added to $18 \mu \mathrm{L} \quad 764$ of luciferin mix (Promega E1500), and luminescence was measured using Spark microplate 765 reader (TECAN) with integration time of 1 second. Luminescence of $0.2 \mu \mathrm{M}$ native luciferase 766 supplemented with $1 \mu \mathrm{M}$ Hsp26 in disaggregation buffer was used to compute reactivation yield. 767

For faster disaggregation using excess molecular chaperones (Figure 3B), $33.8 \mathrm{nM}$ luciferase 768 was heat shocked in the presence of $169 \mathrm{nM} \mathrm{Hsp} 26$ at $42^{\circ} \mathrm{C}$ for 20 minutes in low-salt aggregation $\quad 769$ buffer (25 mM HEPES pH 7.3, $50 \mathrm{mM} \mathrm{KCl,} 0.1 \mathrm{mM}$ EDTA, and $1 \mathrm{mM}$ DTT). Luciferase 770 aggregates were diluted to the final concentration of $20 \mathrm{nM}$ in the disaggregation buffer containing 771 chaperones (Table 2). Luminescence was measured as described above.

For disaggregation of chemically aggregated luciferase using $\mathrm{HAP} / \mathrm{ClpP}$ system (Figure $5 \mathrm{H} \quad 773$ and 5I), luciferase was diluted to $5 \mu \mathrm{M}$ in low-salt urea buffer $(25 \mathrm{mM}$ HEPES pH 7.3, $50 \quad 774$ $\mathrm{mM} \mathrm{KCl}, 0.1 \mathrm{mM}$ EDTA, $1 \mathrm{mM}$ DTT, and $8 \mathrm{M}$ urea) and incubated at $30^{\circ} \mathrm{C}$ for 30 minutes. 775 Aggregation was induced by diluting luciferase 100-fold into the disaggregation buffer containing 776 chaperones and HAP/ClpP (Table 2). Western blot samples were collected at the specified time ${ }_{777}$ points and stained using luciferase antibody (MilliporeSigma L0159). Blots were visualized using 778 Odyssey CLx (LI-COR). Luminescence was measured as described above using mock-treated luciferase as normalization control.

\section{Dynamic light scattering (DLS)}

DLS measurements were performed using DynaPro NanoStar (Wyatt). Sample acquisition 782 was done as described in (Riback et al., 2017). All experiments, unless noted otherwise, were 783 performed with $10 \mu \mathrm{M}$ Pab1 in filtered DLS buffer (20 mM HEPES pH 6.8, $150 \mathrm{mM} \mathrm{KCl,} 2.5784$ $\mathrm{mM} \mathrm{MgCl}_{2}$, and $1 \mathrm{mM} \mathrm{DTT}$ ). All protein samples used for DLS experiments were dialyzed 785 against DLS buffer overnight at $4^{\circ} \mathrm{C}$ and cleared of aggregates by spinning at 20,000 g for 20786 minutes.

\section{GroEL trap assay}

Pab1 dispersal and luciferase reactivation assays were done as described above, but in the presence of 5-fold excess GroEL trap (Table 2). For refolding experiment, $5 \mu \mathrm{M}$ Pab1 was denatured in $8 \mathrm{M}$ urea buffer $(20 \mathrm{mM}$ HEPES pH 6.8, $150 \mathrm{mM} \mathrm{KCl}, 2.5 \mathrm{mM} \mathrm{MgCl} 2,1 \mathrm{mM}$ DTT, and $8 \mathrm{M}$ urea) and incubated at $30^{\circ} \mathrm{C}$ for 30 minutes. Pab1 was first diluted to $0.5 \mu \mathrm{M}$ in refolding buffer (20 mM HEPES pH 7.3, $150 \mathrm{mM} \mathrm{KCl,} 2.5 \mathrm{mM} \mathrm{MgCl}_{2}$, and $1 \mathrm{mM} \mathrm{DTT}$ ) containing no or 10-fold excess GroEL trap, and then to $0.1 \mu \mathrm{M}$ in the same respective refolding buffer with $0.1 \mu \mathrm{M}$ FAM-A19. Pab1's RNA-binding activity was measured by fluorescence anisotropy. 
Digestion by the HAP/ClpP system was done in disaggregation buffer (20 mM HEPES pH 7.3, 798 $150 \mathrm{mM} \mathrm{KCl}, 2.5 \mathrm{mM} \mathrm{MgCl} 2,0.5 \mathrm{mg} / \mathrm{mL}$ BSA, $0.01 \%$ Triton X-100, and $1 \mathrm{mM}$ DTT) with 0.2799 $\mu \mathrm{M}$ Pab1 condensate or monomer, $1.5 \mu \mathrm{M}$ ClpP, $1 \mu \mathrm{M}$ Hsp104 (WT or HAP), $0.5 \mu \mathrm{M}$ Sis1, 1-2 800 $\mu \mathrm{M}$ Ssa2, $5 \mathrm{mM}$ ATP, and $8 \mathrm{mM} \mathrm{CP}$ and $1 \mu \mathrm{M}$ CK for ATP regeneration (Table 2). Reactions 801 were run for 1 hour at $30^{\circ} \mathrm{C}$, then quenched with Laemmli buffer and run on a Bio-rad TGX 802 4-20\% SDS-PAGE gel. Fluorescent gels were imaged using a ChemiDoc (Bio-rad) and westerns 803 were performed using a 1:5000 dilution of Rabbit anti-GFP antibody (Life A11122) and a 804 1:20,000 dilution of secondary (Donkey anti-Rabbit, LiCor 925-32213). Blots were visualized 805 using Odyssey CLx (LI-COR).

The ClpXP digestion reaction was done for 30 minutes at $30^{\circ} \mathrm{C}$ with $0.2 \mu \mathrm{M}$ Pab1-FAM 807 monomer, $0.1 \mu \mathrm{M}$ ClpX and $1 \mu \mathrm{M} \mathrm{ClpP}$ in disaggregation buffer.

\section{Disaggregation data from the literature}

The following data from 18 different studies (Nillegoda et al., 2017; Doyle et al., 2015; Rampelt 810 et al., 2012; Yu et al., 2015; Żwirowski et al., 2017; Martín et al., 2014; Kłosowska et al., 2016; 811 Reidy et al., 2014; Rosenzweig et al., 2013; DeSantis et al., 2012; Shorter, 2011; Haslberger et al., 812 2008; Glover and Lindquist, 1998; Ratajczak et al., 2009; Cashikar et al., 2005; Goloubinoff 813 et al., 1999; Sielaff and Tsai, 2010; Duennwald et al., 2012) were compiled for comparison: 1) 814 substrate identity; 2) concentrations of substrate and molecular chaperones used; 3) maximum 815 yield observed within the experimental time; 4) the names of molecular chaperones; and 5) 816 reference to the source paper with DOI. Only the results from in vitro experiments were recorded. 817 Studies reporting fold-change relative to negative control were omitted because yield cannot 818 be determined from the given information for comparison. For a study which reports multiple 819 disaggregation results with the same substrate, the concentrations of substrate and chaperones 820 which give the highest maximal yield were recorded.

\section{Modeling and simulation}

In our model, free substrates exist in one of the following states: folded $\left(\mathrm{S}_{\mathrm{f}}\right)$, unfolded $\left(\mathrm{S}_{\mathrm{u}}\right),{ }_{823}$ misfolded $\left(\mathrm{S}_{\mathrm{m}}\right)$, and aggregated $\left(\mathrm{S}_{\mathrm{a}}\right)$. Free Hsp70 exists either in an ATP-bound state $\left(\mathrm{Hsp}_{\mathrm{ATP}}\right) \quad 824$ or an ADP-bound state (Hsp70 ATP), and each state can bind certain free substrates to form a 825 complex (e.g., Hsp70ATP:Sa). ATP hydolysis of Hsp70ATP in Hsp70ATP: $\mathrm{S}_{\mathrm{m}}$ complex results in 826 substrate unfolding, a step we call "priming". For an aggregated substate, the same sequence of 827 events do not result in any state transition but instead primes the complex (Hsp70ATP:S $\mathrm{S}_{\text {ap }}$ ) for ${ }_{828}$ interaction with Hsp104. In the cooperative model, a second Hsp70ATP can bind Hsp70ADP:Sap 829 complex to form a ternary complex $\left(\mathrm{Hsp}_{0} 0_{\mathrm{ATP}} \mathrm{ADP}: \mathrm{S}_{\mathrm{ap}}\right)$ and only the ternary complex with both 830 Hsp70s in the ADP-bound state (Hsp70 ADP,ADP:S $\mathrm{Sp}_{\text {ap }}$ ) can engage with Hsp104 for disaggregation. 831 For simplicity, we did not allow unfolding of a natively folded substrate.

The time evolution of the concentrations of all distinct species in the cooperative model was described using the following ODEs:

832

833

$$
\begin{aligned}
& \frac{\mathrm{d}\left[\operatorname{Hsp}_{\mathrm{ATP}}\right]}{\mathrm{dt}}=\mathrm{k}_{\mathrm{DT}}\left[\mathrm{Hsp}_{\mathrm{ADP}}\right]+\mathrm{k}_{\mathrm{off}}^{\mathrm{ATP}}\left(\left[\operatorname{Hsp}_{\mathrm{ATP}}: \mathrm{S}_{\mathrm{a}}\right]+\left[\operatorname{Hsp}_{\mathrm{ATP}}: \mathrm{S}_{\mathrm{ap}}\right]\right. \\
& \left.+\left[\operatorname{Hsp}_{\mathrm{ATP}}: \mathrm{S}_{\mathrm{m}}\right]+\left[\operatorname{Hsp}_{\mathrm{ATP}}: \mathrm{S}_{\mathrm{u}}\right]+\left[\operatorname{Hsp}_{\mathrm{ATP}, \mathrm{ADP}}: \mathrm{S}_{\mathrm{ap}}\right]\right) \\
& -\left[\operatorname{Hsp}_{0} 0_{\mathrm{ATP}}\right]\left(\mathrm{k}_{\mathrm{on}}^{\mathrm{ATP}}\left(\left[\mathrm{S}_{\mathrm{m}}\right]+\left[\mathrm{S}_{\mathrm{a}}\right]\right)+\left(\mathrm{k}_{\mathrm{TD}}+\mathrm{k}_{\mathrm{h}}\right)+0.1 \mathrm{k}_{\mathrm{on}}^{\mathrm{ATP}}\left[\mathrm{Hsp}_{\mathrm{ADP}}: \mathrm{S}_{\mathrm{ap}}\right]\right)
\end{aligned}
$$




$$
\begin{aligned}
& \frac{\mathrm{d}\left[\mathrm{Hsp} 70_{\mathrm{ADP}}\right]}{\mathrm{dt}}=\left(\mathrm{k}_{\mathrm{TD}}+\mathrm{k}_{\mathrm{h}}\right)\left[\mathrm{Hsp}_{\mathrm{ATP}}\right]+\mathrm{k}_{\mathrm{off}}^{\mathrm{ADP}}\left(\left[\mathrm{Hsp}_{\mathrm{ADP}}: \mathrm{S}_{\mathrm{ap}}\right]\right. \\
& \left.+\left[\operatorname{Hsp}_{0} 0_{\mathrm{ADP}}: \mathrm{S}_{\mathrm{u}}\right]\right)+2 \mathrm{k}_{\mathrm{off}}^{\mathrm{ADP}, 104}\left[\mathrm{Hsp}_{\mathrm{ADP}, \mathrm{ADP}}: \mathrm{S}_{\mathrm{ap}}:\right. \text { Hsp104] } \\
& -\left[\mathrm{Hsp}_{0} \mathrm{ADP}\right]\left(\mathrm{k}_{\mathrm{DT}}+\mathrm{k}_{\mathrm{On}}^{\mathrm{ADP}}\left(\left[\mathrm{S}_{\mathrm{a}}\right]+\left[\mathrm{S}_{\mathrm{u}}\right]\right)\right) \\
& \frac{\mathrm{d}[\mathrm{Hsp} 104]}{\mathrm{dt}}=\mathrm{k}_{\mathrm{off}}^{104}\left[\mathrm{Hsp}_{\mathrm{ADP}, \mathrm{ADP}}: \mathrm{S}_{\mathrm{ap}}: \text { Hsp104] }+\mathrm{k}_{\text {disagg }}\left[\mathrm{Hsp} 104: \mathrm{S}_{\mathrm{ap}}\right]\right. \\
& -\left[\text { Hsp104] }\left[H_{s p 70} \text { ADP,ADP : } \mathrm{S}_{\text {ap }}\right] \mathrm{k}_{\mathrm{on}}^{104}\right. \\
& \frac{\mathrm{d}\left[\mathrm{S}_{\mathrm{a}}\right]}{\mathrm{dt}}=\mathrm{k}_{3}\left[\mathrm{~S}_{\mathrm{m}}\right]+\mathrm{k}_{\mathrm{off}}^{\mathrm{ATP}}\left(\left[\operatorname{Hsp}_{\mathrm{ATP}}: \mathrm{S}_{\mathrm{a}}\right]+\left[\operatorname{Hsp}_{\mathrm{ATP}}: \mathrm{S}_{\mathrm{ap}}\right]\right)+\mathrm{k}_{\mathrm{off}}^{\mathrm{ADP}}\left[\mathrm{Hsp}_{\mathrm{ADP}}: \mathrm{S}_{\mathrm{ap}}\right] \\
& -\left[\mathrm{S}_{\mathrm{a}}\right]\left(\mathrm{k}_{\mathrm{on}}^{\mathrm{ATP}}\left[\mathrm{Hsp} 70_{\mathrm{ATP}}\right]+\mathrm{k}_{\mathrm{on}}^{\mathrm{ADP}}\left[\mathrm{Hsp} 70_{\mathrm{ADP}}\right]\right) \\
& \frac{\mathrm{d}\left[\operatorname{Hsp}_{\mathrm{ATP}}: \mathrm{S}_{\mathrm{a}}\right]}{\mathrm{dt}}=\mathrm{k}_{\mathrm{On}}^{\mathrm{ATP}}\left[\operatorname{Hsp}_{\mathrm{ATP}}\right]\left[\mathrm{S}_{\mathrm{a}}\right]+\mathrm{k}_{\mathrm{DT}}^{\mathrm{S}}\left[\operatorname{Hsp}_{\mathrm{ADP}}: \mathrm{S}_{\mathrm{a}}\right] \\
& -\left[\operatorname{Hsp}_{\text {ATP }}: \mathrm{S}_{\mathrm{a}}\right]\left(\mathrm{k}_{\mathrm{off}}^{\mathrm{ATP}}+\mathrm{k}_{\mathrm{TD}}^{\mathrm{S}}+\mathrm{k}_{\mathrm{h}}^{\mathrm{S}}\right) \\
& \frac{\mathrm{d}\left[\operatorname{Hsp}_{0} 0_{\mathrm{ADP}}: \mathrm{S}_{\mathrm{a}}\right]}{\mathrm{dt}}=\left(\mathrm{k}_{\mathrm{TD}}^{\mathrm{s}}+\mathrm{k}_{\mathrm{h}}^{\mathrm{S}}\right)\left[\operatorname{Hsp}_{\mathrm{ATP}}: \mathrm{S}_{\mathrm{a}}\right]+\mathrm{k}_{\text {deprime }}\left[\operatorname{Hsp}_{\mathrm{ADP}}: \mathrm{S}_{\mathrm{ap}}\right] \\
& -\left[\mathrm{Hsp}_{\mathrm{ADP}}: \mathrm{S}_{\mathrm{a}}\right]\left(\mathrm{k}_{\mathrm{DT}}^{\mathrm{S}}+\mathrm{k}_{\mathrm{prime}}\right) \\
& \frac{\mathrm{d}\left[\operatorname{Hsp} 70_{\mathrm{ADP}}: \mathrm{S}_{\mathrm{ap}}\right]}{\mathrm{dt}}=\mathrm{k}_{\text {prime }}\left[\operatorname{Hsp}_{\mathrm{ADP}}: \mathrm{S}_{\mathrm{a}}\right]+\mathrm{k}_{\mathrm{TD}}^{\mathrm{s}}\left[\operatorname{Hsp}_{\mathrm{ATP}}: \mathrm{S}_{\mathrm{ap}}\right] \\
& +\mathrm{k}_{\mathrm{off}}^{\mathrm{ATP}}\left[\mathrm{Hsp}_{\mathrm{ATP}, \mathrm{ADP}}: \mathrm{S}_{\mathrm{ap}}\right]+\mathrm{k}_{\mathrm{On}}^{\mathrm{ADP}}\left[\mathrm{Hsp}_{\mathrm{ADP}}\right]\left[\mathrm{S}_{\mathrm{a}}\right] \\
& -\left[\mathrm{Hsp}_{0} \mathrm{ADP}: \mathrm{S}_{\mathrm{ap}}\right]\left(\mathrm{k}_{\text {deprime }}+\mathrm{k}_{\mathrm{DT}}^{\mathrm{S}}+\mathrm{k}_{\mathrm{off}}^{\mathrm{ADP}}+0.1 \mathrm{k}_{\mathrm{on}}^{\mathrm{ATP}}\left[\mathrm{Hsp}_{\mathrm{ATP}}\right]\right) \\
& \frac{\mathrm{d}\left[\operatorname{Hsp}_{0} 0_{\mathrm{ATP}}: \mathrm{S}_{\mathrm{ap}}\right]}{\mathrm{dt}}=\mathrm{k}_{\mathrm{DT}}^{\mathrm{s}}\left[\mathrm{Hsp}_{\mathrm{ADP}}: \mathrm{S}_{\mathrm{ap}}\right]-\left[\mathrm{Hsp}_{\mathrm{ATP}}: \mathrm{S}_{\mathrm{ap}}\right]\left(\mathrm{k}_{\mathrm{off}}^{\mathrm{ATP}}+\mathrm{k}_{\mathrm{TD}}^{\mathrm{s}}\right) \\
& \frac{\mathrm{d}\left[\mathrm{Hsp}_{\mathrm{ADP}, \mathrm{ADP}}: \mathrm{S}_{\mathrm{ap}}: \mathrm{Hsp} 104\right]}{\mathrm{dt}}=\mathrm{k}_{\mathrm{On}}^{104}\left[\mathrm{Hsp}_{\mathrm{ADP}, \mathrm{ADP}}: \mathrm{S}_{\mathrm{ap}}\right][\mathrm{Hsp} 104] \\
& -\left[H_{s p} 70_{\mathrm{ADP}, \mathrm{ADP}}: \mathrm{S}_{\mathrm{ap}}: \mathrm{Hsp} 104\right]\left(\mathrm{k}_{\mathrm{off}}^{104}+\mathrm{k}_{\mathrm{off}}^{\mathrm{ADP}, 104}\right) \\
& \frac{\mathrm{d}\left[\mathrm{Hsp} 104: \mathrm{S}_{\mathrm{ap}}\right]}{\mathrm{dt}}=\mathrm{k}_{\mathrm{off}}^{\mathrm{ADP}, 104}\left[\mathrm{Hsp}{ }_{\mathrm{ADP}, \mathrm{ADP}}: \mathrm{S}_{\mathrm{ap}}: \text { Hsp104] }-\left[\text { Hsp104 : } \mathrm{S}_{\mathrm{ap}}\right] \mathrm{k}_{\text {disagg }}\right. \\
& \frac{\mathrm{d}\left[\mathrm{S}_{\mathrm{u}}\right]}{\mathrm{dt}}=\mathrm{k}_{2}^{\mathrm{r}}\left[\mathrm{S}_{\mathrm{m}}\right]+\mathrm{k}_{\operatorname{disagg}}\left[\mathrm{Hsp} 104: \mathrm{S}_{\mathrm{ap}}\right] \\
& +\mathrm{k}_{\text {off }}^{\mathrm{ATP}}\left[\mathrm{Hsp}_{\mathrm{ATP}}: \mathrm{S}_{\mathrm{u}}\right]+\mathrm{k}_{\mathrm{off}}^{\mathrm{ADP}}\left[\operatorname{Hsp} 70_{\mathrm{ADP}}: \mathrm{S}_{\mathrm{u}}\right] \\
& -\left[\mathrm{S}_{\mathrm{u}}\right]\left(\mathrm{k}_{1}+\mathrm{k}_{2}+\mathrm{k}_{\mathrm{On}}^{\mathrm{ADP}}\left[\mathrm{Hsp}_{\mathrm{ADP}}\right]\right) \\
& \frac{\mathrm{d}\left[\mathrm{S}_{\mathrm{m}}\right]}{\mathrm{dt}}=\mathrm{k}_{2}\left[\mathrm{~S}_{\mathrm{u}}\right]+\mathrm{k}_{\mathrm{off}}^{\mathrm{ATP}}\left[\mathrm{Hsp}_{\mathrm{ATP}}: \mathrm{S}_{\mathrm{m}}\right] \\
& -\left[\mathrm{S}_{\mathrm{m}}\right]\left(\mathrm{k}_{2}^{\mathrm{r}}+\mathrm{k}_{3}+\mathrm{k}_{\mathrm{on}}^{\mathrm{ATP}}\left[\mathrm{Hsp}_{\mathrm{ATP}}\right]\right)
\end{aligned}
$$




$$
\begin{aligned}
& \frac{\mathrm{d}\left[\mathrm{S}_{\mathrm{f}}\right]}{\mathrm{dt}}=\mathrm{k}_{1}\left[\mathrm{~S}_{\mathrm{u}}\right] \\
& \frac{\mathrm{d}\left[\mathrm{Hsp}_{\mathrm{sp}} \mathrm{ATP}: \mathrm{S}_{\mathrm{m}}\right]}{\mathrm{dt}}=\mathrm{k}_{\mathrm{On}}^{\mathrm{ATP}}\left[\mathrm{S}_{\mathrm{m}}\right]\left[\mathrm{Hsp}_{\mathrm{ATP}}\right]+\mathrm{k}_{\mathrm{DT}}^{\mathrm{s}}\left[\mathrm{Hsp}_{\mathrm{ADP}}: \mathrm{S}_{\mathrm{m}}\right] \\
& -\left[\operatorname{Hsp}_{\mathrm{ATP}}: \mathrm{S}_{\mathrm{m}}\right]\left(\mathrm{k}_{\mathrm{off}}^{\mathrm{ATP}}+\mathrm{k}_{\mathrm{TD}}^{\mathrm{s}}+\mathrm{k}_{\mathrm{h}}^{\mathrm{s}}\right) \\
& \frac{\mathrm{d}\left[\operatorname{Hsp}_{\mathrm{ADP}}: \mathrm{S}_{\mathrm{m}}\right]}{\mathrm{dt}}=\left(\mathrm{k}_{\mathrm{TD}}^{\mathrm{S}}+\mathrm{k}_{\mathrm{h}}^{\mathrm{S}}\right)\left[\operatorname{Hsp}_{\mathrm{ATP}}: \mathrm{S}_{\mathrm{m}}\right]+\mathrm{k}_{\text {deprime }}\left[\operatorname{Hsp}_{\mathrm{ADP}}: \mathrm{S}_{\mathrm{u}}\right] \\
& -\left[\operatorname{Hsp}_{0} 0_{\mathrm{ADP}}: \mathrm{S}_{\mathrm{m}}\right]\left(\mathrm{k}_{\mathrm{DT}}^{\mathrm{s}}+\mathrm{k}_{\text {prime }}\right) \\
& \frac{\mathrm{d}\left[\operatorname{Hsp} 70_{\mathrm{ADP}}: \mathrm{S}_{\mathrm{u}}\right]}{\mathrm{dt}}=\mathrm{k}_{\text {prime }}\left[\operatorname{Hsp}_{\mathrm{A}} 70_{\mathrm{ADP}}: \mathrm{S}_{\mathrm{m}}\right]+\mathrm{k}_{\mathrm{TD}}^{\mathrm{s}}\left[\operatorname{Hsp}_{\mathrm{ATP}}: \mathrm{S}_{\mathrm{u}}\right] \\
& +\mathrm{k}_{\mathrm{On}}^{\mathrm{ADP}}\left[\mathrm{Hsp}_{\mathrm{ADP}}\right]\left[\mathrm{S}_{\mathrm{u}}\right]-\left[\mathrm{Hsp} 70_{\mathrm{ADP}}: \mathrm{S}_{\mathrm{u}}\right]\left(\mathrm{k}_{\text {deprime }}+\mathrm{k}_{\mathrm{DT}}^{\mathrm{S}}+\mathrm{k}_{\mathrm{off}}^{\mathrm{ADP}}\right) \\
& \frac{\mathrm{d}\left[\operatorname{Hsp}_{0} 0_{\mathrm{ATP}}: \mathrm{S}_{\mathrm{u}}\right]}{\mathrm{dt}}=\mathrm{k}_{\mathrm{DT}}^{\mathrm{S}}\left[\operatorname{Hsp} 70_{\mathrm{ADP}}: \mathrm{S}_{\mathrm{u}}\right]-\left[\operatorname{Hsp}_{\mathrm{ATP}}: \mathrm{S}_{\mathrm{u}}\right]\left(\mathrm{k}_{\mathrm{Off}}^{\mathrm{ATP}}+\mathrm{k}_{\mathrm{TD}}^{\mathrm{s}}\right) \\
& \frac{\mathrm{d}\left[\operatorname{Hsp}_{\mathrm{ATP}, \mathrm{ADP}}: \mathrm{S}_{\mathrm{ap}}\right]}{\mathrm{dt}}=0.1 \mathrm{k}_{\mathrm{On}}^{\mathrm{ATP}}\left[\mathrm{Hsp}_{\mathrm{ATP}}\right]\left[\mathrm{Hsp}_{\mathrm{ADP}}: \mathrm{S}_{\mathrm{ap}}\right] \\
& +2 \mathrm{k}_{\mathrm{DT}}^{\mathrm{S}}\left[\mathrm{Hsp} 70_{\mathrm{ADP}, \mathrm{ADP}}: \mathrm{S}_{\mathrm{ap}}\right] \\
& -\left[\mathrm{Hsp}_{0} \mathrm{ATP}, \mathrm{ADP}: \mathrm{S}_{\mathrm{ap}}\right]\left(\mathrm{k}_{\mathrm{off}}^{\mathrm{ATP}}+\mathrm{k}_{\mathrm{TD}}^{\mathrm{S}}+\mathrm{k}_{\mathrm{h}}^{\mathrm{S}}\right) \\
& \frac{\mathrm{d}\left[\mathrm{Hsp} 70_{\mathrm{ADP}, \mathrm{ADP}}: \mathrm{S}_{\mathrm{ap}}\right]}{\mathrm{dt}}=\left(\mathrm{k}_{\mathrm{TD}}^{\mathrm{s}}+\mathrm{k}_{\mathrm{h}}^{\mathrm{s}}\right)\left[\mathrm{Hsp}_{\mathrm{ATP}, \mathrm{ADP}}: \mathrm{S}_{\mathrm{ap}}\right] \\
& +\mathrm{k}_{\mathrm{off}}^{104}\left[\mathrm{Hsp}_{\mathrm{ADP}, \mathrm{ADP}}: \mathrm{S}_{\mathrm{ap}}:\right. \text { Hsp104] } \\
& -\left[\mathrm{Hsp}_{\mathrm{ADP}, \mathrm{ADP}}: \mathrm{S}_{\mathrm{ap}}\right]\left(2 \mathrm{k}_{\mathrm{DT}}^{\mathrm{s}}+\mathrm{k}_{\mathrm{On}}^{104}[\mathrm{Hsp} 104]\right)
\end{aligned}
$$

The parameter values used for the simulation are listed in Table 1. Note that the current 835 model lacks spatial information; an extension of this model allowing spatial segregation of 836 aggregated substrates would allow investigating the effect of aggregate shape and/or size on the 837 efficiency of the disaggregation system. 


\section{Supplemental Figures}
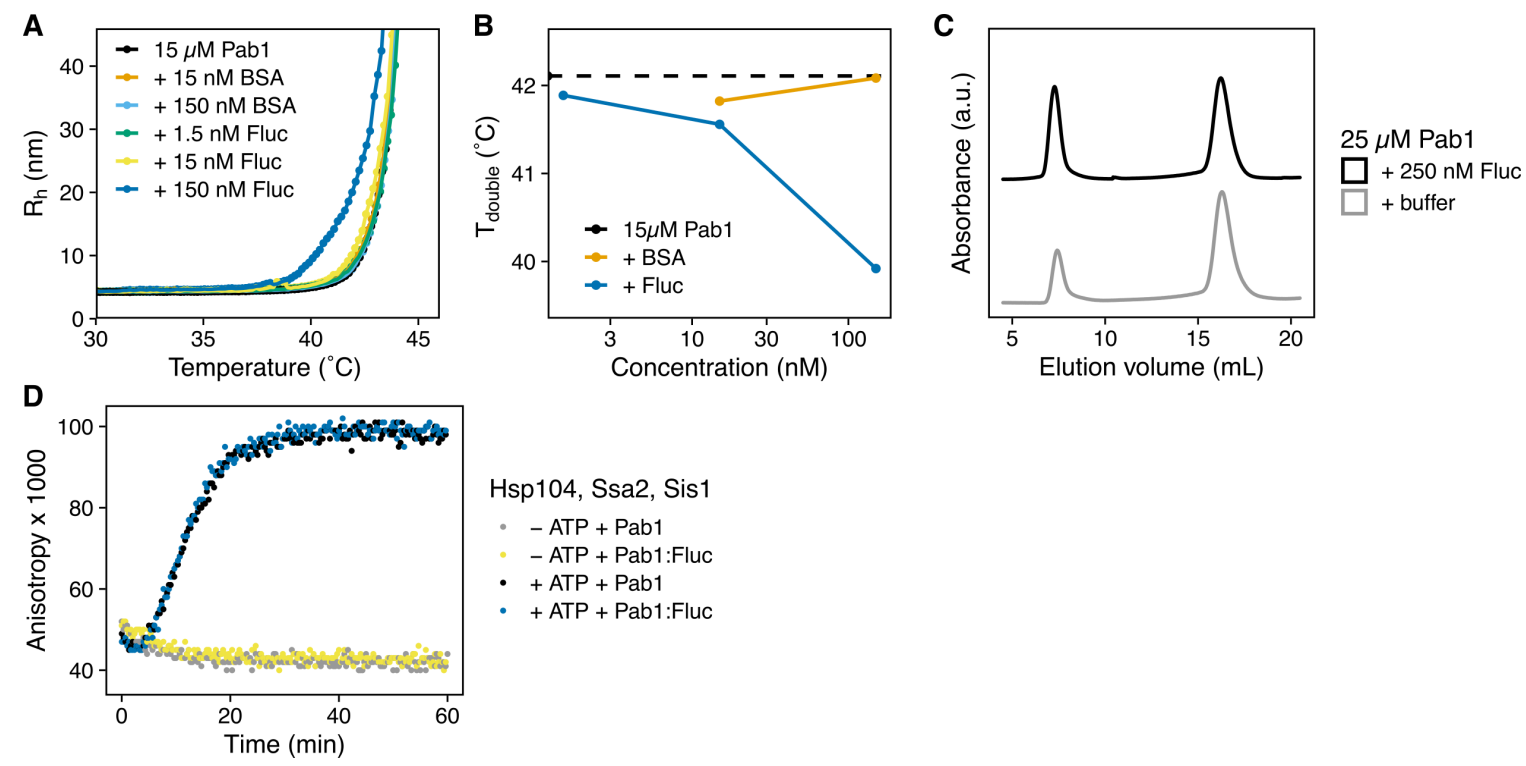

Figure S1. Misfolded protein can nucleate Pab1 condensation; Related to Figure 1.

(A) DLS temperature ramp experiment with $15 \mu \mathrm{M}$ Pab1 in the presence of increasing concentrations of firefly luciferase (Fluc) or BSA. (B) $\mathrm{T}_{\text {double }}$, temperature at which the baseline $\mathrm{R}_{\mathrm{h}}$ doubles, for the DLS temperature ramp experiment shown in $(\mathrm{A})$ is plotted against the concentrations of the additives (either BSA or luciferase). Dashed line indicates $\mathrm{T}_{\text {double }}$ for Pab1 in the absence of any additives. (C) Representative SEC trace of Pab1 heat shocked in the absence or presence of 100-fold lower luciferase. Pab1 condensates and monomers elute around $7.5 \mathrm{~mL}$ and $16 \mathrm{~mL}$, respectively. (D) Dispersal of Pab1 condensates formed in the presence or absence of 100-fold less luciferase. Condensation in the presence of 100-fold lower luciferase does not affect subsequent condensate dispersal by chaperones. 
A
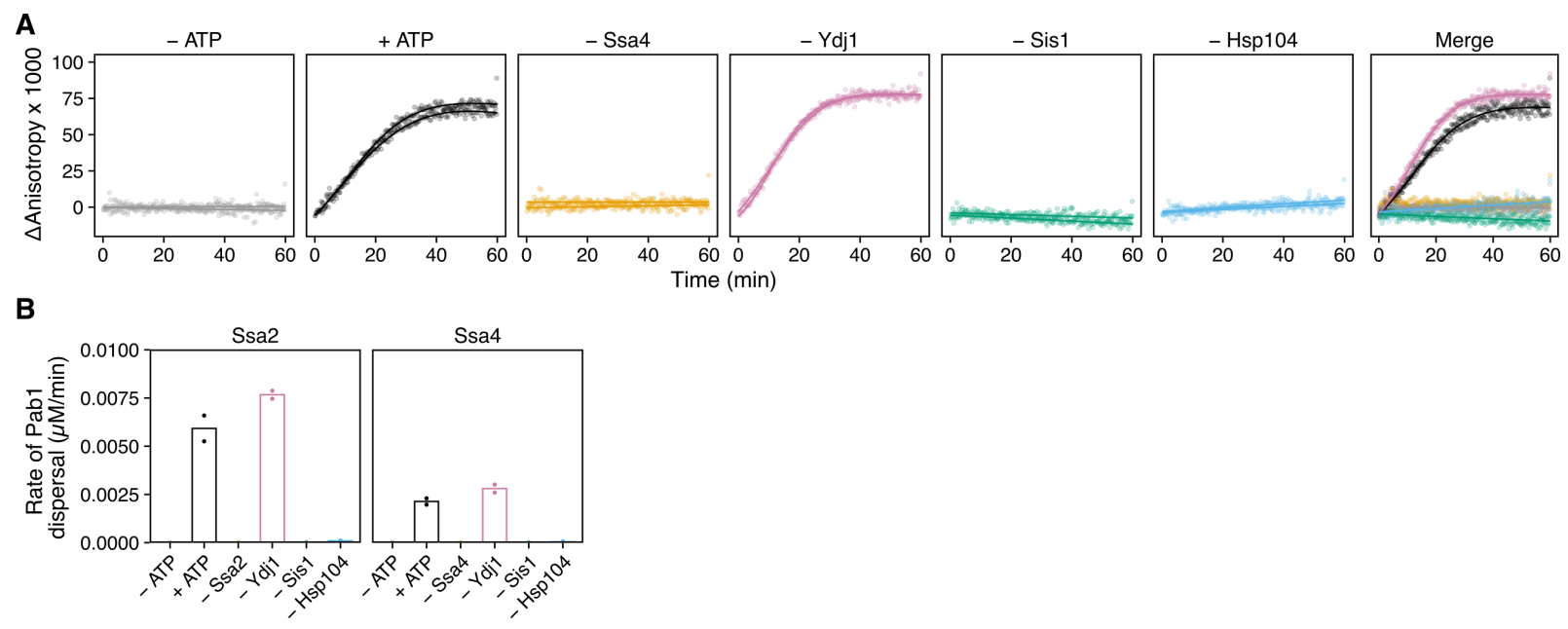

Figure S2. Ssa2 can be replaced by its heat-inducible paralog Ssa4 for Pab1 dispersal; Related to Figure 2.

(A) Time-resolved fluorescence anisotropy of A19 in the presence of Pab1 condensates and molecular chaperones. All chaperones shown in Figure 2A, except Sse1, were included in the experiments. Ssa4 was added instead of Ssa2. Fitted data points from two independent experiments are shown. Merged data points and a solid line fitted to the average of each experimental condition is shown on the right. (B) Maximal rate of dispersal quantified from the dropout experiments in the absence of Sse1. 
A
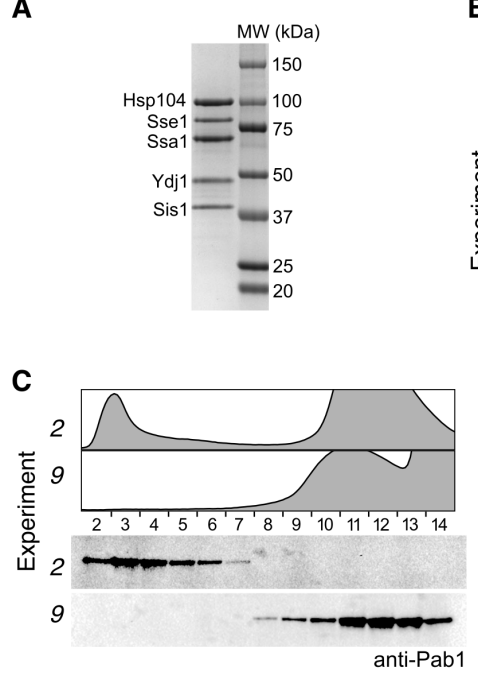

B

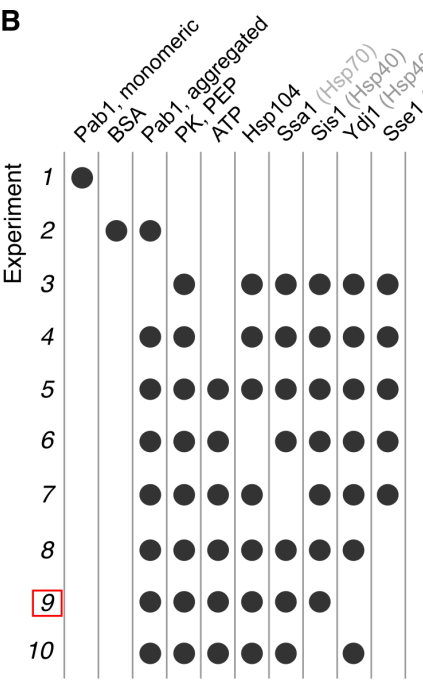

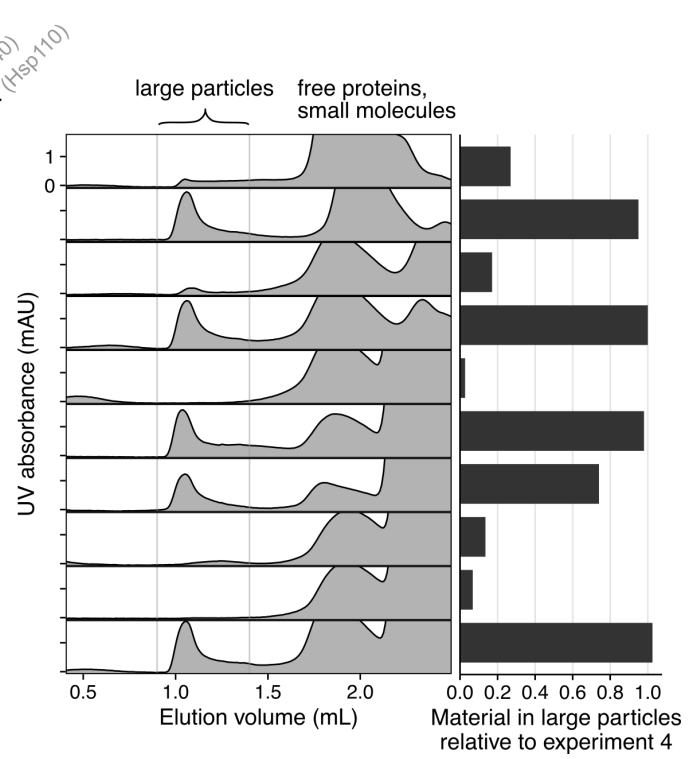

Figure S3. Hsp104, Hsp70, and Sis1 are necessary and sufficient for Pab1 dispersal; Related to Figure 2.

(A) Purification of recombinant chaperones. (B) Dropout experiments to determine the components necessary for dispersal of Pab1 condensates. Pab1 dispersal reaction samples were examined by Superose 6 Precision Column. Red box highlights the minimal set composed of Hsp104, Ssa1, and Sis1. PK and PEP stand for pyruvate kinase and phosphoenolpyruvate, respectively. (C) Verification of Pab1 dispersal by western blot. 
A

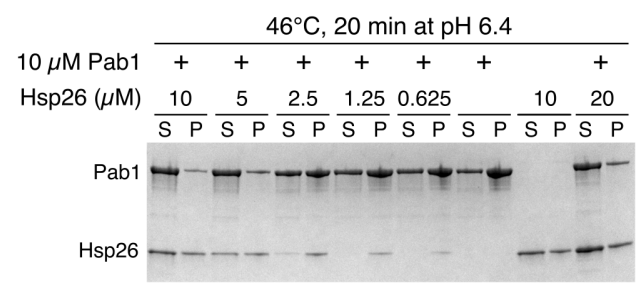

\section{C}

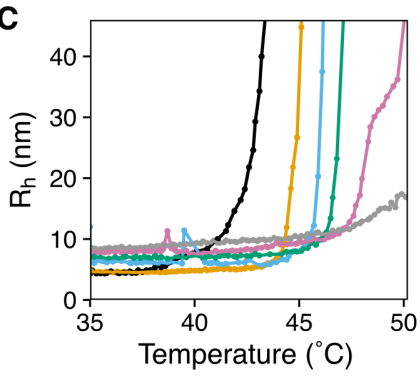

$\mathbf{E}$

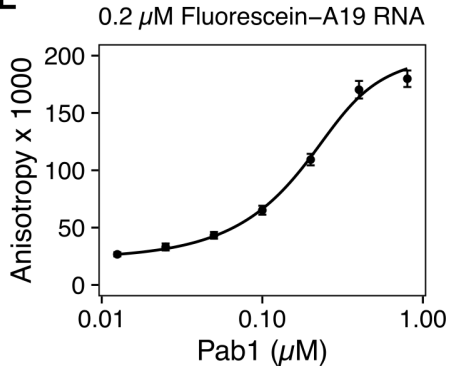

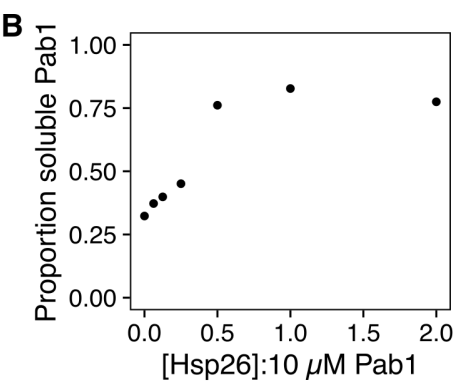

D

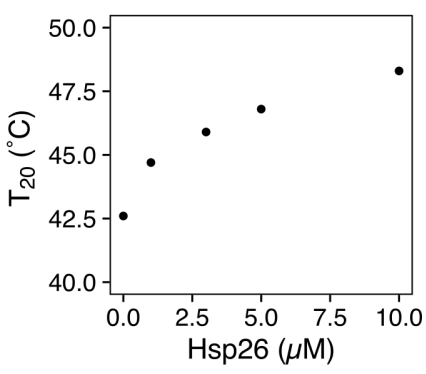

Figure S4. Hsp26 suppresses Pab1 condensation; Related to Figure 3.

(A) DLS temperature ramp experiment with $10 \mu \mathrm{M}$ Pab1 with increasing concentrations of Hsp26 at pH 6.4. Note that the presence of Hsp26, which forms high molecular weight oligomers, shifts the DLS baseline upward. (B) Temperature at which Pab1's hydrodynamic radius crosses $20 \mathrm{~nm}$ in (A) is plotted against Hsp26 concentration. (C) Sedimentation of Pab1 in the absence or presence of increasing concentrations of Hsp26, visualized by Coomassie staining. (D) Quantification of proportion soluble Pab1 in (C) plotted against the ratio of Hsp26 to Pab1. (E) A representative calibration curve showing the increasing fluorescence anisotropy of the labeled A19 RNA as a function of increasing concentration of monomeric Pab1. The calibration curve was used convert the y-axis from fluorescence anisotropy to Pab1 concentration and extract the rate of dispersal. The mean and standard deviation of 8 independent calibration data are shown. Data were fitted with equation 2. 

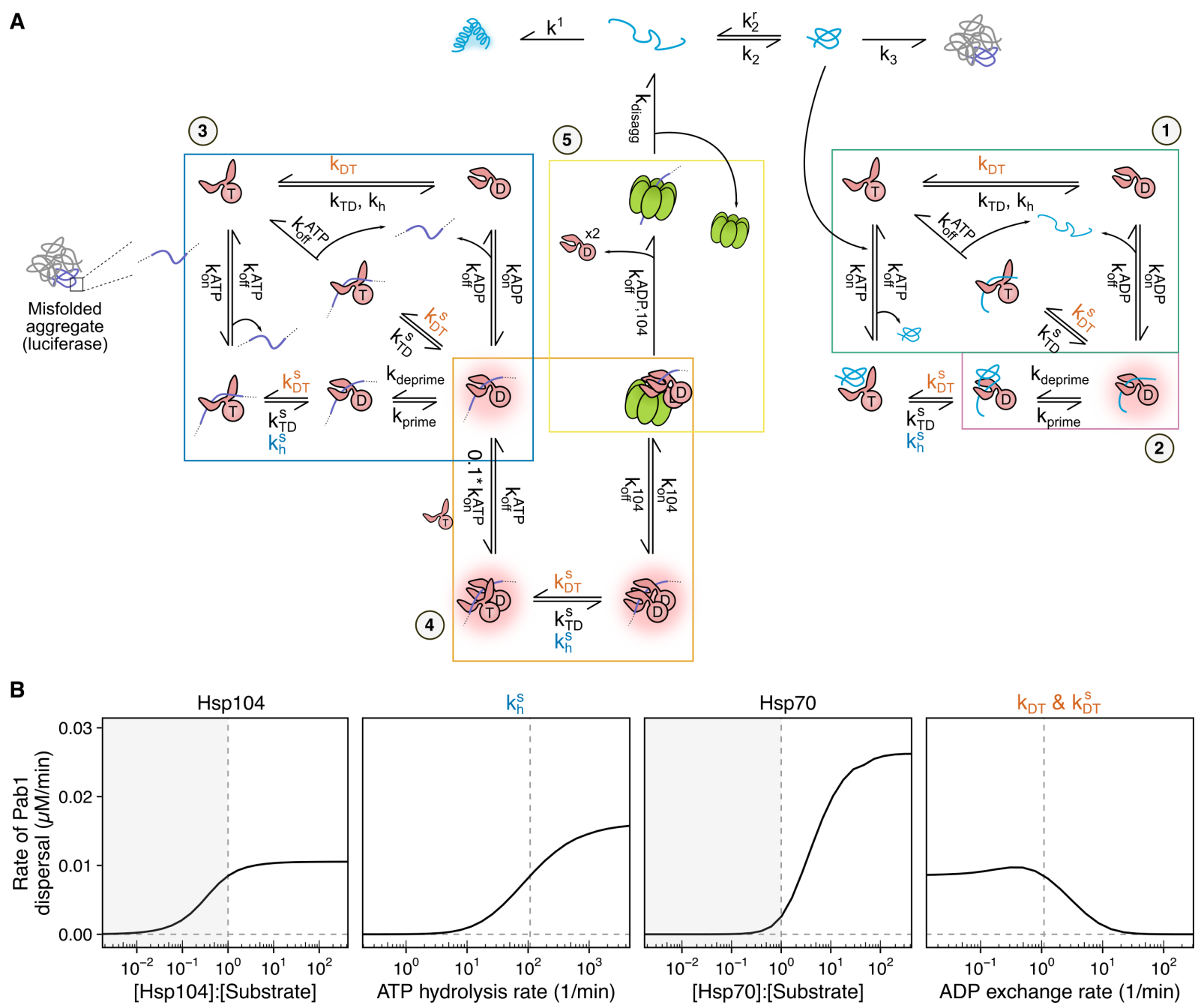

Figure S5. Cooperative model; Related to Figure 4 and Figure 6.

(A) (1) Biochemical model of ATP hydrolysis-coupled substrate binding and release from Hsp70 (De Los Rios and Barducci, 2014; Powers et al., 2012; Nguyen et al., 2017; Xu, 2018). Nucleotide exchange from ADP to ATP facilitates substrate release from Hsp70. (2) Hsp70 binding to a single misfolded protein leads to protein unfolding and expansion (Imamoglu et al., 2020; Assenza et al., 2019). We describe this step a "priming" step, and use pink halo to graphically represent the primed species. (3) Nucleotide state-coupled substrate binding of Hsp70 is assumed to be consistent with aggregated substrates. However, unlike with single misfolded proteins, aggregated proteins do not unfold upon Hsp70 binding and need Hsp104. (4) One Hsp70 molecule is insufficient to activate Hsp104 (Seyffer et al., 2012; Carroni et al., 2014). Second Hsp70 binds the substrate with an order of magnitude lower affinity than the first Hsp70 due to the entropic penalty (Wentink et al., 2020). (5) Exact mechanism of substrate handover is unknown, but substrate handover is described as an irreversible step (Powers et al., 2012). (B) Simulation of chaperone titration experiments shown in Figure 6A. Titration of Sis1 and Sse1 were simulated by varying the ATP hydrolysis rate of substrate-bound Hsp70 (kh_S) and ADP exchange rate (kDT and kDT_S), respectively, from the default level indicated by the dashed line. 

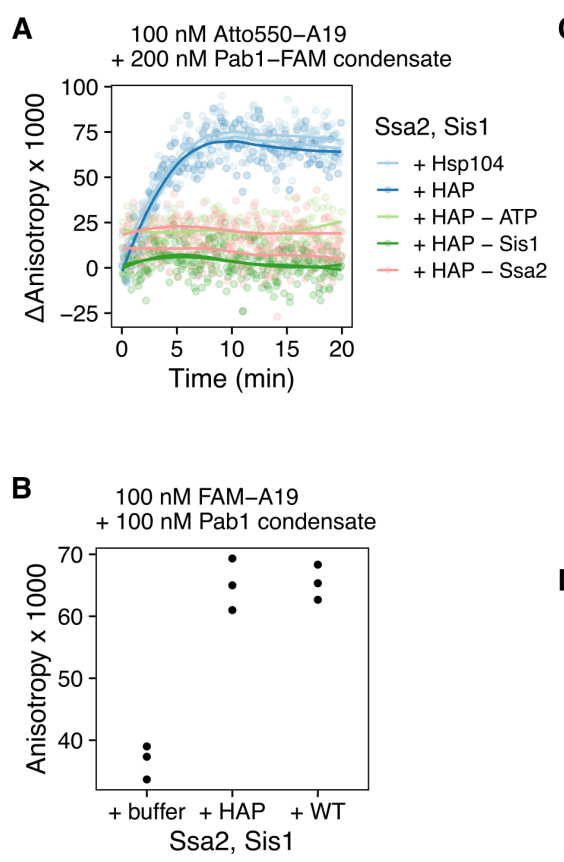

G

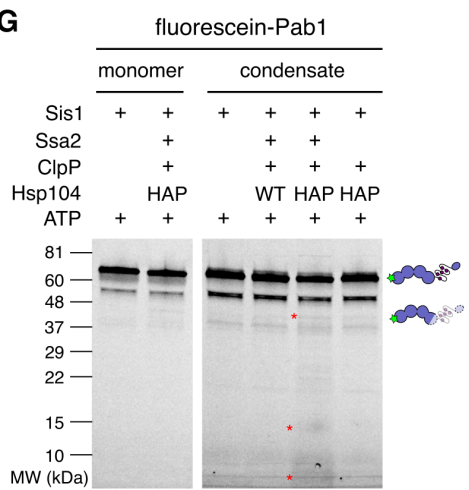

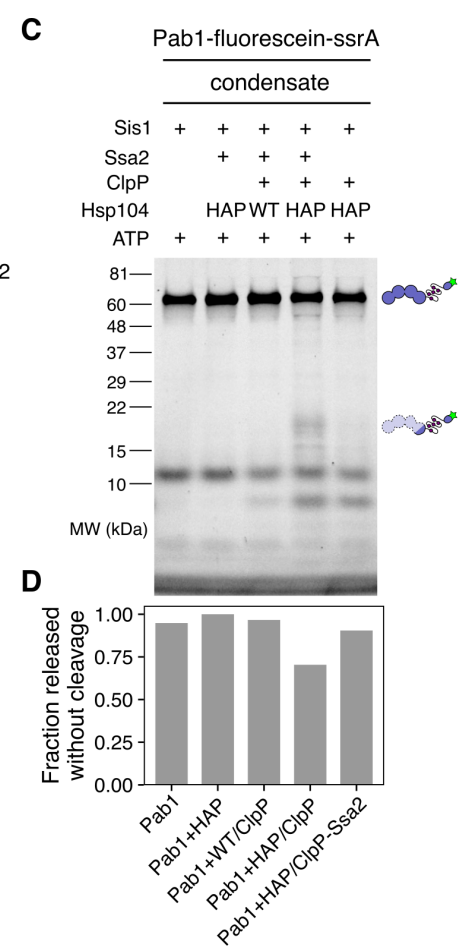

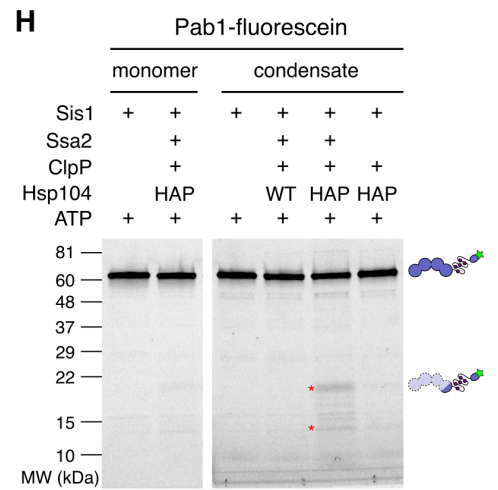

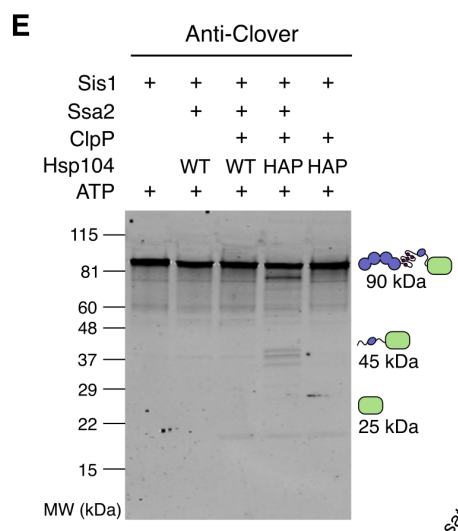

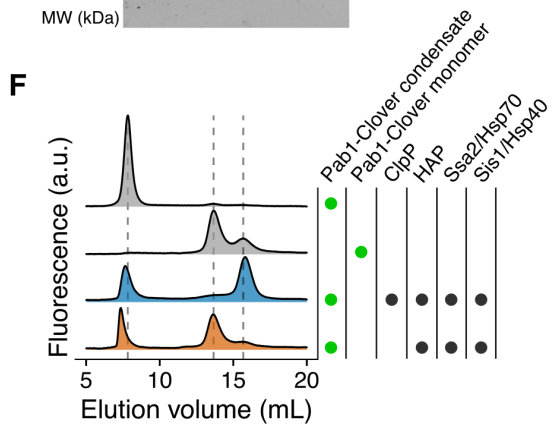

Figure S6. HAP/ClpP-specific cleavage of Pab1 constructs; Related to Figure 5. (A) Condensates of C-terminally fluorescein-labeled Pab1 were dispersed by the indicated components. Fluorescence anisotropy of Atto550-A19 RNA was monitored. (B) End-point measurement of unlabeled Pab1 condensate dispersal. FAM-A19 RNA was added after an hour of reaction incubation to measure fluorescence anisotropy. (C) A replicate of the condensate dispersal experiment shown in Figure 5H.(D) Quantification of full-length Pab1 band intensity in (C) normalized to the HAP control signal. The yield of dispersal was assumed to be the same as seen in the Figure 5K FSEC experiment. (E) Pab1-Clover condensates were incubated with the indicated components and examined by western blot. Schematics of full-length and truncated products, and their corresponding molecular weight are shown. (F) Pab1-Clover condensate was incubated with the indicated components for an hour and examined by FSEC. Dashed lines indicate the elution volume for Pab1-Clover condensates (7.8 mL), Pab1-Clover monomers $(13.7 \mathrm{~mL})$, and HAP/ClpP-specific cleavage products $(15.7 \mathrm{~mL})$. (G-H) SDS-PAGE gels of $\mathrm{N}$ - or $\mathrm{C}$-terminally labeled Pab1 were visualized by detecting fluorescein fluorescence. Asterisks in indicate $\mathrm{HAP} / \mathrm{ClpP}$-specific cleavage products. 
A

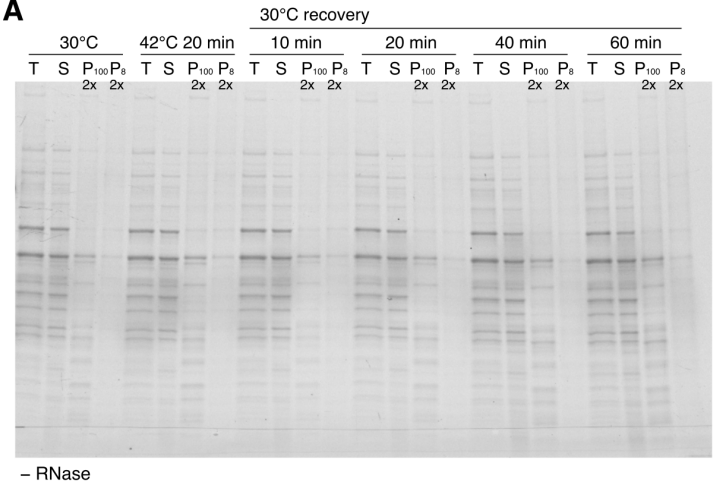

C

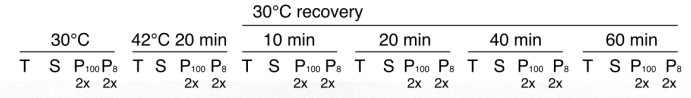

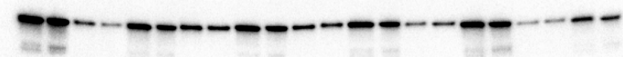

Anti-Pab1

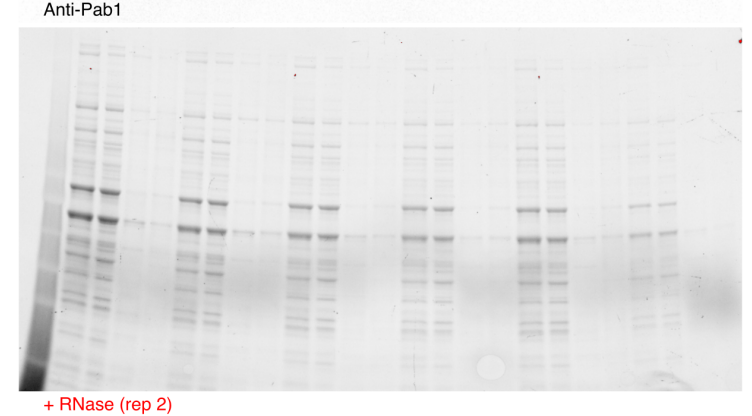

E
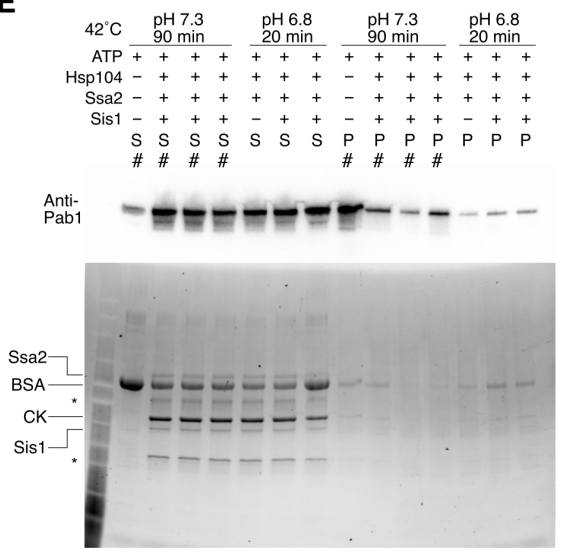

B

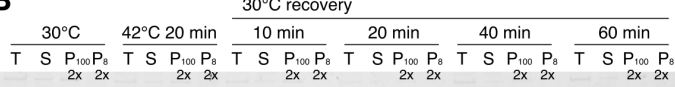

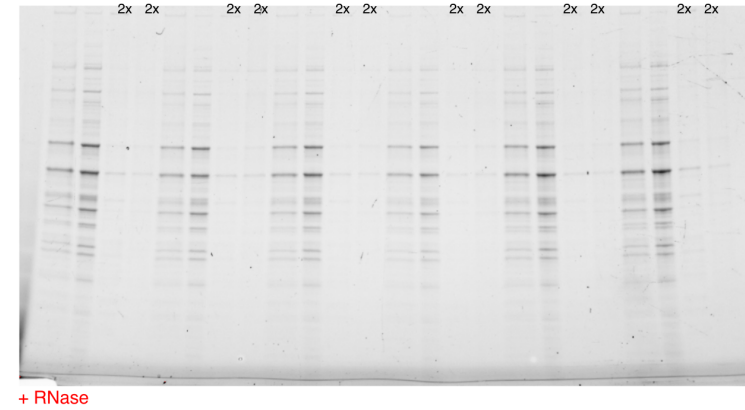

D

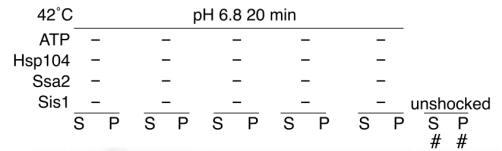

Anti-

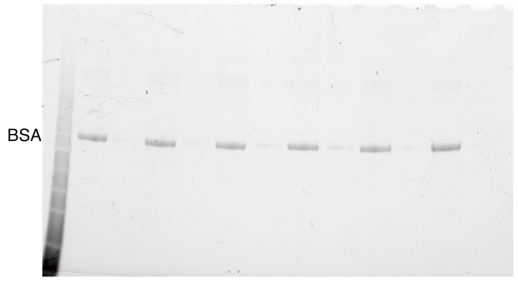

$\mathbf{F}$

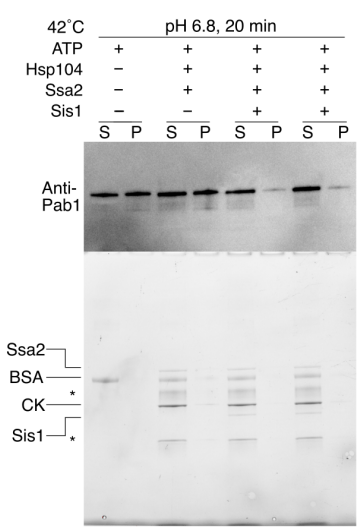

G
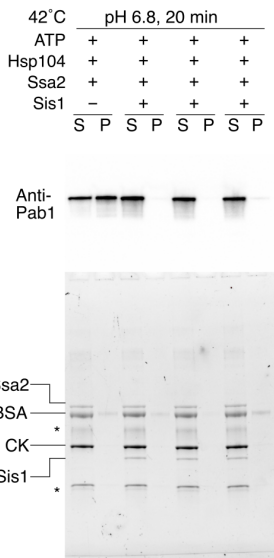

Figure S. Uncropped stain-free total protein gel and western blot images; Related to Figures 1 and Figure 2.

(A and B) SDS-PAGE gel of RNase treated (A) or untreated (B) yeast lysate samples. The corresponding anti-Pab1 western blot images are shown in (Figure 1A). (C) Replicate of (B). (D-G) Western blot (top) and SDS-PAGE images (bottom) of in vitro TSP experiments. Cropped images of $(\mathrm{G})$ is shown in (Figure $2 \mathrm{C}$ ). The quantification results are shown in (Figure 2D). Lanes marked with \# were not quantified. CK stands for creatine kinase. Asterisks indicate unknown contaminant. 
Table 1. Model parameters

\begin{tabular}{|c|c|c|c|c|}
\hline Name & Value & Unit & Description & Source \\
\hline $\mathrm{k}_{\mathrm{h}}$ & 0.036 & $\min ^{-1}$ & ATP hydrolysis rate of free Hsp70 & McCarty et al. (1995)* \\
\hline $\mathrm{k}_{\mathrm{h}}^{\mathrm{s}}$ & 108 & $\min ^{-1}$ & $\begin{array}{l}\text { ATP hydrolysis rate of substrate- } \\
\text { bound Hsp70 }\end{array}$ & Laufen et al. $(1999)^{*}$ \\
\hline $\mathrm{k}_{\mathrm{On}}^{\mathrm{ATP}}$ & 12 & $\min ^{-1} \mu \mathrm{M}^{-1}$ & Substrate onrate to $\mathrm{Hsp} 70_{\mathrm{ATP}}$ & $\begin{array}{l}\text { Schmid et al. (1994); Gisler } \\
\text { et al. (1998)* }\end{array}$ \\
\hline $\mathrm{k}_{\mathrm{off}}^{\mathrm{ATP}}$ & 120 & $\min ^{-1}$ & Substrate offrate to $\mathrm{Hsp} 70_{\mathrm{ATP}}$ & $\begin{array}{l}\text { Schmid et al. (1994); Gisler } \\
\text { et al. (1998)* }\end{array}$ \\
\hline $\mathrm{k}_{\mathrm{on}}^{\mathrm{ADP}}$ & 0.06 & $\min ^{-1} \mu \mathrm{M}^{-1}$ & Substrate onrate to Hsp70 ADP & Mayer et al. $(2000)^{*}$ \\
\hline $\mathrm{k}_{\mathrm{off}}^{\mathrm{ADP}}$ & 0.0282 & $\min ^{-1}$ & Substrate offrate to Hsp $70_{\mathrm{ADP}}$ & Mayer et al. $(2000)^{*}$ \\
\hline $\mathrm{k}_{\mathrm{r}}^{\mathrm{ATP}}$ & 0.008 & $\min ^{-1}$ & ATP offrate from Hsp70 ATP & Russell et al. (1998)* \\
\hline $\mathrm{k}^{\mathrm{ATP}}$ & 7.8 & $\min ^{-1} \mu \mathrm{M}^{-1}$ & ATP onrate to Hsp70 apo & Russell et al. (1998)* \\
\hline $\mathrm{k}_{\mathrm{r}}^{\mathrm{ADP}}$ & 1.32 & $\min ^{-1}$ & ADP offrate from $\mathrm{Hsp} 70_{\mathrm{ADP}}$ & $\begin{array}{l}\text { Theyssen et al. (1996); Rus- } \\
\text { sell et al. (1998)* }\end{array}$ \\
\hline $\mathrm{k}^{\mathrm{ADP}}$ & 16 & $\min ^{-1} \mu \mathrm{M}^{-1}$ & ADP onrate to Hsp70 apo & Russell et al. $(1998)^{*}$ \\
\hline $\begin{array}{l}\mathrm{k}_{\mathrm{TD}} \\
\mathrm{k}_{\mathrm{TD}}^{\mathrm{s}}\end{array}$ & 0.0014 & $\min ^{-1}$ & $\begin{array}{l}\text { Nucleotide exchange rate from ATP } \\
\text { to ADP in free or substrate-bound } \\
\text { Hsp70 }\end{array}$ & $\begin{array}{l}\text { Calculated as described in } \\
\text { De Los Rios and Barducci } \\
\text { (2014) }\end{array}$ \\
\hline $\begin{array}{l}\mathrm{k}_{\mathrm{DT}} \\
\mathrm{k}_{\mathrm{DT}}^{\mathrm{s}}\end{array}$ & 1.0951 & $\min ^{-1}$ & $\begin{array}{l}\text { Nucleotide exchange rate from ADP } \\
\text { to ATP in free or substrate-bound } \\
\text { Hsp70 }\end{array}$ & $\begin{array}{l}\text { Calculated as described in } \\
\text { De Los Rios and Barducci } \\
\text { (2014) }\end{array}$ \\
\hline $\mathrm{k}_{\mathrm{on}}^{104}$ & 30 & $\min ^{-1} \mu \mathrm{M}^{-1}$ & $\begin{array}{l}\text { Hsp104 onrate } \\
\text { Hsp70ADP:substrate complex }\end{array}$ & $\begin{array}{l}\text { Estimated from the } K_{d} \text { re- } \\
\text { ported in Rosenzweig et al. } \\
\text { (2013) }\end{array}$ \\
\hline $\mathrm{k}_{\mathrm{off}}^{104}$ & 60 & $\min ^{-1}$ & $\begin{array}{lcc}\text { Hsp104 offrate } & \text { from } \\
\text { Hsp70ADP:substrate:Hsp104 } & \text { com- } \\
\text { plex } & \\
\end{array}$ & $\begin{array}{l}\text { Estimated from the } K_{d} \text { re- } \\
\text { ported in Rosenzweig et al. } \\
(2013)\end{array}$ \\
\hline $\mathrm{k}_{\mathrm{off}}^{\mathrm{ADP}, 104}$ & 100 & $\min ^{-1}$ & $\begin{array}{l}\text { Hsp70 ADP offrate after substrate } \\
\text { handover to Hsp104 }\end{array}$ & Free parameter \\
\hline $\mathrm{k}_{\text {disagg }}$ & 0.2 & $\min ^{-1}$ & Disaggregation rate & $\begin{array}{l}\text { Estimated from the measu- } \\
\text { rement in this study }\end{array}$ \\
\hline $\mathrm{k}_{\text {prime }}$ & 10 & $\min ^{-1}$ & Substrate remodeling rate & Free parameter \\
\hline $\mathrm{k}_{\text {deprime }}$ & 1 & $\min ^{-1}$ & Reverse substrate remodeling rate & Free parameter \\
\hline $\mathrm{k}_{1}$ & $\begin{array}{l}10 \\
0.001\end{array}$ & $\min ^{-1}$ & $\begin{array}{l}\text { Rate of transition from the unfolded } \\
\text { Pab1/luciferase to the folded state }\end{array}$ & Free parameter \\
\hline $\mathrm{k}_{2}$ & 1 & $\min ^{-1}$ & $\begin{array}{l}\text { Rate of transition from the unfolded } \\
\text { state to the misfolded state }\end{array}$ & Free parameter \\
\hline $\mathrm{k}_{2}^{\mathrm{r}}$ & 0.1 & $\min ^{-1}$ & $\begin{array}{l}\text { Rate of transition from the misfolded } \\
\text { state to the unfolded state }\end{array}$ & Free parameter \\
\hline $\mathrm{k}_{3}$ & 1 & $\min ^{-1}$ & $\begin{array}{l}\text { Rate of transition from the misfolded } \\
\text { state to the aggregated state }\end{array}$ & Free parameter \\
\hline
\end{tabular}




\begin{tabular}{|c|c|}
\hline Panel & Reaction mixture* \\
\hline $1 \mathrm{~d}$ & $25 \mu \mathrm{M}$ Pab1 \\
\hline $1 \mathrm{e}$ & $0.2 \mu \mathrm{M}$ FAM-A19, $0.2 \mu \mathrm{M}$ Pab1 monomers or condensates, $5 \mathrm{mM}$ ATP \\
\hline $2 \mathrm{a}, 2 \mathrm{~b}$ & $\begin{array}{l}0.1 \mu \mathrm{M} \text { FAM-A19, } 0.1 \mu \mathrm{M} \text { Pab1, } 1 \mu \mathrm{M} \text { Ssa2, } 0.1 \mu \mathrm{M} \text { Hsp104, } 0.5 \mu \mathrm{M} \text { Sis1, } 0.5 \mu \mathrm{M} \text { Ydj1, } \\
50 \text { nM Sse1, ATP mix }\end{array}$ \\
\hline $2 c$ & $0.1 \mu \mathrm{M}$ FAM-A19, $0.1 \mu \mathrm{M}$ Pab1, $1 \mu \mathrm{M}$ Ssa2, $0.02 \mu \mathrm{M}$ Hsp104, $0.5 \mu \mathrm{M}$ Sis1, ATP mix \\
\hline $2 \mathrm{e}$ & $\begin{array}{l}0.2 \mu \mathrm{M} \text { Pab1-Clover, } 1 \mu \mathrm{M} \text { Ssa2, } 0.5 \mu \mathrm{M} \text { Sis1, } 0.1 \mu \mathrm{M} \text { Hsp104, } 0.5 \mu \mathrm{M} \text { A90 RNA, ATP } \\
\operatorname{mix}\end{array}$ \\
\hline $3 \mathrm{a}$ & $0.2 \mu \mathrm{M}$ Fluc, $1 \mu \mathrm{M}$ Ssa2, $0.1 \mu \mathrm{M}$ Hsp104, $0.5 \mu \mathrm{M}$ Hsp40, ATP mix \\
\hline $3 \mathrm{~b}$ & $20 \mathrm{nM}$ Fluc, $0.75 \mu \mathrm{M}$ Ssa2, $0.75 \mu \mathrm{M}$ Hsp104, $0.25 \mu \mathrm{M}$ Hsp40, 38 nM Sse1, ATP mix \\
\hline $3 c, 3 d$ & $\begin{array}{l}0.2 \mu \mathrm{M} \text { FAM-A19, } 0.2 \mu \mathrm{M} \text { Pab1, } 0.5 \mu \mathrm{M} \text { Ssa2, } 50 \mathrm{nM} \text { Hsp104, } 0.25 \mu \mathrm{M} \text { Sis1 (plus 0, 0.25, } \\
0.5,1 \text {, or } 2 \mu \mathrm{M} \text { additional Sis1 or Ydj1), ATP mix }\end{array}$ \\
\hline $3 \mathrm{f}$ & $\begin{array}{l}0.2 \mu \mathrm{M} \text { FAM-A19 (for Pab1), } 0.2 \mu \mathrm{M} \text { Pab1 or luciferase, } 1 \mu \mathrm{M} \text { Ssa2, } 0.1 \mu \mathrm{M} \text { Hsp104, } 0.5 \\
\mu \mathrm{M} \text { Sis1, ATP mix }\end{array}$ \\
\hline $5 \mathrm{~b}$ & $\begin{array}{l}20 \mathrm{nM} \text { Fluc, } 0.75 \mu \mathrm{M} \text { Ssa2, } 0.75 \mu \mathrm{M} \text { Hsp104, } 0.125 \mu \mathrm{M} \text { Sis1, } 0.125 \mu \mathrm{M} \text { Ydj1, } 0.1 \mu \mathrm{M} \\
\text { GroEL trap, } 38 \mathrm{nM} \text { Sse1, ATP mix }\end{array}$ \\
\hline $5 c$ & $\begin{array}{l}0.2 \mu \mathrm{M} \text { FAM-A19, } 0.2 \mu \mathrm{M} \text { Pab1, } 1 \mu \mathrm{M} \text { Ssa2, } 0.2 \mu \mathrm{M} \text { Hsp104, } 0.5 \mu \mathrm{M} \text { Sis1, } 1 \mu \mathrm{M} \text { GroEL } \\
\text { trap, ATP mix }\end{array}$ \\
\hline $5 \mathrm{~d}$ & $0.1 \mu \mathrm{M}$ FAM-A19, $0.1 \mu \mathrm{M}$ Pab1, $1 \mu \mathrm{M}$ GroEL trap \\
\hline $5 \mathrm{f}, 5 \mathrm{~g}$ & $10 \mathrm{nM}$ Fluc, $1 \mu \mathrm{M}$ Ssa2, $0.25 \mu \mathrm{M}$ Sis1, $0.25 \mu \mathrm{M}$ Ydj1, $1 \mu \mathrm{M}$ Hsp104/HAP, ATP mix \\
\hline $5 \mathrm{~h}, 5 \mathrm{k}$ & $\begin{array}{l}0.2 \mu \mathrm{M} \text { Pab1-fluorescein-ssrA, } 2 \mu \mathrm{M} \text { Ssa2, } 0.5 \mu \mathrm{M} \text { Sis1, } 1 \mu \mathrm{M} \text { HAP, } 1.5 \mu \mathrm{M} \text { ClpP, ATP } \\
\text { mix; For ClpXP: } 0.2 \mu \mathrm{M} \text { nM Pab1-fluorescein-SsrA, 0.1 } \mu \mathrm{M} \text { ClpX, } 1 \mu \mathrm{M} \text { ClpP }\end{array}$ \\
\hline $6 \mathrm{a}, 6 \mathrm{~g}$ & $\begin{array}{l}\text { Default: } 0.2 \mu \mathrm{M} \text { FAM-A19, } 0.2 \mu \mathrm{M} \text { Pab1, } 0.5 \mu \mathrm{M} \text { Ssa2, } 0.2 \mu \mathrm{M} \text { Hsp104, } 0.5 \mu \mathrm{M} \text { Sis1, } 0.1 \\
\mu \mathrm{M} \text { Sse1, ATP mix }\end{array}$ \\
\hline $6 \mathrm{e}$ & $0.2 \mu \mathrm{M}$ FAM-A19, $0.14 \mu \mathrm{M}$ Pab1, varying Ssa2, $0.02 \mu \mathrm{M}$ Hsp104, $0.5 \mu \mathrm{M}$ Sis1, ATP mix \\
\hline S1a & $15 \mu \mathrm{M}$ Pab1 + BSA or Fluc as indicated \\
\hline $\mathrm{S} 1 \mathrm{c}$ & $25 \mu \mathrm{M}$ Pab1 + Fluc as indicated \\
\hline S1d & $0.1 \mu \mathrm{M}$ FAM-A19, $0.1 \mu \mathrm{M}$ Pab1, $0.5 \mu \mathrm{M}$ Ssa2, $0.05 \mu \mathrm{M}$ Hsp104, $0.1 \mu \mathrm{M}$ Sis1, ATP mix \\
\hline $\mathrm{S} 2 \mathrm{a}$ & $\begin{array}{l}0.1 \mu \mathrm{M} \text { FAM-A19, } 0.1 \mu \mathrm{M} \text { Pab1, } 1 \mu \mathrm{M} \text { Ssa4, } 0.1 \mu \mathrm{M} \text { Hsp104, } 0.5 \mu \mathrm{M} \text { Sis1, } 0.5 \mu \mathrm{M} \text { Ydj1, } \\
\text { ATP mix }\end{array}$ \\
\hline $\mathrm{S} 3 \mathrm{~b}$ & $\begin{array}{l}0.5 \mu \mathrm{M} \text { Pab1, } 1.2 \mu \mathrm{M} \text { Ssa1, } 0.2 \mu \mathrm{M} \text { Hsp104, } 0.3 \mu \mathrm{M} \text { Sse1, } 0.3 \mu \mathrm{M} \text { Ydj1, } 0.3 \mu \mathrm{M} \text { Sis1, } 3 \\
\text { mM PEP, } 10 \text { units } / \mathrm{mL} \text { PK, } 2 \text { mM ATP }\end{array}$ \\
\hline S4a & $10 \mu \mathrm{M}$ Pab1 + Hsp26 as indicated \\
\hline $\mathrm{S} 4 \mathrm{c}$ & $10 \mu \mathrm{M}$ Pab1 + Hsp26 as indicated \\
\hline $\mathrm{S} 4 \mathrm{e}$ & $0.2 \mu \mathrm{M}$ FAM-A19 + Pab1 monomer as indicated \\
\hline S6c & $\begin{array}{l}0.1 \mu \mathrm{M} \text { Pab1-fluorescein-ssrA, } 2 \mu \mathrm{M} \text { Ssa2, } 0.5 \mu \mathrm{M} \text { Sis1, } 1 \mu \mathrm{M} \text { Hsp104/HAP, } 1.5 \mu \mathrm{M} \text { ClpP, } \\
\text { ATP mix }\end{array}$ \\
\hline S6e, S6f & $\begin{array}{l}0.2 \mu \mathrm{M} \text { Pab1-Clover, } 1.5 \mu \mathrm{M} \text { ClpP, } 1 \mu \mathrm{M} \text { Hsp104/HAP, } 0.5 \mu \mathrm{M} \text { Sis } 1,2 \mu \mathrm{M} \text { Ssa } 2 \text {, ATP } \\
\operatorname{mix}\end{array}$ \\
\hline S6g, S6h & $\begin{array}{l}0.2 \mu \mathrm{M} \text { fluorescein-Pab1 or Pab1-fluorescein, } 1.5 \mu \mathrm{M} \text { ClpP, } 1 \mu \mathrm{M} \text { Hsp104/HAP, } 0.5 \mu \mathrm{M} \\
\text { Sis1, } 2 \mu \mathrm{M} \text { Ssa2, ATP mix }\end{array}$ \\
\hline
\end{tabular}

*Concentrations of Hsp104/HAP, Hsp40, and GroEL indicate the concentrations for the hexamers, dimers, and 846 14-mers, respectively; ATP mix includes $1 \mu \mathrm{M} \mathrm{CK}, 8 \mathrm{mM} \mathrm{CP}, 5 \mathrm{mM}$ ATP. 847 


\section{Competing Interests}

The authors declare no competing interests.

\section{Acknowledgements}

We thank the members of the Drummond lab for helpful comments and discussions. We 851 also thank Tobin Sosnick and Ruofan Chen for helpful comments and discussions, Zachary ${ }_{852}$ March for providing the original protocol for Hsp70 purification, Axel Mogk for providing 853 the plasmid for GroEL trap, Andreas Martin for providing the plasmids for ClpX and ClpP, 854 David Pincus and Michael Rust for their feedback on modeling, the Perozo lab for providing 855 the FSEC instrument, and Elena Solomaha at the Biophysics Core for assistance with DLS 856 experiments. Research reported in this publication was supported by the National Institute 857 of General Medical Sciences and the National Institute of Environmental Health Sciences of 858 the National Institutes of Health (NIH) through awards to HY (award numbers T32GM007183 859 and F31ES030697). JAMB acknowledges fellowship support from the Helen Hay Whitney 860 Foundation. DAD acknowledges support from the NIH (award numbers R01GM126547 and 861 R01GM127406) and from the US Army Research Office (award number W911NF-14-1-0411). 862 The content is solely the responsibility of the authors and does not necessarily represent the ${ }^{863}$ official views of the NIH.

\section{References}

Assenza, S., A. S. Sassi, R. Kellner, B. Schuler, P. De Los Rios, and A. Barducci (2019, 866 December). Efficient conversion of chemical energy into mechanical work by hsp70 chaperones. 867 Elife 8.

Avellaneda, M. J., K. B. Franke, V. Sunderlikova, B. Bukau, A. Mogk, and S. J. Tans (2020, Fe- 869 bruary). Processive extrusion of polypeptide loops by a hsp100 disaggregase. Nature 578(7794), 870 317-320.

Banani, S. F., H. O. Lee, A. A. Hyman, and M. K. Rosen (2017, May). Biomolecular condensates: 872 organizers of cellular biochemistry. Nat. Rev. Mol. Cell Biol. 18(5), 285-298. 873

Begovich, K. and J. E. Wilhelm (2020). An inÂ vitro assembly system identifies roles for rna 874 nucleation and atp in yeast stress granule formation. Molecular Cell.

Ben-Zvi, A., P. De Los Rios, G. Dietler, and P. Goloubinoff (2004, September). Active 876 solubilization and refolding of stable protein aggregates by cooperative unfolding action of 877 individual hsp70 chaperones. J. Biol. Chem. 279(36), 37298-37303.

Bresson, S., V. Shchepachev, C. Spanos, T. Turowski, J. Rappsilber, and D. Tollervey (2020, 879 May). Stress-induced translation inhibition through rapid displacement of scanning initiation 880 factors.

Carroni, M., E. Kummer, Y. Oguchi, P. Wendler, D. K. Clare, I. Sinning, J. Kopp, A. Mogk, 882 B. Bukau, and H. R. Saibil (2014, April). Head-to-tail interactions of the coiled-coil domains 883 regulate $\mathrm{ClpB}$ activity and cooperation with hsp70 in protein disaggregation. Elife 3, e02481. 884 
Cashikar, A. G., M. Duennwald, and S. L. Lindquist (2005, June). A chaperone pathway in 885 protein disaggregation. hsp26 alters the nature of protein aggregates to facilitate reactivation 886 by hsp104. J. Biol. Chem. 280(25), 23869-23875.

Cherkasov, V., T. Grousl, P. Theer, Y. Vainshtein, C. Glässer, C. Mongis, G. Kramer, G. Sto- 888 ecklin, M. Knop, A. Mogk, and B. Bukau (2015, November). Systemic control of protein 889 synthesis through sequestration of translation and ribosome biogenesis factors during severe 890 heat stress. FEBS Lett. $589(23), 3654-3664$.

Cherkasov, V., S. Hofmann, S. Druffel-Augustin, A. Mogk, J. Tyedmers, G. Stoecklin, and 892 B. Bukau (2013, December). Coordination of translational control and protein homeostasis 893 during severe heat stress. Curr. Biol. 23(24), 2452-2462.

De Los Rios, P. and A. Barducci (2014, May). Hsp70 chaperones are non-equilibrium machines 895 that achieve ultra-affinity by energy consumption. Elife 3, e02218. 896

DeSantis, M. E., E. H. Leung, E. A. Sweeny, M. E. Jackrel, M. Cushman-Nick, A. Neuhaus- 897 Follini, S. Vashist, M. A. Sochor, M. N. Knight, and J. Shorter (2012, November). Operational 898 plasticity enables hsp104 to disaggregate diverse amyloid and nonamyloid clients. Cell 151(4), 899 778-793.

Doyle, S. M., S. Shastry, A. N. Kravats, Y.-H. Shih, M. Miot, J. R. Hoskins, G. Stan, and 901 S. Wickner (2015, January). Interplay between e. coli DnaK, ClpB and GrpE during protein 902 disaggregation. J. Mol. Biol. 427(2), 312-327.

Duennwald, M. L., A. Echeverria, and J. Shorter (2012, June). Small heat shock proteins 904 potentiate amyloid dissolution by protein disaggregases from yeast and humans. PLoS 905 Biol. 10(6), e1001346.

Erives, A. J. and J. S. Fassler (2015, February). Metabolic and chaperone gene loss marks the 907 origin of animals: Evidence for hsp104 and hsp78 chaperones sharing mitochondrial enzymes 908 as clients. PLoS One 10(2), e0117192.

Faust, O., M. Abayev-Avraham, A. S. Wentink, M. Maurer, N. B. Nillegoda, N. London, 910 B. Bukau, and R. Rosenzweig (2020, November). HSP40 proteins use class-specific regulation 911 to drive HSP70 functional diversity. Nature 587(7834), 489-494.

Feder, Z. A., A. Ali, A. Singh, J. Krakowiak, X. Zheng, V. P. Bindokas, D. Wolfgeher, S. J. 913 Kron, and D. Pincus (2021, January). Subcellular localization of the j-protein sis1 regulates 914 the heat shock response. J. Cell Biol. 220(1).

Gao, X., M. Carroni, C. Nussbaum-Krammer, A. Mogk, N. B. Nillegoda, A. Szlachcic, D. L. 916 Guilbride, H. R. Saibil, M. P. Mayer, and B. Bukau (2015, September). Human hsp70 917 disaggregase reverses Parkinson's-Linked $\alpha$-Synuclein amyloid fibrils. Mol. Cell 59(5), 781- 918 793.

Gates, S. N., A. L. Yokom, J. Lin, M. E. Jackrel, A. N. Rizo, N. M. Kendsersky, C. E. Buell, E. A. 920 Sweeny, K. L. Mack, E. Chuang, M. P. Torrente, M. Su, J. Shorter, and D. R. Southworth $9_{21}$ (2017, July). Ratchet-like polypeptide translocation mechanism of the AAA+ disaggregase 922 hsp104. Science 357(6348), 273-279. 
Geiler-Samerotte, K. A., M. F. Dion, B. A. Budnik, S. M. Wang, D. L. Hartl, and D. A. 924 Drummond (2011, January). Misfolded proteins impose a dosage-dependent fitness cost and 925 trigger a cytosolic unfolded protein response in yeast. Proc. Natl. Acad. Sci. U. S. A. 108(2), 926 680-685.

Gisler, S. M., E. V. Pierpaoli, and P. Christen (1998, June). Catapult mechanism renders the 928 chaperone action of hsp70 unidirectional. J. Mol. Biol. 279(4), 833-840. 929

Glover, J. R. and S. Lindquist (1998, July). Hsp104, hsp70, and hsp40: a novel chaperone 930 system that rescues previously aggregated proteins. Cell 94(1), 73-82. 931

Goloubinoff, P., A. Mogk, A. P. Zvi, T. Tomoyasu, and B. Bukau (1999, November). Sequential 932 mechanism of solubilization and refolding of stable protein aggregates by a bichaperone 933 network. Proc. Natl. Acad. Sci. U. S. A. 96(24), 13732-13737.

Goloubinoff, P., A. S. Sassi, B. Fauvet, A. Barducci, and P. De Los Rios (2018, April). Chaperones 935 convert the energy from ATP into the nonequilibrium stabilization of native proteins. Nat. 936 Chem. Biol. 14 (4), 388-395.

Guimaraes, C. P., M. D. Witte, C. S. Theile, G. Bozkurt, L. Kundrat, A. E. M. Blom, and H. L. 938 Ploegh (2013, August). Site-specific c-terminal and internal loop labeling of proteins using 939 sortase-mediated reactions. Nat. Protoc. 8(9), 1787-1799.

Guo, L., H. J. Kim, H. Wang, J. Monaghan, F. Freyermuth, J. C. Sung, K. O'Donovan, C. M. ${ }_{941}$ Fare, Z. Diaz, N. Singh, Z. C. Zhang, M. Coughlin, E. A. Sweeny, M. E. DeSantis, M. E. Jackrel, ${ }_{942}$ C. B. Rodell, J. A. Burdick, O. D. King, A. D. Gitler, C. Lagier-Tourenne, U. B. Pandey, 943 Y. M. Chook, J. P. Taylor, and J. Shorter (2018, April). Nuclear-Import receptors reverse 944 aberrant phase transitions of RNA-Binding proteins with prion-like domains. Cell 173(3), 945 677-692.e20.

Haslberger, T., J. Weibezahn, R. Zahn, S. Lee, F. T. F. Tsai, B. Bukau, and A. Mogk (2007, 947 January). M domains couple the ClpB threading motor with the DnaK chaperone activity. 948 Mol. Cell 25(2), 247-260.

Haslberger, T., A. Zdanowicz, I. Brand, J. Kirstein, K. Turgay, A. Mogk, and B. Bukau (2008, 950 June). Protein disaggregation by the AAA + chaperone ClpB involves partial threading of 951 looped polypeptide segments. Nat. Struct. Mol. Biol. 15(6), 641-650.

Hirakawa, H., S. Ishikawa, and T. Nagamune (2015, September). Ca2+ -independent sortase-a 953 exhibits high selective protein ligation activity in the cytoplasm of escherichia coli. Biotechnol. 954 J. $10(9), 1487-1492$.

Houry, W. A., D. Frishman, C. Eckerskorn, F. Lottspeich, and F. Ulrich Hartl (1999). Identifi- 956 cation of in vivo substrates of the chaperonin GroEL.

Imamoglu, R., D. Balchin, M. Hayer-Hartl, and F. U. Hartl (2020, January). Bacterial hsp70 958 resolves misfolded states and accelerates productive folding of a multi-domain protein. Nat. 959 Commun. 11(1), 365.

Inoue, Y., H. Taguchi, A. Kishimoto, and M. Yoshida (2004, December). Hsp104 binds to yeast 961 sup35 prion fiber but needs other factor(s) to sever it. J. Biol. Chem. 279(50), 52319-52323. 962 
Iserman, C., C. Desroches Altamirano, C. Jegers, U. Friedrich, T. Zarin, A. W. Fritsch, M. Mit- 963 tasch, A. Domingues, L. Hersemann, M. Jahnel, D. Richter, U.-P. Guenther, M. W. Hentze, 964 A. M. Moses, A. A. Hyman, G. Kramer, M. Kreysing, T. M. Franzmann, and S. Alberti (2020, 965 May). Condensation of ded1p promotes a translational switch from housekeeping to stress 966 protein production. Cell 181(4), 818-831.e19.

Jiang, Y., P. Rossi, and C. G. Kalodimos (2019, September). Structural basis for client 968 recognition and activity of hsp40 chaperones. Science 365(6459), 1313-1319. 969

Kaimal, J. M., G. Kandasamy, F. Gasser, and C. Andréasson (2017, June). Coordinated hsp110 970 and hsp104 activities power protein disaggregation in saccharomyces cerevisiae. Mol. Cell. 971 Biol. $37(11)$.

Kampinga, H. H. and E. A. Craig (2010, August). The HSP70 chaperone machinery: J proteins 973 as drivers of functional specificity. Nat. Rev. Mol. Cell Biol. 11(8), 579-592.

Kłosowska, A., T. Chamera, and K. Liberek (2016, May). Adenosine diphosphate restricts the 975 protein remodeling activity of the hsp104 chaperone to hsp70 assisted disaggregation. Elife 5. 976

Kluyver, T., B. Ragan-Kelley, F. Pérez, B. Granger, M. Bussonnier, J. Frederic, K. Kelley, 977 J. Hamrick, J. Grout, S. Corlay, P. Ivanov, D. Avila, S. Abdalla, C. Willing, and Jupy- 978 ter development team (2016). Jupyter notebooks - a publishing format for reproducible 979 computational workflows. pp. 87-90. IOS Press.

Krakowiak, J., X. Zheng, N. Patel, Z. A. Feder, J. Anandhakumar, K. Valerius, D. S. Gross, 981 A. S. Khalil, and D. Pincus (2018, February). Hsf1 and hsp70 constitute a two-component 982 feedback loop that regulates the yeast heat shock response. Elife $\%$.

Kroschwald, S., S. Maharana, D. Mateju, L. Malinovska, E. Nüske, I. Poser, D. Richter, and 984 S. Alberti (2015, August). Promiscuous interactions and protein disaggregases determine the 985 material state of stress-inducible RNP granules. Elife 4, e06807.

Kroschwald, S., M. C. Munder, S. Maharana, T. M. Franzmann, D. Richter, M. Ruer, A. A. 987 Hyman, and S. Alberti (2018, June). Different material states of pub1 condensates define 988 distinct modes of stress adaptation and recovery. Cell Rep. 23(11), 3327-3339.

Laufen, T., M. P. Mayer, C. Beisel, D. Klostermeier, A. Mogk, J. Reinstein, and B. Bukau 990 (1999, May). Mechanism of regulation of hsp70 chaperones by DnaJ cochaperones. Proc. 991 Natl. Acad. Sci. U. S. A. $96(10), 5452-5457$.

Lindquist, S. (1986). The heat-shock response. Annu. Rev. Biochem. 55, 1151-1191.

Liu, Z., S. Zhang, J. Gu, Y. Tong, Y. Li, X. Gui, H. Long, C. Wang, C. Zhao, J. Lu, L. He, 994 Y. Li, Z. Liu, D. Li, and C. Liu (2020, April). Hsp27 chaperones FUS phase separation under 995 the modulation of stress-induced phosphorylation. Nat. Struct. Mol. Biol. 27(4), 363-372. 996

Lu, Z. and D. M. Cyr (1998, October). Protein folding activity of hsp70 is modified differentially 997 by the hsp40 co-chaperones sis1 and ydj1. J. Biol. Chem. 273(43), 27824-27830. 998

Martin, A., T. A. Baker, and R. T. Sauer (2005, October). Rebuilt AAA + motors reveal 999 operating principles for ATP-fuelled machines. Nature 437(7062), 1115-1120. 
Martín, I., G. Celaya, C. Alfonso, F. Moro, G. Rivas, and A. Muga (2014, May). Crowding acti- 1001 vates $\mathrm{ClpB}$ and enhances its association with DnaK for efficient protein aggregate reactivation. 1002 Biophys. J. 106(9), 2017-2027.

1003

Masser, A. E., W. Kang, J. Roy, J. Mohanakrishnan Kaimal, J. Quintana-Cordero, M. R. 1004 Friedländer, and C. Andréasson (2019, September). Cytoplasmic protein misfolding titrates 1005 hsp70 to activate nuclear hsf1. Elife 8.

1006

Mayer, M. P., H. Schröder, S. Rüdiger, K. Paal, T. Laufen, and B. Bukau (2000, July). Multistep 1007 mechanism of substrate binding determines chaperone activity of hsp70. Nat. Struct. Biol. 7(7), 1008 $586-593$.

1009

McCarty, J. S., A. Buchberger, J. Reinstein, and B. Bukau (1995, May). The role of ATP in 1010 the functional cycle of the DnaK chaperone system. J. Mol. Biol. 249(1), 126-137. 1011

Mogk, A., B. Bukau, and H. H. Kampinga (2018, January). Cellular handling of protein 1012 aggregates by disaggregation machines. Mol. Cell 69(2), 214-226.

Morimoto, R. I. (2008, June). Proteotoxic stress and inducible chaperone networks in neurode- 1014 generative disease and aging. Genes Dev. 22(11), 1427-1438.

Nguyen, B., D. Hartich, U. Seifert, and P. D. L. Rios (2017, July). Thermodynamic bounds on 1016 the ultra- and infra-affinity of hsp70 for its substrates. Biophys. J. 113(2), 362-370. 1017

Nillegoda, N. B., J. Kirstein, A. Szlachcic, M. Berynskyy, A. Stank, F. Stengel, K. Arnsburg, 1018 X. Gao, A. Scior, R. Aebersold, D. L. Guilbride, R. C. Wade, R. I. Morimoto, M. P. Mayer, 1019 and B. Bukau (2015, August). Crucial HSP70 co-chaperone complex unlocks metazoan protein 1020 disaggregation. Nature 524(7564), 247-251.

1021

Nillegoda, N. B., A. Stank, D. Malinverni, N. Alberts, A. Szlachcic, A. Barducci, P. De Los Rios, 1022 R. C. Wade, and B. Bukau (2017, May). Evolution of an intricate j-protein network driving 1023 protein disaggregation in eukaryotes. Elife 6 .

1024

Parsell, D. A. and S. Lindquist (1993). The function of heat-shock proteins in stress tolerance: 1025 degradation and reactivation of damaged proteins. Annu. Rev. Genet. 27, 437-496. 1026

Peffer, S., D. Gonçalves, and K. A. Morano (2019, August). Regulation of the hsf1-dependent 1027 transcriptome via conserved bipartite contacts with hsp70 promotes survival in yeast. J. Biol. 1028 Chem. 294(32), 12191-12202.

Powers, E. T., D. L. Powers, and L. M. Gierasch (2012, March). FoldEco: a model for proteostasis 1030 in e. coli. Cell Rep. 1(3), 265-276.

Rampelt, H., J. Kirstein-Miles, N. B. Nillegoda, K. Chi, S. R. Scholz, R. I. Morimoto, and B. Bu- 1032 kau (2012, November). Metazoan hsp70 machines use hsp110 to power protein disaggregation. 1033 EMBO J. $31(21), 4221-4235$.

Ratajczak, E., S. Zietkiewicz, and K. Liberek (2009, February). Distinct activities of escherichia 1035 coli small heat shock proteins IbpA and IbpB promote efficient protein disaggregation. J. 1036 Mol. Biol. $386(1), 178-189$. 
Reidy, M., R. Sharma, S. Shastry, B.-L. Roberts, I. Albino-Flores, S. Wickner, and D. C. Masison 1038 (2014, October). Hsp40s specify functions of hsp104 and hsp90 protein chaperone machines. 1039 PLoS Genet. 10(10), e1004720.

Riback, J. A., C. D. Katanski, J. L. Kear-Scott, E. V. Pilipenko, A. E. Rojek, T. R. Sosnick, 1041 and D. A. Drummond (2017). Stress-triggered phase separation is an adaptive, evolutionarily 1042 tuned response. Cell 168(6), 1028 - 1040.e19.

1043

Rosenzweig, R., S. Moradi, A. Zarrine-Afsar, J. R. Glover, and L. E. Kay (2013, March). 1044 Unraveling the mechanism of protein disaggregation through a ClpB-DnaK interaction. 1045 Science 339 (6123), 1080-1083.

1046

RStudio Team (2018). RStudio: Integrated Development Environment for R. Boston, MA: 1047 RStudio, Inc.

1048

Russell, R., R. Jordan, and R. McMacken (1998, January). Kinetic characterization of the 1049 ATPase cycle of the DnaK molecular chaperone. Biochemistry 37(2), 596-607.

1050

Sachs, A. B., R. W. Davis, and R. D. Kornberg (1987). A single domain of yeast poly (a)-binding 1051 protein is necessary and sufficient for RNA binding and cell viability. Mol. Cell. Biol. 7(9), ${ }_{1052}$ $3268-3276$.

Schmid, D., A. Baici, H. Gehring, and P. Christen (1994, February). Kinetics of molecular 1054 chaperone action. Science 263(5149), 971-973.

Scior, A., A. Buntru, K. Arnsburg, A. Ast, M. Iburg, K. Juenemann, M. L. Pigazzini, B. Mlody, 1056 D. Puchkov, J. Priller, E. E. Wanker, A. Prigione, and J. Kirstein (2018, January). Complete 1057 suppression of htt fibrilization and disaggregation of htt fibrils by a trimeric chaperone 1058 complex. EMBO J. 37(2), 282-299.

Seyffer, F., E. Kummer, Y. Oguchi, J. Winkler, M. Kumar, R. Zahn, V. Sourjik, B. Bukau, and 1060 A. Mogk (2012, December). Hsp70 proteins bind hsp100 regulatory M domains to activate 1061 AAA+ disaggregase at aggregate surfaces. Nat. Struct. Mol. Biol. 19(12), 1347-1355. 1062

Shorter, J. (2011, October). The mammalian disaggregase machinery: Hsp110 synergizes with 1063 hsp70 and hsp40 to catalyze protein disaggregation and reactivation in a cell-free system. 1064 PLoS One 6(10), e26319.

Shorter, J. and S. Lindquist (2004, June). Hsp104 catalyzes formation and elimination of 1066 self-replicating sup35 prion conformers. Science 304 (5678), 1793-1797.

Sielaff, B. and F. T. F. Tsai (2010, September). The m-domain controls hsp104 protein 1068 remodeling activity in an Hsp70/Hsp40-dependent manner. J. Mol. Biol. 402(1), 30-37. 1069

Simpson-Lavy, K., T. Xu, M. Johnston, and M. Kupiec (2017, December). The std1 activator of 1070 the Snf1/AMPK kinase controls glucose response in yeast by a regulated protein aggregation. 1071 Mol. Cell 68(6), 1120-1133.e3.

Snead, W. T. and A. S. Gladfelter (2019, October). The control centers of biomolecular phase 1073 separation: How membrane surfaces, PTMs, and active processes regulate condensation. Mol. 1074 Cell 76(2), 295-305. 
Sweeny, E. A. and J. Shorter (2016, May). Mechanistic and structural insights into the 1076 Prion-Disaggregase activity of hsp104. J. Mol. Biol. 428(9 Pt B), 1870-1885.

Tessarz, P., A. Mogk, and B. Bukau (2008, April). Substrate threading through the central 1078 pore of the hsp104 chaperone as a common mechanism for protein disaggregation and prion 1079 propagation. Mol. Microbiol. 68(1), 87-97.

Theyssen, H., H. P. Schuster, L. Packschies, B. Bukau, and J. Reinstein (1996, November). The 1081 second step of ATP binding to DnaK induces peptide release. J. Mol. Biol. 263(5), 657-670. 1082

Triandafillou, C. G., C. D. Katanski, A. R. Dinner, and D. A. Drummond (2020, August). 1083 Transient intracellular acidification regulates the core transcriptional heat shock response. 1084 eLife 9, e54880.

Truman, A. W., K. Kristjansdottir, D. Wolfgeher, N. Hasin, S. Polier, H. Zhang, S. Perrett, 1086 C. Prodromou, G. W. Jones, and S. J. Kron (2012, December). CDK-dependent hsp70 1087 phosphorylation controls G1 cyclin abundance and cell-cycle progression. Cell 151(6), 1308- 1088 1318.

Ungelenk, S., F. Moayed, C.-T. Ho, T. Grousl, A. Scharf, A. Mashaghi, S. Tans, M. P. Mayer, 1090 A. Mogk, and B. Bukau (2016, November). Small heat shock proteins sequester misfolding 1091 proteins in near-native conformation for cellular protection and efficient refolding. Nat. 1092 Commun. 7(1), 13673.

Vabulas, R. M., S. Raychaudhuri, M. Hayer-Hartl, and F. U. Hartl (2010). Protein folding in 1094 the cytoplasm and the heat shock response. Cold Spring Harb. Perspect. Biol. 2(12), a004390. 1095

Wallace, E. W. J., J. L. Kear-Scott, E. V. Pilipenko, M. H. Schwartz, P. R. Laskowski, A. E. 1096 Rojek, C. D. Katanski, J. A. Riback, M. F. Dion, A. M. Franks, E. M. Airoldi, T. Pan, B. A. 1097 Budnik, and D. A. Drummond (2015, September). Reversible, specific, active aggregates of 1098 endogenous proteins assemble upon heat stress. Cell 162(6), 1286-1298.

1099

Walters, R. W., D. Muhlrad, J. Garcia, and R. Parker (2015, September). Differential effects 1100 of ydj1 and sis1 on hsp70-mediated clearance of stress granules in saccharomyces cerevisiae. 1101 RNA $21(9), 1660-1671$.

Weber-Ban, E. U., B. G. Reid, A. D. Miranker, and A. L. Horwich (1999, September). Global 1103 unfolding of a substrate protein by the hsp100 chaperone ClpA. Nature 401(6748), 90-93. 1104

Wentink, A. S., N. B. Nillegoda, J. Feufel, G. Ubartaitè, C. P. Schneider, P. De Los Rios, 1105 J. Hennig, A. Barducci, and B. Bukau (2020, November). Molecular dissection of amyloid 1106 disaggregation by human HSP70. Nature 587(7834), 483-488.

1107

Wippich, F., B. Bodenmiller, M. G. Trajkovska, S. Wanka, R. Aebersold, and L. Pelkmans (2013, 1108 February). Dual specificity kinase DYRK3 couples stress granule condensation/dissolution to 1109 mTORC1 signaling. Cell 152(4), 791-805.

Xu, H. (2018, September). Cochaperones enable hsp70 to use ATP energy to stabilize native 1111 proteins out of the folding equilibrium. Sci. Rep. 8(1), 1-15.

Yoo, H., C. Triandafillou, and D. A. Drummond (2019, May). Cellular sensing by phase 1113 separation: Using the process, not just the products. J. Biol. Chem. 294(18), 7151-7159. 1114 
Yu, H. Y., T. Ziegelhoffer, J. Osipiuk, S. J. Ciesielski, M. Baranowski, M. Zhou, A. Joachimiak, 1115 and E. A. Craig (2015, April). Roles of intramolecular and intermolecular interactions in 1116 functional regulation of the hsp70 j-protein co-chaperone sis1. J. Mol. Biol. 427(7), 1632-1643. 1117

Zheng, X., J. Krakowiak, N. Patel, A. Beyzavi, J. Ezike, A. S. Khalil, and D. Pincus (2016, 1118 November). Dynamic control of hsf1 during heat shock by a chaperone switch and phospho- 1119 rylation. Elife 5.

Żwirowski, S., A. Kłosowska, I. Obuchowski, N. B. Nillegoda, A. Piróg, S. Ziętkiewicz, B. Bukau, 1121 A. Mogk, and K. Liberek (2017, March). Hsp70 displaces small heat shock proteins from 1122 aggregates to initiate protein refolding. EMBO J. 36(6), 783-796. 